\title{
Macroeconomic Effects of Disruptions in Global Food Commodity Markets: Evidence for the United States
}

\begin{abstract}
We use two approaches to examine the macroeconomic consequences for the United States of disruptions in global food commodity markets. First, we embed a novel quarterly composite global production index for the four basic staples — corn, wheat, rice, and soybeans - in a standard vector autoregression model, and we estimate the dynamic effects of global food commodity supply shocks on the U.S. economy. As an alternative, we also estimate the consequences of 13 narratively identified global food commodity price shocks. Both approaches lead to similar conclusions. Specifically, an unfavorable food commodity market shock raises food commodity prices, and leads to a rise in food, energy, and core inflation, and also to a persistent decline in real GDP and consumer expenditures. A closer inspection of the pass-through reveals that households do not only reduce food consumption. In fact, there is a much greater decline in durable consumption and investment. Overall, the macroeconomic effects turn out to be a multiple of the maximum impact implied by the share of food commodities in the consumer price index and household consumption.
\end{abstract}

It is almost a truism to say that the characters of the seasons exert a very great influence on the amount and quality of our home-produce of wheat from year to year; and that upon the amount of food which the crop supplies depends very materially, though less than formerly, the general prosperity of the nation.

—John Bennet Lawes and Joseph Henry Gilbert (1868, p. 359)

ntil the beginning of the 20th century, agricultural fluctuations were considered very important for the business cycles of advanced economies (Giffen 1879), but the attention given to these fluctuations vanished 
Figure 1. Evolution of Food Commodity Prices over Time, 1960-2015

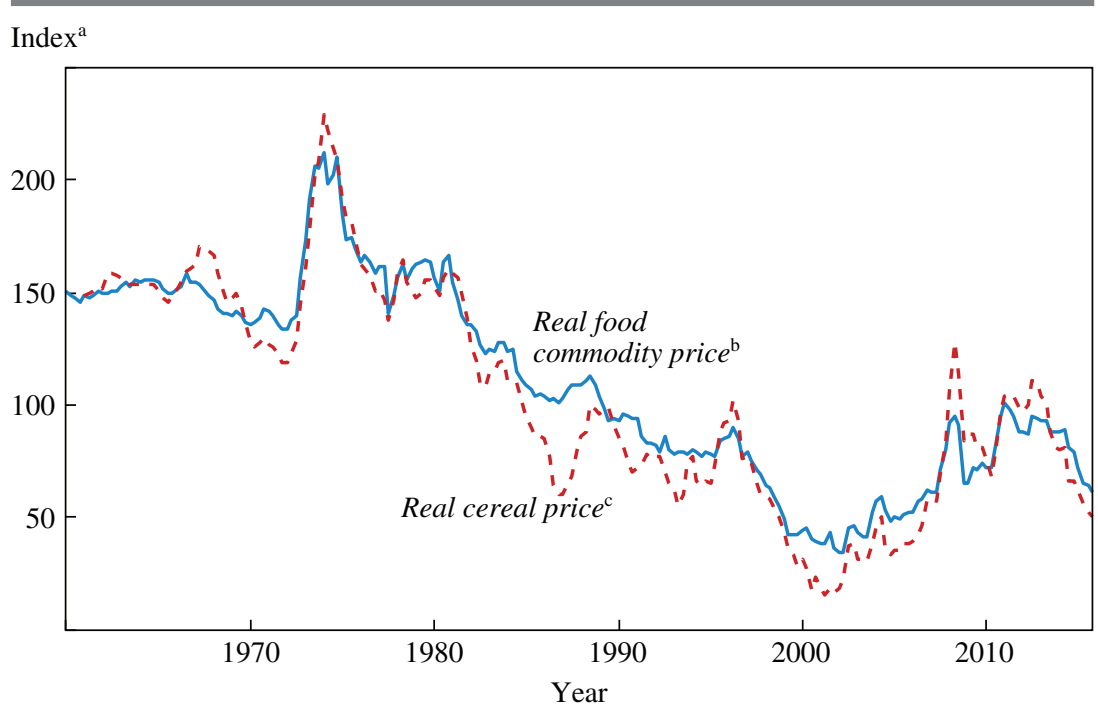

Source: International Monetary Fund.

a. Variables are measured as 100 times the natural $\log$ of the index deflated by the U.S. consumer price index.

b. Real food commodity price is a trade-weighted average of benchmark food prices in U.S. dollars for cereals, vegetable oils, meat, seafood, sugar, bananas, and oranges.

c. Real cereal price is an aggregate of the price of corn, wheat, rice, and soybeans on a trend productionweighted basis.

as agricultural sectors in developed countries contracted. However, the huge swings in food commodity prices since the start of the millennium, depicted in figure 1 , have reignited interest in the linkages between food commodity markets and the macroeconomy. In particular, the surge of real global food commodity prices by 67 percent between 2002 and 2011, a period that has been described as a "global food crisis," and their subsequent decline by 40 percent, have attracted a vast interest in understanding the economic causes and consequences of developments in food commodity markets. ${ }^{1}$

1. Two examples of newspaper articles addressing this topic are "The World Food Crisis" (New York Times, April 10, 2008) and "Global Food Crisis Forecast as Prices Reach Record Highs" (The Guardian, October 25, 2010). In 2012, the National Bureau of Economic Research directed a panel of academic experts to study the economics of food price volatility (Chavas, Hummels, and Wright 2014). See also a number of reports from policy institutions on the sources and potential consequences of the surge in food prices (Headey and Fan 2010; Abbott, Hurt, and Tyner 2011; Trostle and others 2011) or recent microeconomic studies that examine the welfare implications of food price shocks for households in developing economies (Ivanic and Martin 2008; Baquedano and Liefert 2014; Dawe and Maltsoglou 2014). 
However, surprisingly little is known about the repercussions of disruptions in global food commodity markets for the business cycles of the United States and other advanced countries. This lack of quantitative evidence for the macroeconomic effects might be justified by the relatively low and declining share of agriculture in real GDP, and the fact that the United States is a modest net exporter of cereals, two features that are documented in figure 2; but these explanations appear to be misleading. The share of agriculture in real GDP has, on average, indeed been slightly below 2 percent since the 1960s, but this ignores the fact that food commodities are a critical input factor in the production function of the food-processing sector, while food and beverages have accounted for approximately 17 percent of U.S. household spending between the 1960s and today. ${ }^{2}$ Accordingly, food commodity market fluctuations could also have important indirect effects on the U.S. economy; that is, food commodity market shocks could affect the economy through their impact on consumer spending. Examples include the costs of reallocating labor and capital across alternative production activities, precautionary savings, or a monetary policy response amplifying output effects. Such effects have been put forward in the literature on oil and energy price shocks (Bernanke, Gertler, and Watson 1997; Hamilton 2008), but could also apply to food commodity price shocks. Moreover, there has been a substantial rise in the use of food commodities to produce energy goods in recent periods. For example, the share of biofuels in petroleum consumption is currently more than 5 percent (see figure 2). Fluctuations in food commodity markets may therefore also affect the economy via energy prices.

Quantitative evidence for the macroeconomic consequences is not only important for gaining a better understanding of business cycle fluctuations. It is also vital for examining the optimal monetary policy response

2. According to the U.S. Bureau of Economic Analysis, the average share of food and beverages in total household expenditures was 17.3 percent between 1960 and 2015. The share of food commodities in final food products and beverages expenditures, in turn, was 14.1 percent, according to the U.S. Department of Agriculture's Economic Research Service data, which are only available for the period $1993-2014$. This corresponds to $\$ 928$ in food commodity expenditures per capita per year (measured in constant 2015 dollar values). Overall, only housing and utilities absorb a greater share (17.8 percent) of household expenditures. The share of oil products (heating oil and motor fuel), for example, was on average only 3.8 percent over the same period, while numerous studies have analyzed the macroeconomic effects of shocks in the global crude oil market (Hamilton 1983; Kilian 2009; Peersman and Van Robays 2009). Notice that about half of gasoline prices are determined by the cost of crude oil. Combined with an average share of oil products in household expenditures of 3.8 percent, this implies that crude oil expenditures are roughly $\$ 764$ per capita per year. 
Figure 2. Food and the U.S. Economy, 1960-2015

Share of agriculture and net food commodity exports in GDP

Percent

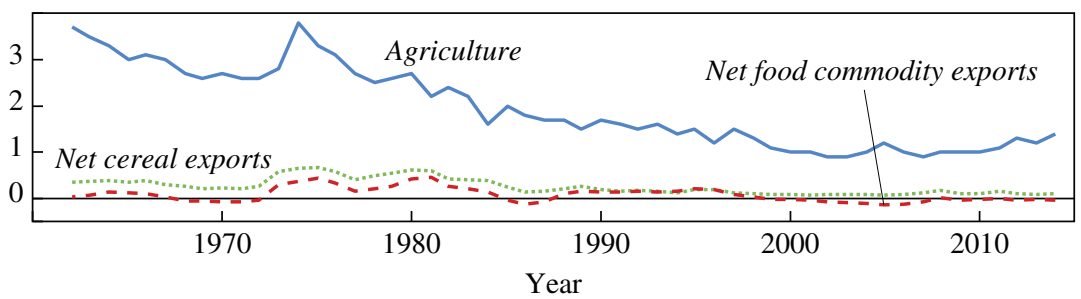

Components of personal consumption expenditures

Other services, $11 \%$

Financial services and insurance, $6 \%$

Recreation services, $3 \%$

Housing and utilities, $18 \%$

Transportation services, $3 \%$ Health care, $12 \%$

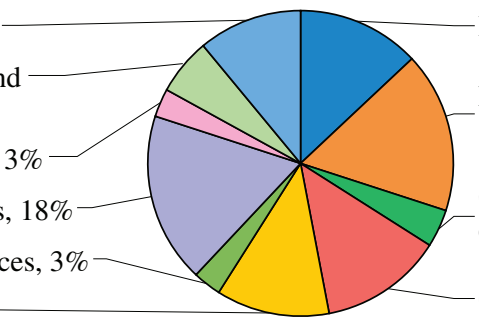

Durable goods, $13 \%$

Food and beverages

(including food services), $17 \%$

Gasoline and other energy goods, $4 \%$

Other nondurable goods, $13 \%$

Share of food and beverages in personal consumption

Percent

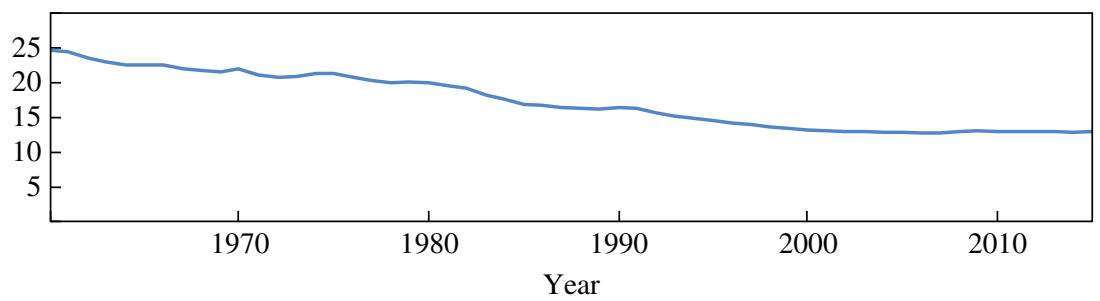

Share of biofuels in energy

Percent

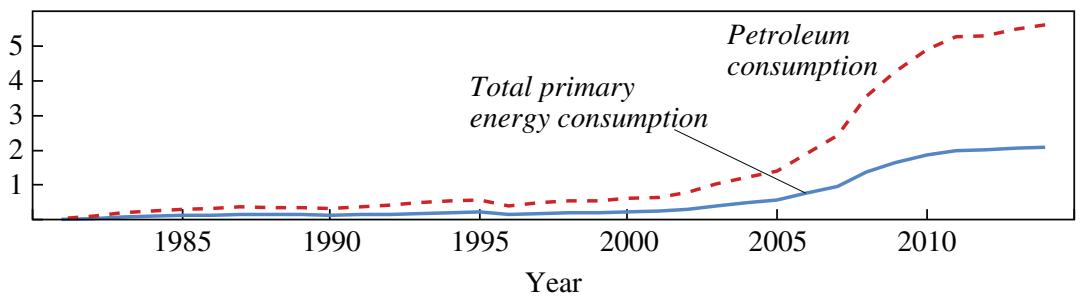

Sources: U.S. Bureau of Economic Analysis; U.S. Energy Information Administration; UN Comtrade Database (1-digit SITC). 
to changes in food prices or in assessing the usefulness of public food security programs, such as the Federal Agricultural Improvement and Reform (FAIR) Act and the Supplemental Nutrition Assistance Program (SNAP, formerly known as the Food Stamp Program). Furthermore, it is necessary to analyze the repercussions of several policy measures that may influence the price of food, such as trade policies (for example, export bans or restrictions on food imports) or policies to reduce carbon dioxide emissions (for example, ethanol subsidies or carbon offset programs). Finally, empirical evidence for the macroeconomic effects of food market disruptions should help to assess the consequences of climate change, which could increase the likelihood of significant weather shocks in agriculture.

In this paper, we estimate the effects of disturbances in global food commodity markets on the U.S. economy during the period 1963:Q1-2013:Q4. An empirical analysis of the macroeconomic effects of fluctuations in food commodity markets is challenging because food prices likely respond substantially to both supply and demand conditions, implying that there are also reverse causality effects from macroeconomic aggregates on food prices. For instance, the unconditional correlation between changes in real global food commodity prices and U.S. real GDP is positive. If one is interested in a unique causal interpretation, it is thus crucial to isolate movements in food prices that are strictly exogenous. We explore two strategies for identifying such movements.

The first strategy is a joint structural vector autoregression (VAR) model for the global food commodity market and the U.S. economy. To identify food market disturbances that are unrelated to macroeconomic conditions, we construct a novel quarterly composite global production index for the four most important staples: corn, wheat, rice and soybeans. Together, these commodities make up approximately 75 percent of the caloric content of food production worldwide. Annual production data for these four crops are available from the Food and Agriculture Organization of the United Nations (FAO) for 192 countries starting in the early 1960s. Michael Roberts and Wolfram Schlenker (2013) aggregate the four crops on a calorie-weighted basis to construct an annual indicator of world food production. We use the same principium to construct a quarterly indicator, which is an appropriate frequency for a business cycle analysis. Specifically, we combine the annual production data for each individual country with that country's planting and harvesting calendars for the four crops. Because most countries have only one relatively short harvest season for each crop, and there is a delay between planting and harvesting, we can assign two-thirds of world food production (or harvests) to a quarterly 
production index that fulfills the condition that the decision to produce (that is, to plant) did occur in an earlier quarter. Accordingly, in a quarterly VAR, innovations to the food production index (essentially unanticipated harvest shocks) are by construction exogenous to the macroeconomy, and the subsequent changes in real GDP, consumer prices, and other macroeconomic variables can be given a causal interpretation.

The estimation results assert that global food market disruptions have a considerable influence on the U.S. economy. An unfavorable shock to the global food production index of 1 standard deviation raises real food commodity prices by approximately 1.7 percent, which in turn leads to a 0.16 percent rise in consumer prices and a persistent decline in real GDP and personal consumption of almost 0.3 percent. According to a simple back-of-the-envelope calculation, the effects on consumer prices and personal consumption are approximately four to six times larger than the maximum impact implied by the share of food commodities in the consumer price index (CPI) and total consumption expenditures (that is, maximum discretionary loss in purchasing power). This denotes that indirect effects prevail and magnify the macroeconomic consequences. As a reference point, the effects on real GDP are roughly twice as large as the impact of a similar rise in global crude oil prices induced by an oil supply shock identified within the same VAR model. Additionally, Paul Edelstein and Lutz Kilian (2009) find that the response of personal consumption to an energy price shock is approximately four times the magnitude of the maximum discretionary purchasing power loss.

The stylized facts obtained from the VAR turn out to be robust for a battery of sensitivity tests and perturbations to the benchmark model. We also verify whether the innovations to the global production index are picking up other shocks, such as oil price or aggregate demand shocks; whether the underlying disturbances have effects on the economy other than via fluctuations in food commodity markets (for example, through direct effects of weather conditions on economic activity); and whether the results are distorted by possible time variation or nonlinearities. Overall, we do not find support for these conjectures or that such effects have a meaningful influence on the results.

As an alternative strategy to address the identification problem, we use a narrative approach in the spirit of James Hamilton (1983), Christina and David Romer (1989, 2010), Valerie Ramey and Matthew Shapiro (1998), and Ramey (2011). The advantage of narrative methods compared with the VAR analysis is that it requires fewer assumptions, and we can use a very large information set to identify exogenous food market shocks. 
More precisely, based on FAO reports, newspaper articles, and several other sources, we identify 13 historical episodes in which major changes in food commodity prices were mainly driven by exogenous disturbances that had little to do with macroeconomic conditions. Examples of unambiguously unfavorable food commodity market shocks are the Russian Wheat Deal (combined with a failed monsoon in southeast Asia) in the summer of 1972, and the more recent Russian and Ukrainian droughts of 2010 and 2012. In contrast, a number of unanticipated significant upward revisions in the expected harvest volume can be classified as episodes of favorable food market shocks (for example, in 1975, 1996, and 2004). As the next step, we construct a dummy variable based on these episodes, which is then used as an instrument to estimate the consequences of global food commodity price shocks for the U.S. economy.

The dynamic effects of the narratively identified shocks are estimated using Òscar Jordà's (2005) local projection method. The results confirm the conclusions of the VAR analysis. Whereas the narratively identified shocks have a more persistent impact on global food commodity prices and macroeconomic variables, the magnitudes of the effects on economic activity are very similar to those of the VAR results. The effects on consumer prices are even greater. Overall, the macroeconomic consequences of food market disturbances turn out to be substantial.

In our next step, we use the VAR model to examine the pass-through to consumer prices and economic activity in more detail. To do this, we extend the VAR and estimate the effects of food commodity supply shocks on inflation components, household expenditure categories, and other relevant variables, while we also compare the dynamics with oil supply shocks. The results reveal that not only do food prices increase after an unfavorable food commodity supply shock, but so too does core inflation, as well as inflation expectations - and, in recent periods, even energy prices. Oil supply shocks, in contrast, only raise energy prices. The significant effects on core inflation and inflation expectations are presumably the reason why we also observe a monetary policy tightening by the Federal Reserve in response to food market disruptions, in contrast to a policy easing following unfavorable oil supply shocks. A closer inspection of the impact on the components of output further reveal that households do not only reduce food consumption expenditures. A key mechanism whereby food market shocks affect the economy is through a decline in spending on other goods and services, in particular durable consumption and investment.

The monetary policy response can be considered as a first amplification mechanism for the strong impact of food commodity supply shocks on 
economic activity. We argue that this can explain at most one-third of the overall output consequences, and that the magnitudes and propagation of the remaining (nonmonetary policy) output effects are comparable to those of oil supply shocks. More specifically, though food supply shocks have a significant impact on food consumption, and oil supply shocks have a significant impact on energy consumption (and not the other way around), the pass-through of both shocks to all other components of household expenditures and investment appear to be quantitatively and qualitatively very much alike. This is even the case for the consumption of motor vehicles and parts, a component of expenditures that is typically considered to be complementary in use with oil, and thus is perceived as much more sensitive to oil shocks. Our results suggest that other effects are more important for the propagation of both shocks. We discuss a number of alternative channels that could potentially explain the amplification and composition of the output effects, but the relevance of these mechanisms is hard to identify definitively with the methods used in this paper and is left for future research.

In sum, the macroeconomic effects of food market disturbances are compelling, and should be taken into account for business cycle analysis, countercyclical policies, public risk management schemes for the stabilization of food markets, and the assessment of climate change and policy measures that may influence food prices.

In section I, we describe the baseline VAR model, the construction of the global food production index, and the other variables that are used for the estimations. In section II, we discuss the VAR results and several sensitivity checks. The narrative approach is discussed in section III. The comparison with oil supply shocks and the pass-through to inflation and economic activity are analyzed in section IV. Section V concludes.

\section{A VAR Model for the Global Food Market and the U.S. Economy}

In this section, we discuss our benchmark VAR model. We propose a strategy to identify exogenous food market disturbances within the VAR model, and explain the construction of the quarterly global composite food production index. We discuss other variables used in the model in subsection I.D.

\section{I.A. Methodology}

To estimate the macroeconomic consequences of disruptions in global food commodity markets, it is crucial to identify unanticipated shocks in 
these markets that are exogenous with respect to the macroeconomy. Our first strategy is a structural VAR approach in the spirit of Christopher Sims (1980), which has been a popular tool in the literature for estimating the effects of shocks related to monetary policy (Bernanke and Mihov 1998), fiscal policy (Blanchard and Perotti 2002), the oil market (Kilian 2009), technology (Galí 1999), and news (Beaudry and Portier 2006). This method allows us to capture the dynamic relationships between macroeconomic variables within a linear model, isolate structural innovations in the variables that are independent of each other, and measure the dynamic effects of these innovations on all the variables in the VAR system.

The VAR model that we use has the following reduced form representation:

$$
Z_{t}=\alpha+A(L) Z_{t-1}+u_{t},
$$

where $Z_{t}$ is a vector of endogenous variables representing the global food commodity market and the U.S. economy, $\alpha$ is a vector of constants and seasonal dummies, $A(L)$ is a polynomial in the lag operator $L$, and $u_{t}$ is a vector of reduced form residuals. The frequency $t$ of the data is quarterly because, as we discuss below, this is essential for the identification of exogenous food commodity market shocks.

Because food commodity prices are determined in global markets, $Z_{t}$ contains six key variables characterizing these markets: global food commodity production, real food commodity prices, global economic activity, the real price of crude oil, global crude oil production, and the volume of seeds set aside for planting. It is evident that global food production and prices portray fluctuations in food markets. Global economic activity measures changes in global income and the business cycle that could affect the demand for food commodities. ${ }^{3}$ Global oil production and the real price of crude oil capture a possible link between oil prices and food commodity prices because biofuels can be considered a substitute for crude oil to produce refined energy products. ${ }^{4}$ For example, corn is used for producing ethanol, and soybeans for producing biodiesel. Alternatively, food commodity prices may be affected by oil prices because oil is used in the production, processing, and distribution of food commodities. The VAR

3. This is also typically done in VAR models analyzing the crude oil market (Peersman and Van Robays 2009; Kilian 2009; Baumeister and Peersman 2013a).

4. We include both oil market variables because this allows us to also identify oil supply shocks in section IV. 
also includes the volume of harvested seeds that are set aside for planting, which should be an important determinant of future food production. Finally, the VAR contains a set of conventional variables representing the U.S. macroeconomy: real GDP, real personal consumption, the CPI, and the federal funds rate.

\section{I.B. Identifying Exogenous Food Market Disturbances}

U.S. and global macroeconomic variables typically have an influence on food commodity markets, implying that there is reverse causality from macroeconomic aggregates to food market variables. ${ }^{5}$ For example, a surge in global or U.S. economic activity very likely leads to higher food commodity prices relatively quickly. This problem is ignored in existing studies from policy institutions (for example, the Federal Reserve, the European Central Bank, and the International Monetary Fund) analyzing the passthrough of changes in food commodity prices to consumer prices. ${ }^{6}$ These studies typically impose a pricing chain assumption; that is, innovations in food commodity prices are not contemporaneously affected by shifts in consumer prices. The motivation is that commodity prices are determined in flexible markets, whereas consumer prices respond to shocks with a delay due to the presence of frictions in final goods markets. However, it is possible (and likely) that innovations to real GDP will also have an immediate impact on food commodity prices, and a delayed effect on consumer prices. Similarly, oil shocks could simultaneously affect food commodity prices (on impact) and consumer prices (with a delay). At best, such estimates or correlations can be informative about the signaling role of food commodity prices for future inflation; but they cannot be given a causal interpretation. The same endogeneity problem applies to the analysis of the output effects of fluctuations in food prices.

To investigate the causal macroeconomic effects of disruptions in global food markets, it is hence crucial to isolate a series of exogenous shocks that are specific to global food commodity markets. In this subsection, we identify unanticipated supply shocks to global food production. To achieve identification, we explore the time lag between the decision to produce

5. In essence, the reduced form residuals in equation 1 can be thought of as linear combinations of, on one hand, the contemporaneous (within the quarter) endogenous response of a variable to innovations in the other variables, and on the other hand, exogenous structural shocks.

6. See, for example, Furlong and Ingenito (1996); Ferrucci, Jiménez-Rodríguez, and Onorante (2012); Pedersen (2011); and Furceri and others (2015). For a similar approach, see Rigobon (2010). 
(planting) and the actual production (harvest), and the fact that actual production is subject to random shocks, which are caused, for example, by changes in weather conditions. More specifically, though farmers can respond contemporaneously (within the quarter) to macroeconomic developments by increasing or decreasing the volume of planting, this is not the case for actual production because of the time lag between both activities. In subsection I.C, we derive a quarterly global food commodity production index that explicitly fulfills this criterion. Hence, innovations to this index are exogenous food market disruptions (essentially unanticipated harvest shocks) that are uncorrelated with other structural shocks. This is identical to a Cholesky decomposition of the variance-covariance matrix $u_{t} u_{t}^{\prime}$ of the VAR, in which the food production index is ordered before the other variables. ${ }^{7}$

\section{I.C. Quarterly Composite Global Food Production Index}

Measuring world food commodity production is not straightforward. Many distinct commodities matter for food consumption and can be considered as close substitutes for each other. To simplify the analysis, we follow Roberts and Schlenker (2013) by transforming the quantities of the four most important staples-corn, wheat, rice, and soybeans-into calorie equivalents, which are then aggregated into a single composite index. Together, these four commodities account for approximately 75 percent of the caloric content of global food production, whereas the prices and quantities of other staple food items are also typically linked to these four commodities (Roberts and Schlenker 2013). ${ }^{8}$

Annual production data for each of the four commodities are published by the FAO Statistics Division for 192 countries over the period 1961-2013. ${ }^{9}$ Roberts and Schlenker (2013) convert the production data, which are measured in tons, into edible calories using the conversion factors developed by Lucille and Paul Williamson (1942). The calories are then aggregated across countries and crops. However, annual production data are not suitable for our analysis. In particular, the time lag between planting and the actual production of a crop typically varies between 3 and

7. Notice that the ordering of the other variables does not matter for the identification and the estimation of the dynamic effects of food commodity market shocks.

8. Corn and soybeans have respectively the greatest and smallest shares of the four major staples. Wheat and rice are between the other two, and have approximately equal shares. Roberts and Schlenker (2013) use the composite index of the four staples to estimate annual global supply and demand elasticities of agricultural commodities.

9. This database is available at http://faostat3.fao.org/. 
10 months, which implies that production could endogenously respond to macroeconomic developments when annual data are used. We therefore extend the Roberts and Schlenker (2013) approach to a quarterly frequency by combining the annual production data with the crop calendars of each individual country. This is feasible because the bulk of the countries have only one harvesting season for each crop, which lasts for only a few months.

The harvesting and planting dates of the crop calendars are obtained from various sources: the Agricultural Market Information System (AMIS) crop calendars for the largest producers and exporters; the Global Information and Early Warning System (GIEWS) country briefs; and FAO crop calendars. ${ }^{10}$ These calendars have a monthly frequency. For some very small producers, for which no crop calendar was found, the harvesting and planting dates of the nearest relevant country are used. The final crop calendar, including country- and crop-specific sources and assumptions, can be found in the online appendix to this paper. ${ }^{11}$ If a single harvesting season is spread over two subsequent quarters, we allocate the production volume to the first quarter. We only consider harvests for which there is no overlap with the planting season at a quarterly frequency. Figure 3 shows some examples to illustrate how we have assigned the annual food production data to a specific quarter based on the crop calendars (planting and harvesting seasons) of the countries:

-For several crops and countries, the allocation to a specific quarter is very obvious. The examples given in figure 3 are for Kazakhstan (wheat), Russia (rice), South Africa (corn), and Argentina (soybeans). The harvesting seasons clearly occur within a single quarter, whereas the planting seasons are one or more quarters beforehand.

-Whenever a single harvesting season is spread over two subsequent quarters, we allocate the production volume to the first quarter. The examples given in figure 3 are Mexico (wheat), China (corn), the United States (rice), and Brazil (soybeans).

- Some countries have two planting seasons for some crops, such as winter and spring wheat in Russia and Canada. However, because their harvesting seasons still occur within a single quarter and the planting seasons

10. The AMIS crop calendars are available at http://www.amis-outlook.org/amis-about/ calendars/en/; the GIEWS country briefs are available at http://www.fao.org/giews/country brief/index.jsp; and the FAO crop calendars are available at http://www.fao.org/agriculture/ seed/cropcalendar/welcome.do.

11. The online appendixes for this and all other papers in this volume may be found at the Brookings Papers web page, www.brookings.edu/bpea, under "Past BPEA Editions." 
are in an earlier quarter, it is possible to allocate the production to a specific quarter.

-Whenever part of the planting and harvesting seasons overlap at the quarterly frequency - for example, for wheat in Brazil-we do not allocate the production. This production is not included in the index.

-For some countries, it is not possible to assign the annual production data to a specific quarter because there is more than one harvesting period, or because the crops are harvested almost uniformly throughout the year. Examples given in figure 3 are Thailand (soybeans) and India (rice). This production is not included in the index.

Accordingly, we have managed to assign approximately two-thirds of annual world food production to a specific quarter. ${ }^{12}$ Because of the time lag between planting and harvesting of at least one quarter, innovations to food production are thus by construction predetermined or exogenous relative to the other variables included in the VAR. After aggregating the quarterly production data across crops and countries, the quarterly global food production index is seasonally adjusted using the U.S. Census Bureau's X-13ARIMA-SEATS seasonal adjustment program. ${ }^{13}$

A couple of points about the index in the context of the VAR analysis are worth mentioning. First, although this index does not capture all disturbances to global food production, the production volume covered by the index should be sufficiently meaningful to influence global food commodity markets, including food commodity prices, which is a prerequisite for examining the impact of exogenous food supply shocks on the U.S. macroeconomy. Second, the identified shocks only capture unanticipated changes in food production in the harvesting quarter. More specifically, anticipated changes in food production before the start of the harvesting season (for example, bad weather between planting and harvesting) should already be reflected in the other variables and innovations in the VAR, particularly food commodity prices. ${ }^{14}$ Third, our approach assumes that the information

12. For the individual crops, the index covers 84 percent of global corn production, 16 percent of rice production, 96 percent of soybean production, and 82 percent of wheat production. The coverage of rice production is quite low due to the existence of more than one harvesting season in several important producing countries.

13. Information about the program can be found at https://www.census.gov/srd/www/ x13as/.

14. An arbitrage condition ensures that changes in futures prices also shift spot prices of storable commodities (Pindyck 1993). If there is a rise in expected food commodity pricesthat is, futures prices increase - traders will buy inventories in the spot market. Hence, spot commodity prices also increase. 


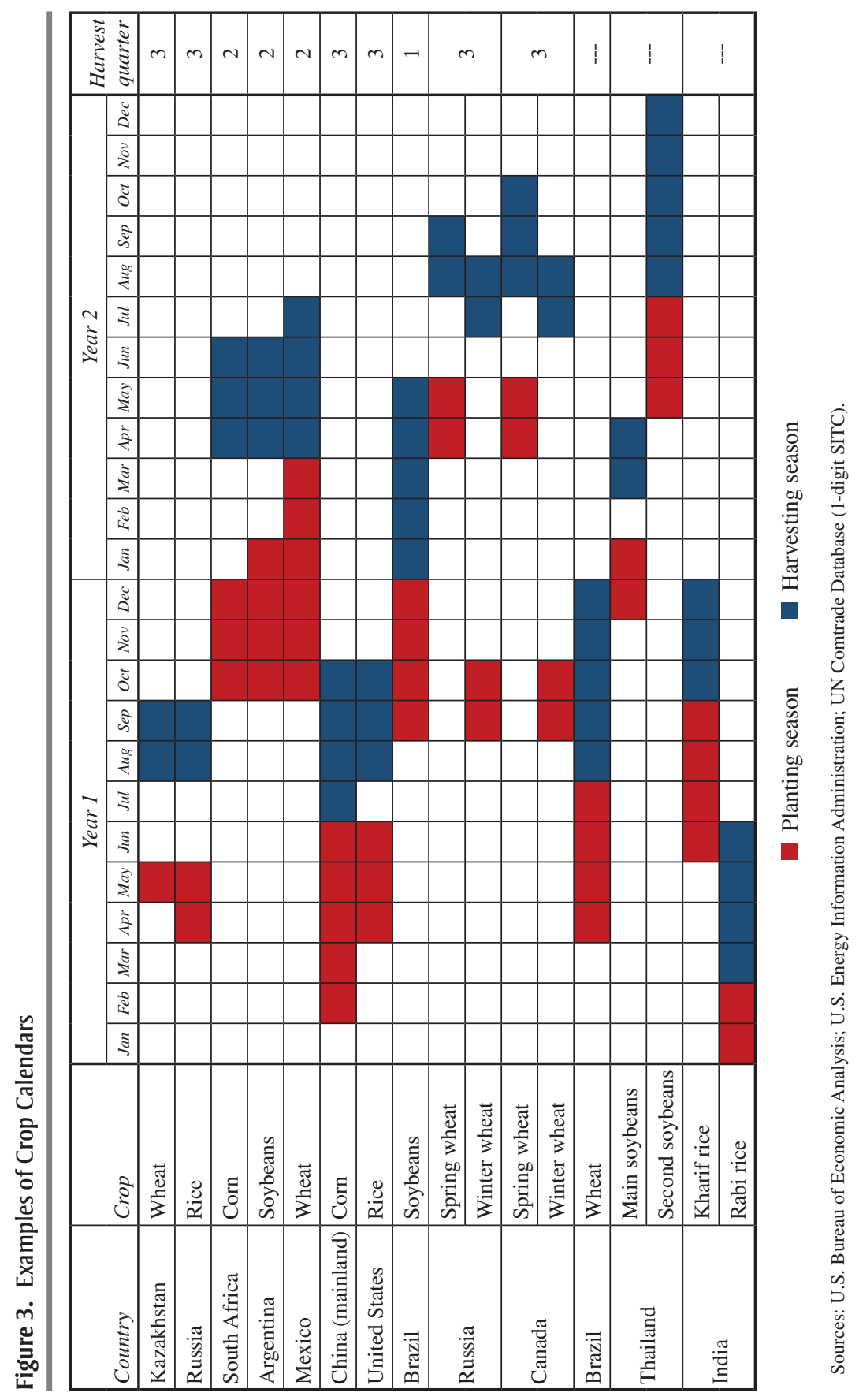


sets of local farmers are no greater than the global VAR model. Since we do not consider food production forecasts by country, the shocks are hence not necessarily identified using the full information sets available to the farmers when planting. Finally, our identification strategy also assumes that food producers cannot influence the production volume within the harvesting quarter. For example, a rise in economic activity or food commodity prices could endogenously induce farmers to increase food production by increasing fertilization activity. Several studies, however, have shown that in-season fertilization is not an efficient way to increase grain yields and is not recommended for the food commodities that we consider (Mallarino 2010; Schmitt and others 2001; Fanning 2012; Scharf, Wiebold, and Lory 2002). Specifically, the best times to apply fertilizer to these crops is before or shortly after planting, while fertilization should be completed before the jointing stage. In fact, fertilizing strategies in the last months before the harvest may even be counterproductive and lead to irreversible yield loss. ${ }^{15}$ Whereas some endogenous response might be present, this should be meager relative to the variation induced by other factors, for example, weather. ${ }^{16}$

Figure 4 shows the time series of the global food commodity production index. There has been an upward trend in food production since the 1960s. However, there has also been considerable variation around this trend, with spikes of up to 10 percent, suggesting that there have been serious food production disruptions. The figure also shows an index of global food production excluding U.S. production, and an index of global production yields. Both indicators are used below in a sensitivity analysis of the benchmark results (subsection II.D). The production yield is defined as the ratio of food production to the area harvested, which is also obtained from the FAO database (see footnote 9). The upward trend in this variable is flatter than the production volume, implying that part of the food production

15. The bottom line is that fertilization strategies (for example, nitrogen and phosphate applications) enhance plant cell multiplication and stimulate vegetative growth of the plant in order to grow as much as possible before the onset of the ripening phase. However, applying such strategies after the vegetative stage implies that the plant can spend less energy on ripening, which could result in lower grain yields. In principle, farmers could always reduce food production, for example, by destroying crops or an insufficient treatment of diseases during the harvesting season, but that is not likely to happen at a large scale.

16. Notice also that the production volume of the four staples that is not covered by our index cannot endogenously respond to macroeconomic conditions within the quarter due to a standard time lag between planting and harvesting of at least three months. 
Figure 4. Global Food Commodity Production Index, 1961-2014a

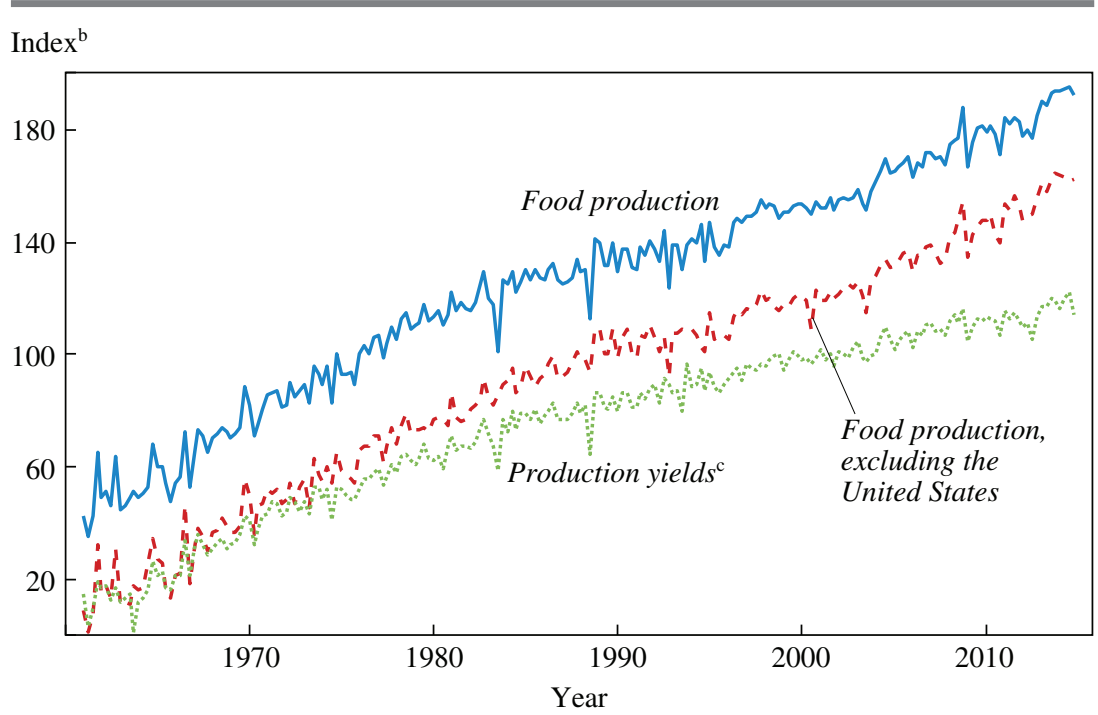

Source: Authors' calculations.

a. The production index aggregates the production of corn, wheat, rice, and soybeans on a calorie-weighted basis.

b. Variables are measured as 100 times the natural log of the global food commodity production index (see the text).

c. The production yield is defined as the ratio of food production to the area harvested.

expansion is driven by an increase in the amount of land that is used in crop production.

\section{I.D. Other Variables}

For the baseline estimations, we use the broad food commodity price index from the International Monetary Fund. The index is a trade-weighted average of different benchmark food prices in U.S. dollars for cereals, vegetable oils, meat, seafood, sugar, bananas, and oranges. These benchmark prices are representative of the global market and are determined by the largest exporter of each commodity. The nominal price index has been deflated by the U.S. CPI. The time series is shown in figure 1 above. Real food commodity prices reached a peak in the 1970s, after which there was a steady decline until the early 2000s. The trend is again positive until the summer of 2012, and negative afterward. However, there have also been many fluctuations around the long-run evolution of commodity prices, with noticeable upward spikes in the second half of 
the 1970s, and in 1983, 1987-88, 1995-96, 2002-04, 2007-08, 2010, and 2012. Overall, the standard deviation of the quarter-on-quarter change in real food commodity prices is 5.7 percent. $^{17}$

Because our production index is limited to the four major staples, we have also constructed an alternative composite cereal price index containing only the prices of corn, wheat, rice, and soybeans. This index, which is also shown in figure 1 above, is based on the trend production weights of the four commodities and is used below in another sensitivity check of the benchmark results. As observed in figure 1, the correlation with the International Monetary Fund's broad index is very high, which is in line with the premise that prices for all food commodities tend to vary synchronously. The variation of the cereal price index has, however, been higher than the broader food price index, with a quarterly standard deviation of 7.8 percent.

The volume of seeds from harvests that are set aside for planting is also made available by the FAO on an annual basis. We have used the same procedure to allocate the annual data to a quarterly series, as described in subsection I.C for the production index. Other data are standard. Global oil production is obtained from the Oil \& Gas Journal for the period before 1973, and from the U.S. Energy Information Administration afterward, following Christiane Baumeister and Peersman (2013b). Similar to Kilian (2009), among others, the real oil price series is the refiner acquisition cost of imported crude oil, deflated by the U.S. CPI. To proxy global economic activity, we follow Baumeister and Peersman (2013a) by using the world industrial production index from the Netherlands Bureau for Economic Policy Analysis, which is backcasted for the period before 1991 using the growth rate of industrial production from the United Nations. Finally, U.S. macroeconomic data are obtained from the Federal Reserve Bank of St. Louis's FRED database.

\section{VAR Results}

In this section we describe the estimation of the VAR model. We show the identified shocks and their contribution to real food commodity prices, and discuss the dynamic effects on the U.S. economy. In subsection II.D, we examine the sensitivity and robustness of the results.

17. As a benchmark, the standard deviation of the change in real crude oil prices is 11.3 percent over the same period. 


\section{II.A. Inference}

The benchmark VAR model for the global food commodity market and the U.S. economy has been estimated over the sample period 1963: Q1-2013:Q4. All variables are seasonally adjusted natural logarithms (multiplied by 100), except for the federal funds rate, which is measured in percent. Estimation in log levels gives consistent estimates and allows for implicit cointegrating relationships in the data. ${ }^{18}$ Based on the Akaike information criterion, we include five lags of the endogenous variables. However, the qualitative results are not sensitive to the lag order choice. In subsection II.D, we examine the robustness of the results across subsamples. In the figures, we show the median estimates of the impulse responses, together with percentile error bands based on 10,000 draws. These are constructed as proposed by Sims and Tao Zha (1999).

\section{II.B. Identified Shocks and Contribution to Real Food Commodity Prices}

Figure 5 shows the historical contribution of the identified global food commodity supply shocks to the evolution of real food commodity prices (solid line), as well as the contribution of all shocks implied by the VAR model (dashed line). Overall, the shocks explain approximately 10 percent of food commodity price volatility. The contribution of the shocks to real food commodity prices corroborates very well with several episodes that have been described as (un)favorable developments in food markets. For example, the VAR model identifies major favorable food supply shocks during the periods or years 1967-72, the mid-1980s, 1992, 1994, 19962000, and 2004-05. In contrast, shocks to the global food production index have been unfavorable in the periods or years 1972-77, 1985-88, 1996, 2000-03, 2005-07, and 2009-12. Almost all these episodes have been characterized by significantly falling or rising food commodity prices and correlate with many spikes discussed in subsection I.D.

18. See Sims, Stock, and Watson (1990) for inference in VAR models when some or all the variables have unit roots. In particular, they show that even when variables have stochastic trends and are cointegrated, the log levels specification gives consistent estimates. Conversely, pretesting and imposing the unit root and cointegration relationships could lead to serious distortions when regressors almost have unit roots (Elliott 1998). Notice that the results are robust when we estimate the VAR with a linear (or quadratic) time trend. 
Figure 5. Historical Contribution of Identified Shocks to Real Food Commodity Prices, 1963-2013

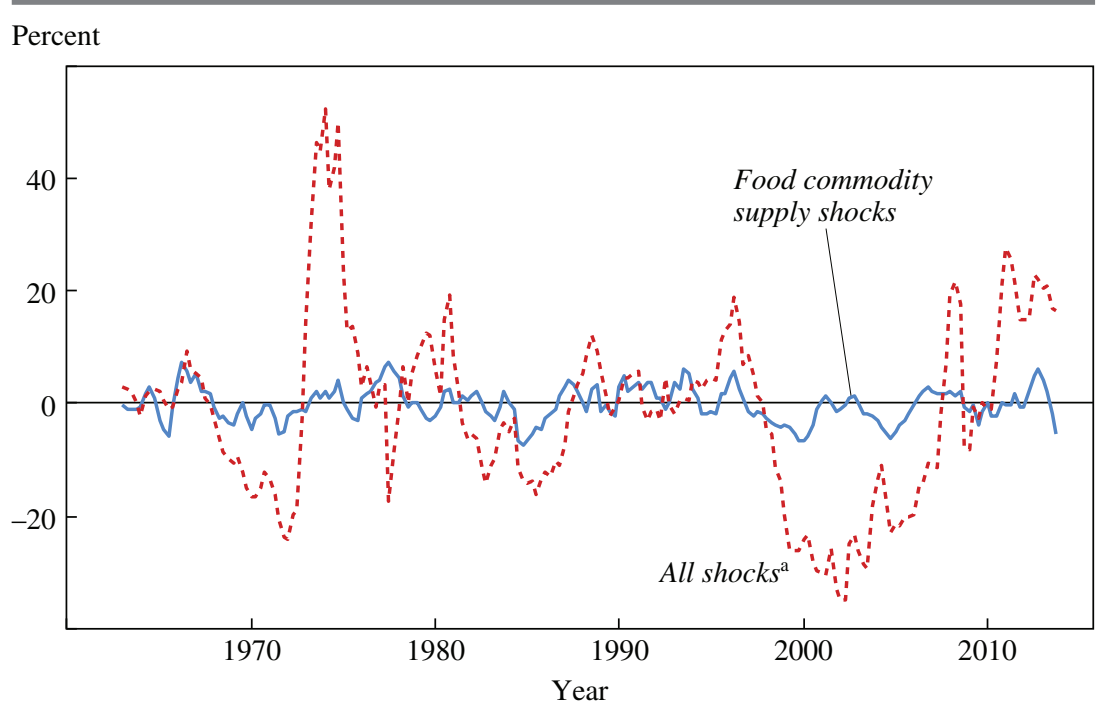

Source: Authors' calculations.

a. Calculated as the actual data minus the baseline of the VAR.

The cumulative contribution of the identified food commodity supply shocks to the surges in food commodity prices between 2005-07 and 2009-12 has been more than 10 percentage points each time. Accordingly, unfavorable harvests contributed significantly to the so-called global food crisis between 2002 and 2011. Nevertheless, as observed in the figure, the bulk of the crisis has been caused by other shocks. This is not surprising and is in line with common perceptions and several studies that have analyzed the sources of the food crisis. A popular source that has been postulated by pundits is the considerable rise of food commodity demand induced by biofuels. Specifically, policy measures to encourage biofuels production-for example, renewable fuel standard mandates-and the simultaneous surge in oil prices appear to have triggered a persistent demand for corn and upward pressure on corn and food commodity prices (Abbott, Hurt, and Tyner 2011). For instance, the share of U.S. corn production used to produce ethanol increased from 12 percent in 2004 to almost 40 percent in 2010, and ethanol production absorbed 70 percent of the increase in global corn production over that period (Headey and 
Fan 2010). ${ }^{19}$ Examples of other shocks mentioned in the literature are the strong income growth in the BRIC countries (Brazil, Russia, India, and China) during that period-which allowed citizens of these countries to incorporate larger quantities of cereals, meat, and other proteins into their diets (Zhang and Law 2010)-low interest rates, the depreciation of the U.S. dollar, and financial market speculation (Enders and Holt 2014). A final interesting feature revealed by the historical contribution of the identified global food commodity market disturbances is that favorable harvests seemed to have lowered food commodity prices by more than 10 percent in 2013.

\section{II.C. Impact of Food Market Disruptions on the U.S. Economy}

The impulse responses to a shock of 1 standard deviation in the global food production index are shown in figure 6 . These should be interpreted as the dynamic effects of an unanticipated decline in the food production index on all the variables in the VAR, controlling for other changes in the economy that may also have an impact on the variables. The shock corresponds to a decline in the food production index of 4 percent. The drop in food production leads to a significant temporary rise in real (nominal) food commodity prices, which reaches a peak of approximately 1.7 percent (1.8 percent) after one quarter, and a persistent decline in global economic activity. Global oil production starts to decrease after approximately two quarters, which is in line with the pattern of the decline in global economic activity, while the impact on the real price of oil is insignificant at all horizons.

Global food commodity production returns to the baseline after one quarter. This pattern, together with the persistent response of food commodity prices, is consistent with John Muth's (1961) rational expectations model for commodity markets with speculation, and is at odds with the so-called cobweb theorem. Specifically, Muth (1961) shows that the introduction of rational expectations into a linear model with a production lag of storable commodities and random shocks to production should generate first-order serial correlation in prices, while actual production is just a

19. Notice that biofuels demand did not only strongly account for corn price increases during that period but also price increases in other staples. For example, the rapid expansion of the U.S. corn area by 23 percent in 2007 resulted in a 16 percent decline in the soybean area, which reduced soybean production, contributing to the strong rise in soybean prices (Mitchell 2008). Furthermore, European biofuels production has mainly been concentrated on biodiesel, which resulted in a crowding-out of the wheat area by oilseeds and hence higher wheat prices. 
Figure 6. Impulse Responses to Global Food Commodity Supply Shocks:

Benchmark VAR Results ${ }^{\mathrm{a}}$

\section{Global food production index}

Percent

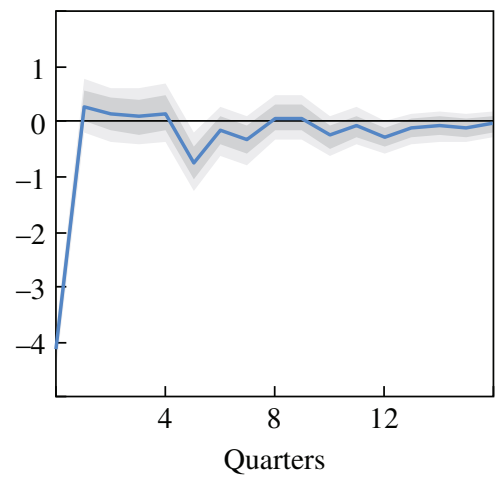

Volume of seeds set aside for planting

Percent

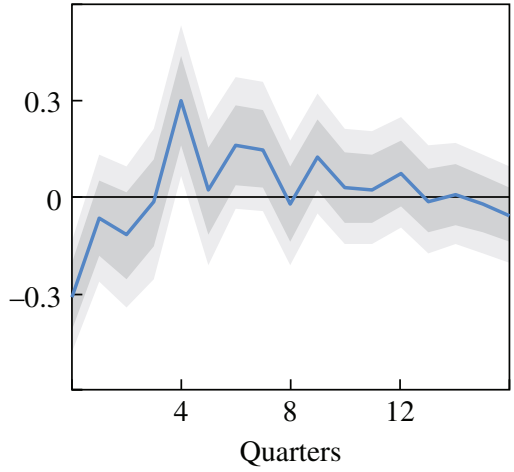

Global oil production

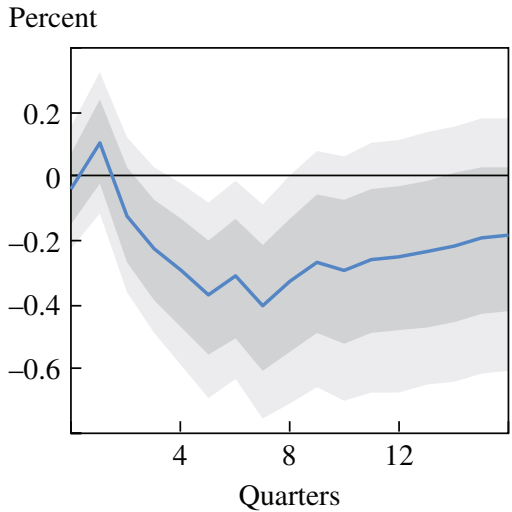

\section{Real food commodity prices}

Percent

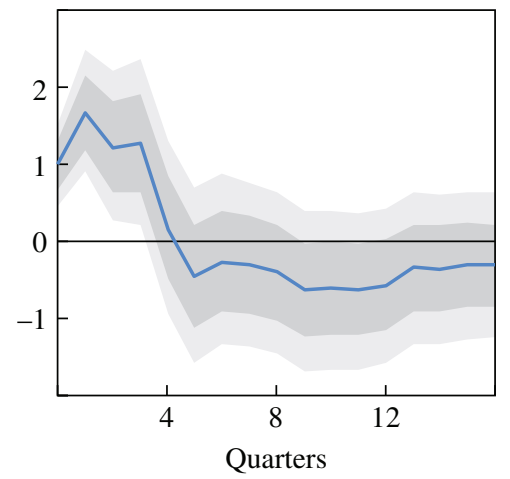

Global economic activity

Percent

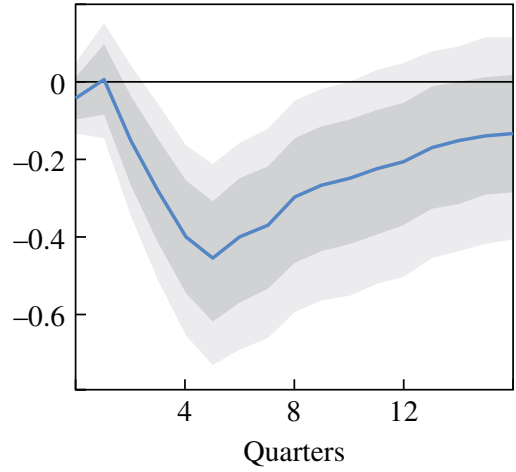

Real oil price

Percent

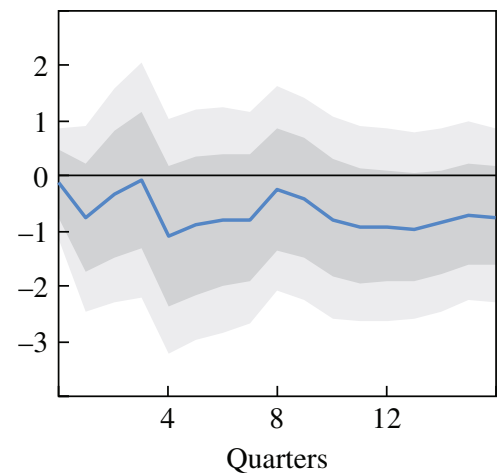

(continued) 
Figure 6. Impulse Responses to Global Food Commodity Supply Shocks: Benchmark VAR Results ${ }^{\mathrm{a}}$ (Continued)

\section{U.S. real GDP}

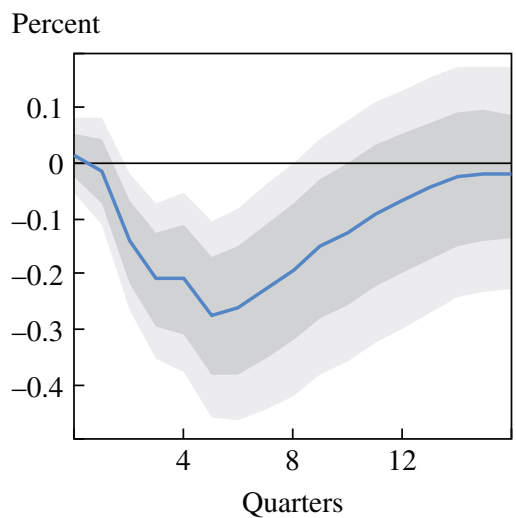

U.S. CPI

Percent

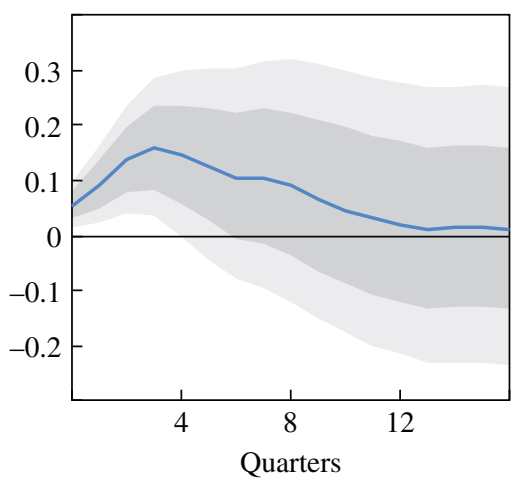

\section{U.S. real personal consumption}

Percent

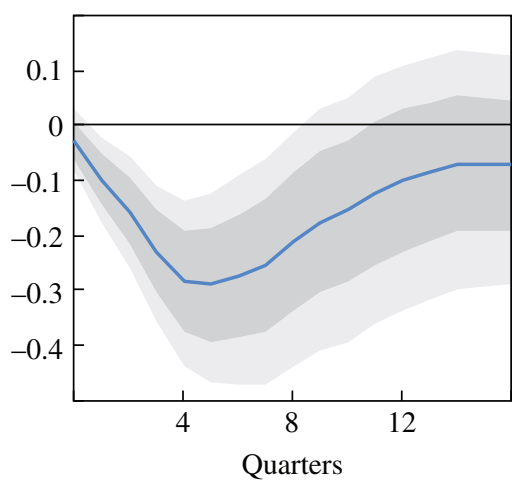

Federal funds rate

Percent

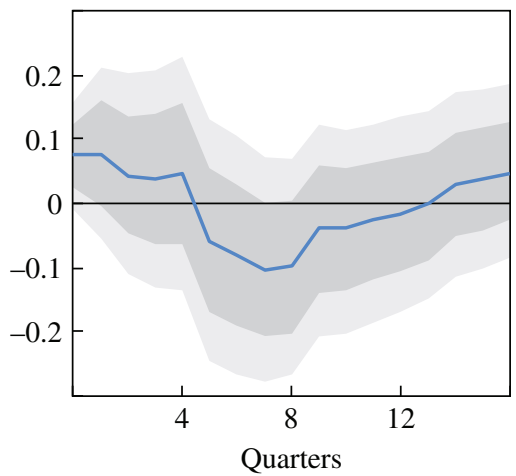

Source: Authors' calculations.

a. The sample period is 1963:Q1-2013:Q4. The darker shading indicates the 16th and 84th percentile error bands; the lighter shading indicates the 5 th and 95 th percentile error bands.

perturbation around its steady state. Cobweb models, in contrast, predict negative serial correlation in prices and oscillatory commodity cycles (Ezekiel 1938). Our findings clearly support the former, which is in line with most empirical studies testing the rational-expectations, competitivestorage model of agricultural commodities (Gouel 2012). The contemporaneous decline in the volume of seeds that are set aside for planting, followed by a similar rise one year after the shock, also suggests that farmers use inventories to smooth sales and production over time. 
The influence of global food market disruptions on the U.S. economy is considerable. In particular, real GDP starts to decrease after two quarters, reaching a maximum decline of 0.28 percent after five to six quarters, and then gradually returns to the baseline. Although the rise in real food commodity prices lasts for only four quarters, the decline in real GDP is still significant after two years. The macroeconomic consequences are thus very persistent. A similar pattern appears for the response of households' real personal consumption expenditures. The shock in global food commodity markets also leads to a temporary surge in consumer prices with a peak of 0.16 percent, while there is a rise in the federal funds rate of 8 basis points on impact.

The magnitudes of the effects are striking. According to a simple backof-the-envelope calculation, the responses of consumer prices and total consumption are about four to six times larger than the maximum direct influence that food commodities may have on the CPI and personal consumption. More precisely, the rise of nominal commodity prices is 1.8 percent at its peak. Given an average share of food commodities in final food products and beverages of 14.1 percent and a share of food and beverages in total household expenditures of 17.3 percent, the maximum direct effect of the rise in food commodity prices on consumer prices and total consumption is approximately 0.04 to 0.05 percent. ${ }^{20}$ This suggests that indirect effects are important in magnifying the macroeconomic repercussions; that is, not only food prices but also other components of the CPI should increase after a surge in food commodity prices, while the decline in consumption cannot solely be the consequence of a discretionary income effect. In section IV, we analyze this in more detail.

Whereas disturbances in food commodity markets have obviously not been the main driver of the U.S. business cycle, the identified global food market shocks did contribute to several post-World War II recessions. This can be observed in figure 7, which shows the cumulative contribution of the identified shocks to real GDP over time (solid line), the contribution of all shocks to real GDP implied by the benchmark VAR model (dashed line),

20. The implicit assumption for the upper bound of the direct effect on total consumption is that the rise in food commodity prices is fully induced by higher prices for imported food commodities, which leads to a reduction in discretionary income of households to buy consumption goods. In addition, households are assumed not to borrow or dissave in response to the shock. For the average share of food and beverages in total household expenditures over the sample period, and the share of food commodities in final food products and beverages, we refer to figure 2 and footnote 2 . 
Figure 7. Historical Contribution of Identified Shocks to U.S. Real GDP, 1963-2013

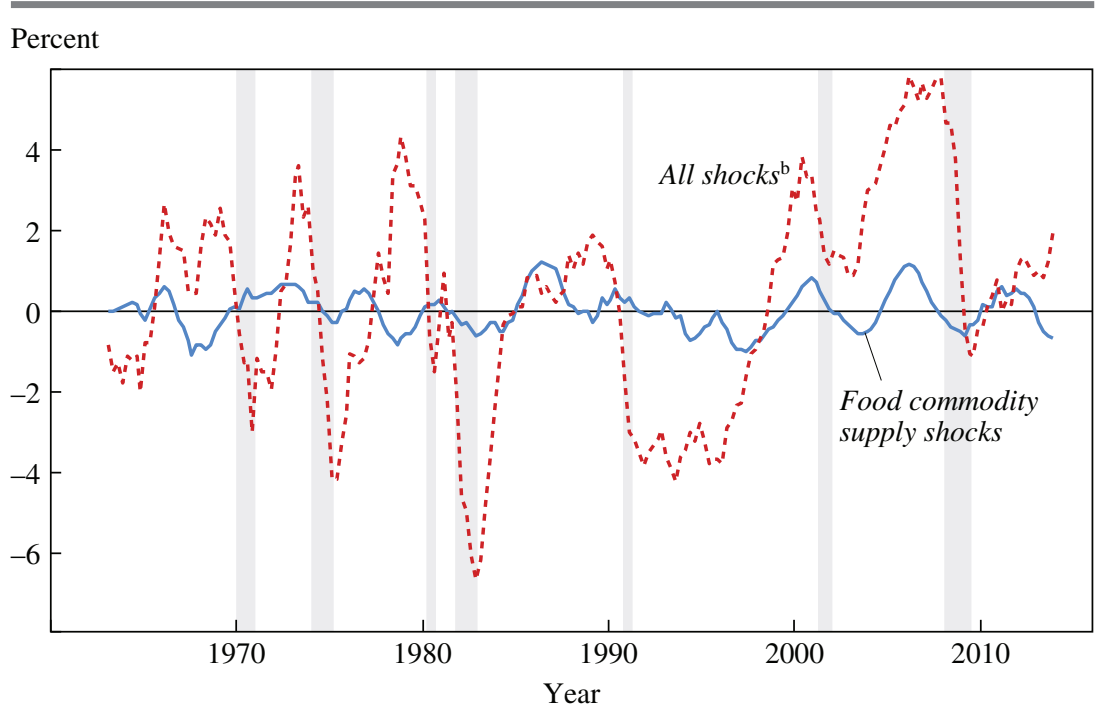

Source: Authors' calculations.

a. Gray areas indicate recessions.

b. Calculated as the actual data minus the baseline of the VAR.

and the National Bureau of Economic Research's recession periods (gray bars). Although our index only captures a subset of food market disruptions, unfavorable shocks to global food production seem to have contributed to the recessions in 1974 ( 0.3 percent contribution to the decline in real GDP), 1982 (0.6 percent), the early 1990s (0.2 percent), 2001 (0.7 percent), and the Great Recession of 2008-09 (0.5 percent). In nonrecessionary periods, food commodity market shocks also had a meaningful influence on economic activity. For example, favorable food supply shocks increased real GDP by roughly 2 percent in the period $1967-72$, by 1.7 percent in the mid-1980s, by 1.8 percent in 1997-2000, and by 1.7 percent between 2003 and 2005. In sum, the macroeconomic repercussions of food market disturbances have been important for the U.S. economy.

\section{II.D. The Sensitivity and Robustness of Benchmark Results}

In section III, we examine the robustness of the results by using a narrative approach that does not rely on the global food commodity production index and VAR methodology. But before doing this, we consider a set of alternative VAR specifications to assess the sensitivity of the results that 
are based on the production index. We also investigate whether the estimations are picking up other effects and the stability of the results across subsamples.

DID WE IDENTIFY EXOGENOUS FOOD COMMODITY MARKET SHOCKS? Due to the time lag between the planting and the harvesting seasons, shocks to the global food commodity production index should in principle be exogenous with respect to the macroeconomy. In subsection I.C, we also argued that farmers cannot influence grain yields any more in the harvesting quarter, for example, by raising fertilization activity. As noted above, fertilizer applications must be implemented before or early in the growing season and may even lead to yield loss if they are implemented shortly before harvesting. Nevertheless, it is worth verifying whether the innovations are picking up other shocks, such as oil price or aggregate demand shocks. Furthermore, it is important to check whether the identified disturbances have effects on the economy other than via fluctuations in food commodity markets. In particular, given that food production shocks are primarily the consequence of weather variation, changes in U.S. weather conditions may simultaneously affect food production and economic activity. ${ }^{21}$ Michael Boldin and Jonathan Wright (2015) find that unusual temperatures have a statistically significant effect on U.S. real GDP growth in the first and second quarters. For example, several panel studies find significant negative effects of hotter temperatures on agricultural output, and also on labor productivity and labor supply at the spatial level (Dell, Jones, and Olken 2014). ${ }^{22}$ Additionally, storms may distort the estimations and exaggerate the role of food commodity markets in macroeconomic developments.

Overall, we do not find compelling support for the hypothesis that the innovations are picking up other shocks or are having meaningful direct effects on economic activity, other than through food commodity markets, for several reasons. First, a closer inspection of the impulse responses

21. This evidence is usually only found for poor countries; several papers have found that temperature shocks have little effect on per capita income or industrial value-added output at the spatial level in rich countries (Dell, Jones, and Olken 2014).

22. Boldin and Wright (2015) do not find a significant impact of unusual snowfall on real GDP growth. Based on their estimations, they construct a counterfactual weatheradjusted series for GDP growth. Unfortunately, we cannot use their series as a robustness check because the series only starts in 1990:Q1. The series also has the property that weather shocks cannot have a permanent effect on the level of real GDP. Any influence of weather conditions on the level of real GDP is therefore "neutralized" in subsequent quarters. This is clearly different from the pattern of the impulse responses in figure 6 . 
shown in figure 6 conveys the perception that both issues probably do not have an important influence on the results. Specifically, global economic activity and U.S. real GDP only start to decline with a delay of at least two quarters after the identified food market disruptions. Put differently, the shocks are not reflected in economic activity on impact, which implies that the innovations are not aggregate demand shocks and that the direct effects of the underlying global weather conditions on the U.S. economy cannot be large. ${ }^{23}$ Similarly, global oil production only decreases after approximately three quarters, whereas the response of crude oil prices is never significant and is even slightly negative at longer horizons.

In addition, the return to the baseline of global food production after one quarter in the benchmark VAR confirms that the innovations do not capture endogenous responses to macroeconomic conditions. If food producers endogenously adjust their production yields to changes in economic activity, we should instead observe a persistent response function. Specifically, if farmers are able to augment (reduce) grain yields within one quarter, this should also (and even more) be the case in the subsequent quarter. The absence of autocorrelation in the production response, however, is at odds with such endogenous behavior. Notice that it is also unlikely that the identified shocks capture an endogenous response of farmers to changes in expected (future) economic activity. This is illustrated in the top panel of figure 8 . The panel shows the dynamic effects of food commodity supply shocks on equity prices (as measured by the S\&P 500 index) and implied stock market volatility (as measured by the VIX volatility index). These impulse responses have been estimated by adding both variables one by one to the benchmark VAR model. If the innovations pick up shocks in expected economic activity or economic uncertainty, there should be a significant contemporaneous shift in equity prices or stock market volatility. This is clearly not the case. Equity prices only start to decline with a delay, whereas the impact on stock market volatility is insignificant at all horizons.

In contrast to the macroeconomic and financial market variables, the contemporaneous responses of all the global food commodity market variables in the benchmark VAR are statistically significant. The patterns of the impulse response functions - that is, food production and prices shifting

23. We also find no correlation between the series of the annualized food commodity supply shocks and the annual occurrence (-.09), the total number of deaths (.11), or the total dollar damage estimate (.07) of U.S. natural disasters reported in the EM-DAT database (http://www.emdat.be/database). 
Figure 8. Did We Identify Exogenous Food Commodity Market Shocks?

\section{Impact of food commodity supply shocks on financial markets ${ }^{\mathrm{a}}$}

S\&P 500 index

Percent

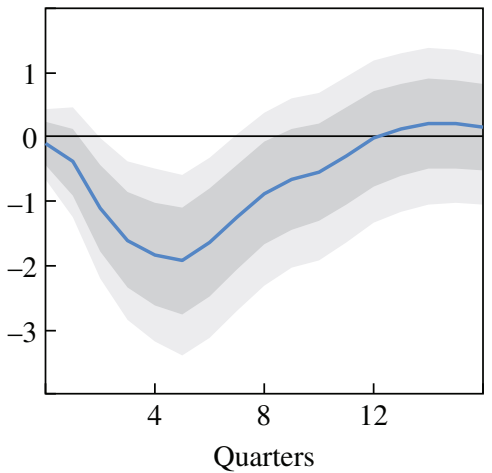

VIX volatility index

Percent

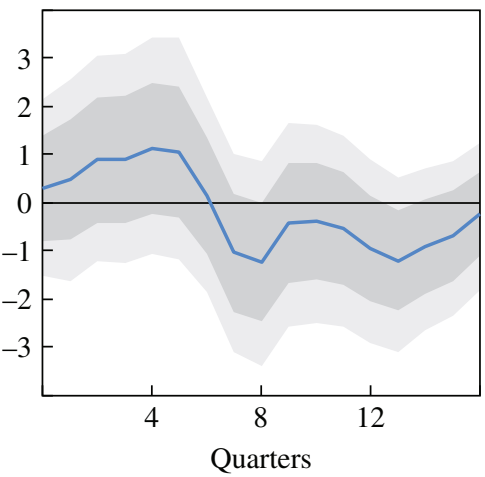

Correlation of food commodity supply shocks and USDA forecast revisions ${ }^{\mathrm{b}}$

Percent

Standard deviation

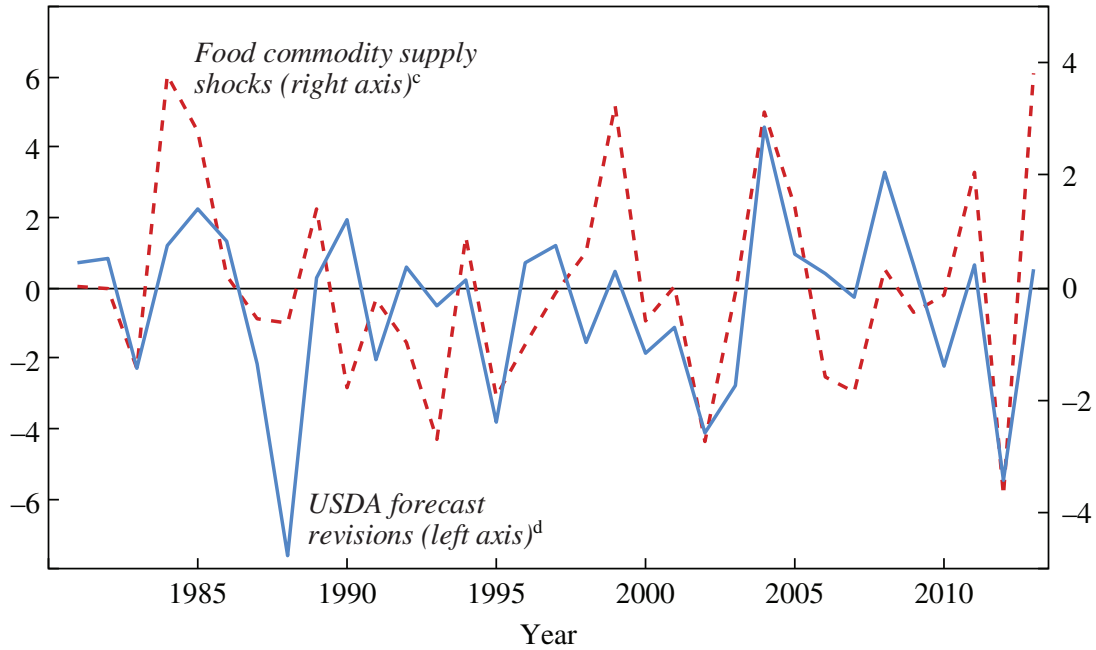

Sources: Authors' calculations; USDA.

a. Shows the impulse response function of the S\&P 500 index and the VIX stock market volatility index by adding these variables to the benchmark VAR. The darker shading indicates the 16th and 84th percentile error bands; the lighter shading indicates the 5 th and 95 th percentile error bands.

b. Shows the annual USDA forecast revisions for world grains output and annual food commodity supply shocks.

c. Food commodity supply shocks are calorie-weighted aggregates of corn, wheat, rice, and soybeans. Annual shocks are the sum of the four quarters.

d. USDA forecasts are millions of metric tons of wheat, coarse grains (corn, sorghum, barley, oats, rye, millet, and mixed grains), and milled rice. Forecast revisions are the sum of forecast revisions for the periods MayDecember and December-April. 
in opposite directions - are also consistent with food supply shocks and are hard to reconcile with other types of disturbances. Moreover, as can be observed in the bottom panel of figure 8, the estimated innovations coincide quite well with the U.S. Department of Agriculture's (USDA's) forecast revisions. Since the early 1980s, the USDA's World Agricultural Outlook Board has regularly published projections of world annual grains production. ${ }^{24}$ These projections are always for the period May-April (known as the marketing year), and are an aggregate (millions of metric tons) of wheat, coarse grains (corn, sorghum, barley, oats, rye, millet, and mixed grains), and milled rice. In order to match with the calendar year frequency of the supply shocks obtained from the VAR, we take the sum of the USDA's forecast revisions for the periods May-December and December-April. Despite the different compositions and weighting schemes, and the fact that the annual USDA forecast revisions also capture anticipated production innovations before the planting and harvesting quarter, the correlation between both series (.53) turns out to be relatively high. In sum, both the impulse responses and shock series corroborate that we have identified global food commodity market disruptions, and it is unlikely that the innovations capture other important effects or endogenous responses to the macroeconomy.

This reasoning is also confirmed by the first sensitivity check reported in figure 9, which shows the results of several alternative VAR models. The first sensitivity check orders the global food production index after global oil production, the real price of oil, and global economic activity in the Cholesky decomposition. This implies that the identified food commodity production shocks are by construction orthogonal to all possible innovations in global economic activity and the crude oil market. All variables are the same as in the benchmark VAR; to save space, however, we only show the impulse responses of six key variables. As observed in panel A of the figure, the impulse responses are nearly identical to the benchmark results.

As a second sensitivity test, we exclude U.S. food commodity production from the global production index and reestimate the VAR model with this alternative index. Accordingly, we only identify external food commodity supply shocks, which could in principle not have a direct effect on

24. An archive of these World Agricultural Supply and Demand Estimates can be found at http://usda.mannlib.cornell.edu/MannUsda/viewDocumentInfo.do?documentID=1194. 
Figure 9. Effects of Global Food Commodity Supply Shocks on Key Variables: Sensitivity Analysis ${ }^{\mathrm{a}}$

\section{Panel A. Alternative ordering of food production in VAR}

Global food production

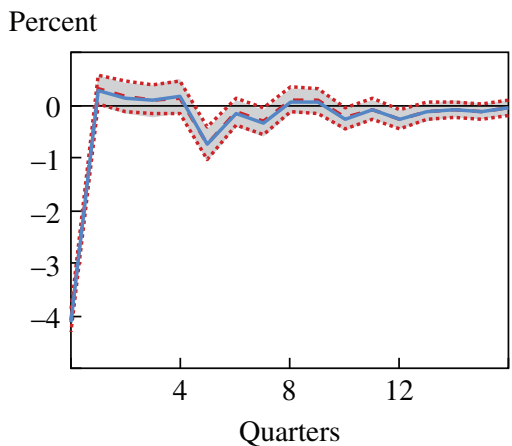

U.S. real GDP

Percent

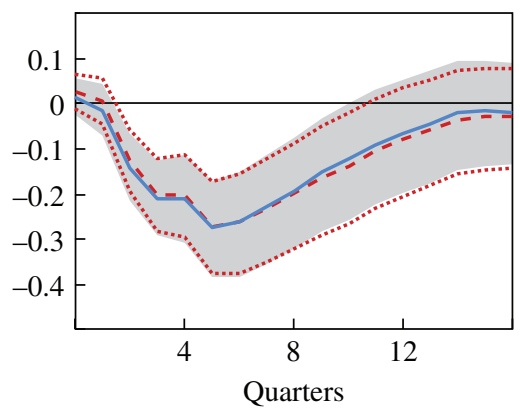

U.S. CPI

Percent

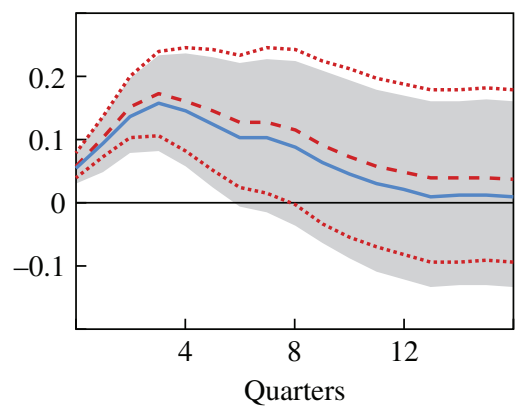

Real food commodity prices

Percent

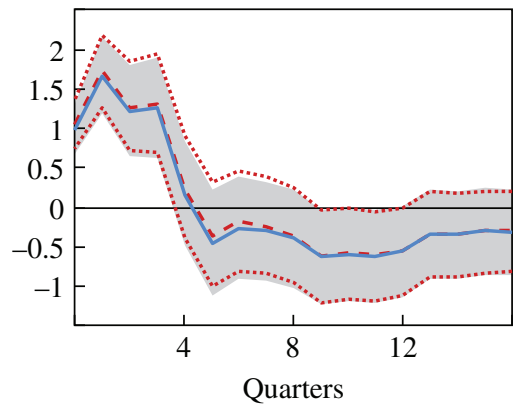

U.S. real personal consumption Percent

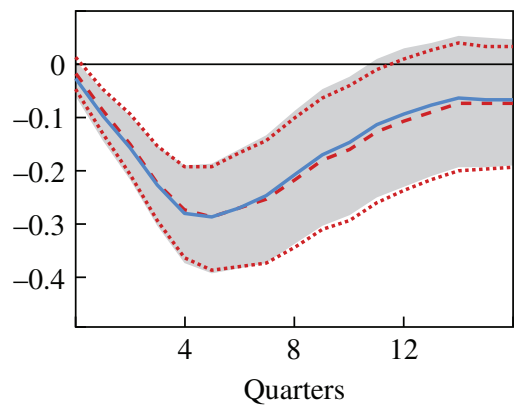

Federal funds rate

Percent

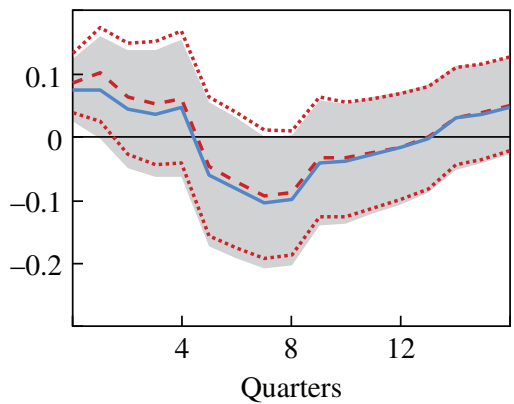

(continued) 
Figure 9. Effects of Global Food Commodity Supply Shocks on Key Variables:

Sensitivity Analysis ${ }^{a}$ (Continued)

Panel B. Global food production index, excluding U.S. food production, as a measure of food production

Global food production

Percent

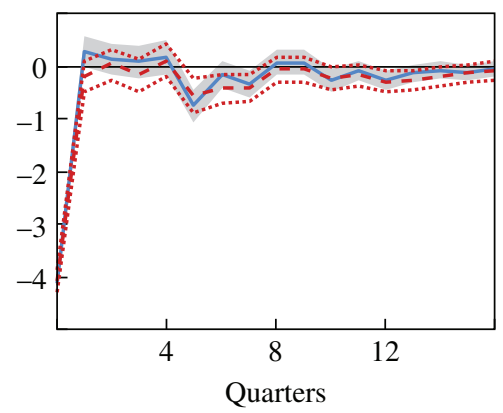

U.S. real GDP

Percent

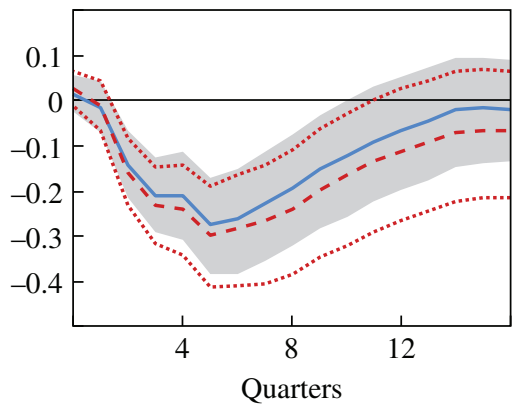

U.S. CPI

Percent

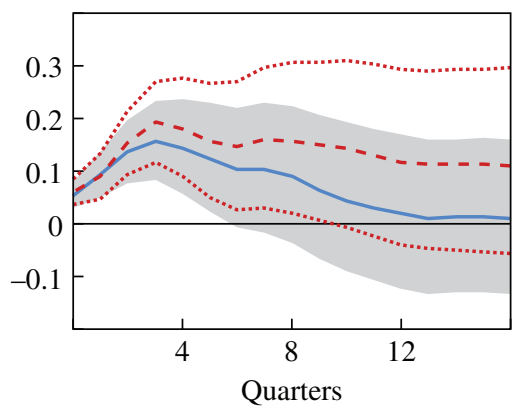

Real food commodity prices

Percent

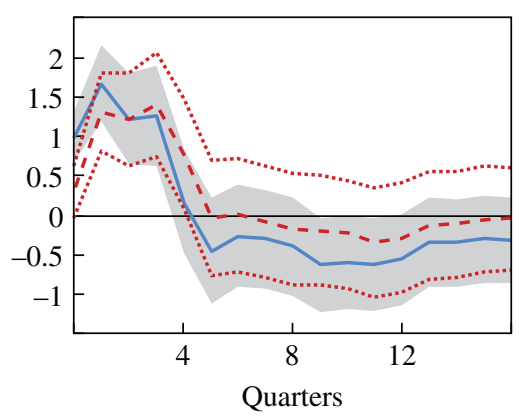

U.S. real personal consumption

Percent

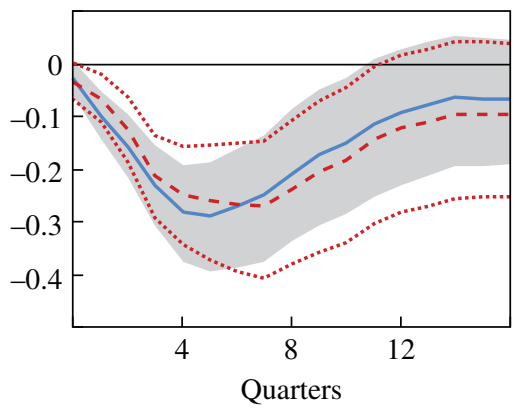

Federal funds rate

Percent

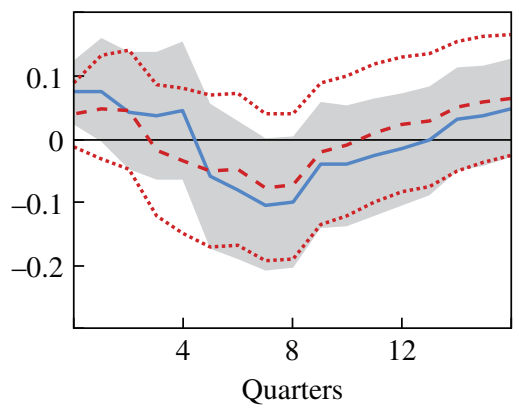


Figure 9. Effects of Global Food Commodity Supply Shocks on Key Variables: Sensitivity Analysis ${ }^{\mathrm{a}}$ (Continued)

Panel C. Real cereal prices as a measure of the food commodity price

Global food production

Percent

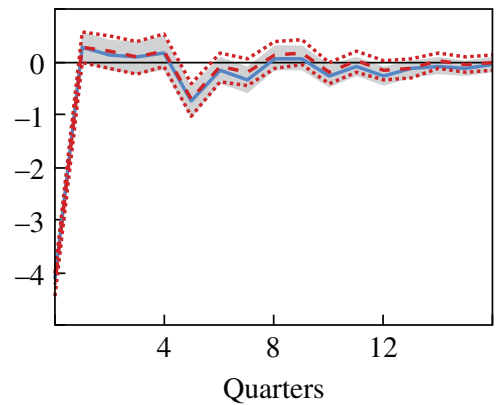

U.S. real GDP

Percent

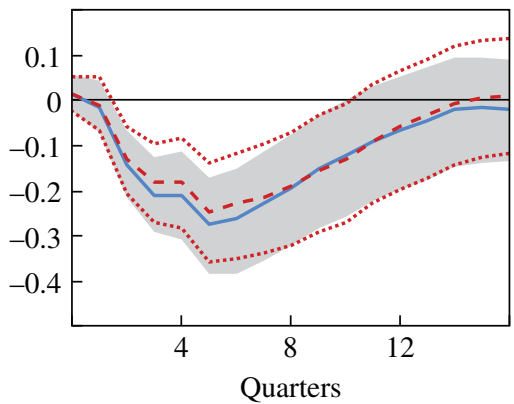

U.S. CPI

Percent

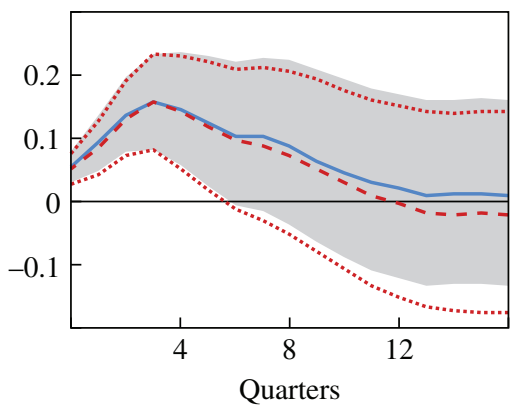

Real food commodity prices

Percent

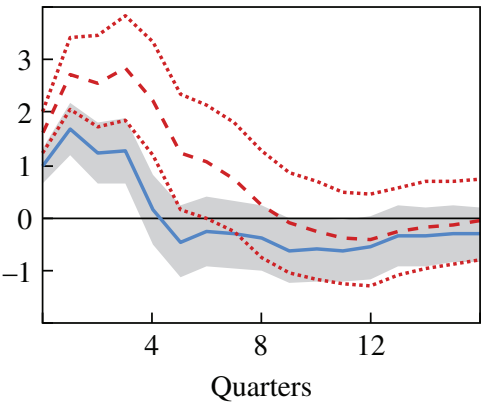

U.S. real personal consumption Percent

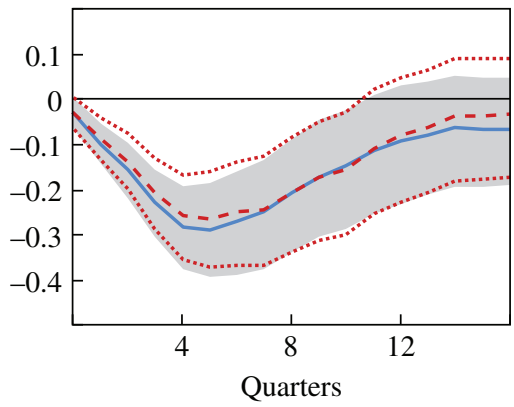

Federal funds rate

Percent

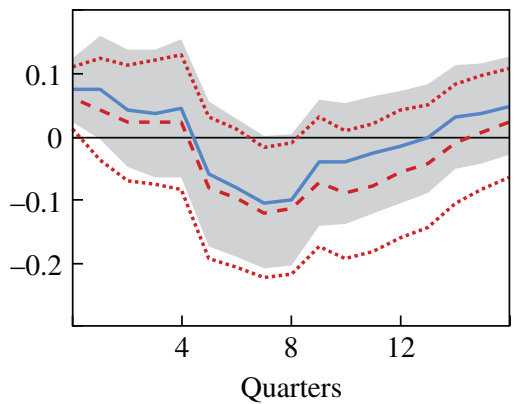

(continued) 
Figure 9. Effects of Global Food Commodity Supply Shocks on Key Variables:

Sensitivity Analysis ${ }^{a}$ (Continued)

Panel D. Global food production yields as a measure of food production

Global food production

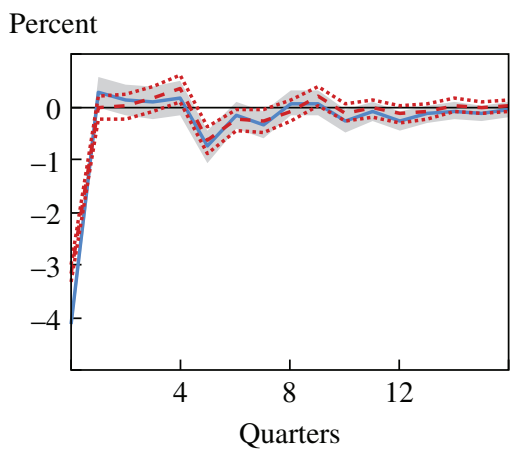

U.S. real GDP

Percent

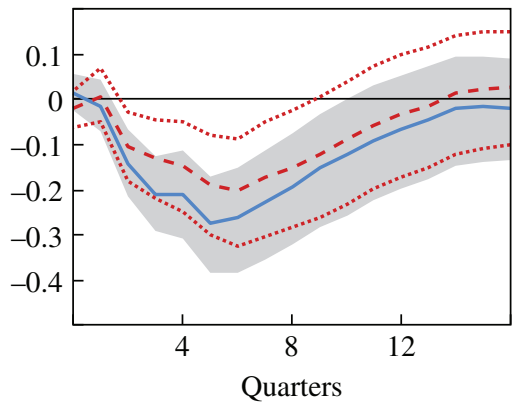

U.S. CPI

Percent

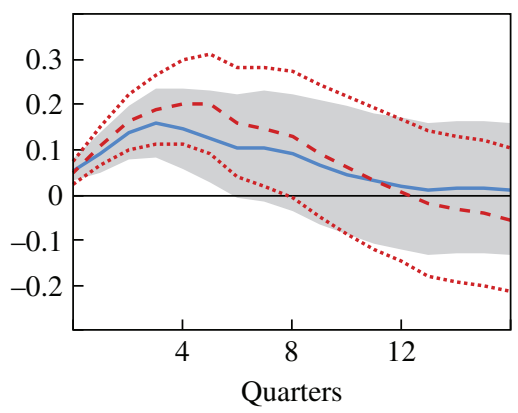

Real food commodity prices

Percent

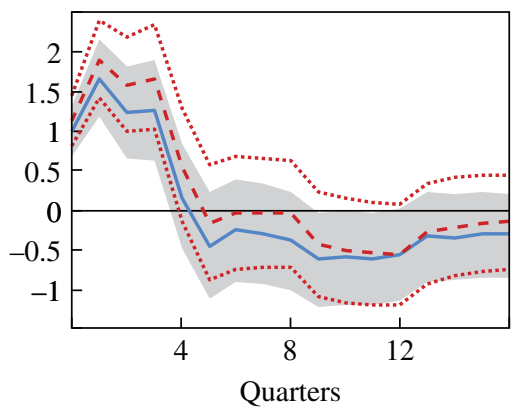

U.S. real personal consumption Percent

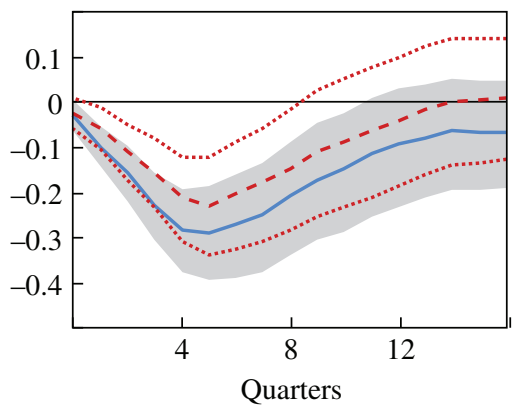

Federal funds rate

Percent

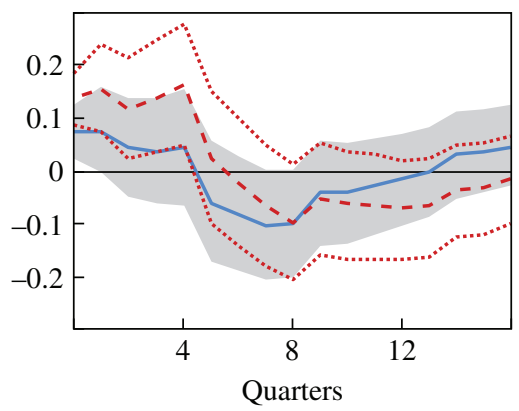


Figure 9. Effects of Global Food Commodity Supply Shocks on Key Variables: Sensitivity Analysis ${ }^{\mathrm{a}}$ (Continued)

\section{Panel E. VAR estimated in first differences}

Global food production

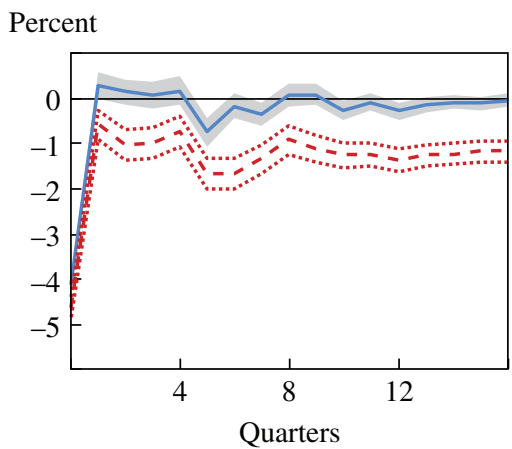

U.S. real GDP

Percent

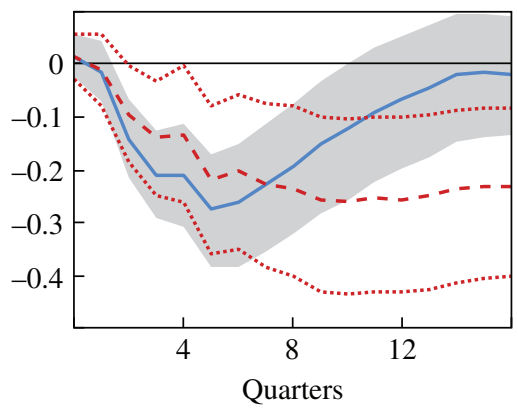

U.S. CPI

Percent

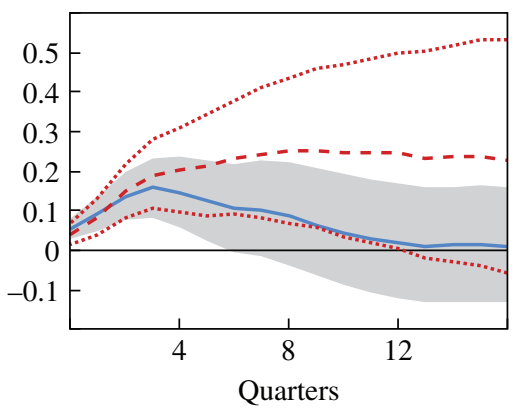

Real food commodity prices

Percent

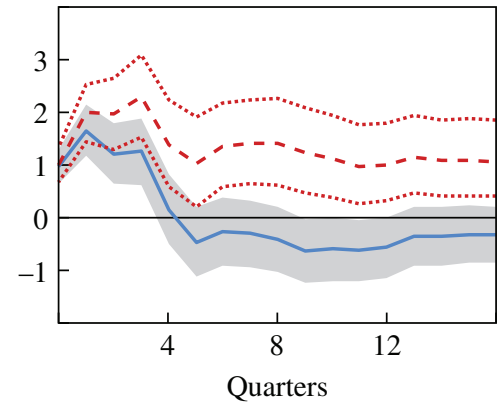

\section{U.S. real personal consumption}

Percent

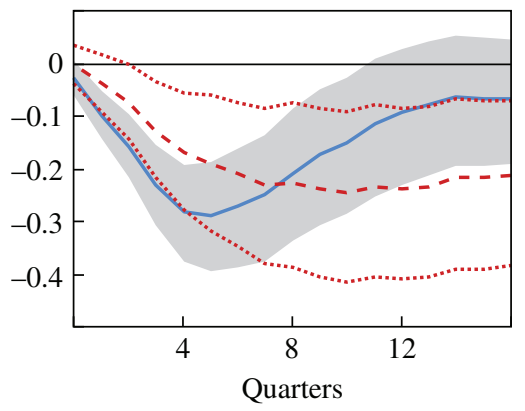

Federal funds rate

Percent

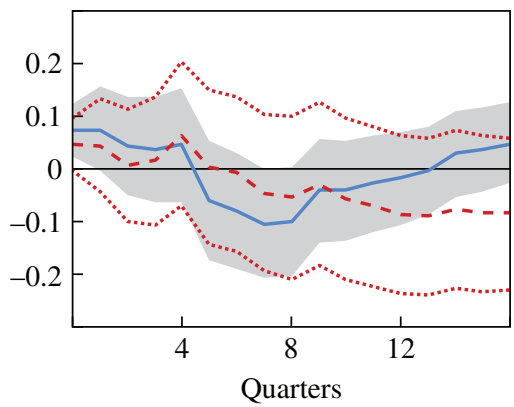

(continued) 
Figure 9. Effects of Global Food Commodity Supply Shocks on Key Variables: Sensitivity Analysis ${ }^{\mathrm{a}}$ (Continued)

Panel F. FAVAR with six unobserved macroeconomic factors, global food production, and real food commodity prices

\section{Global food production}

Percent

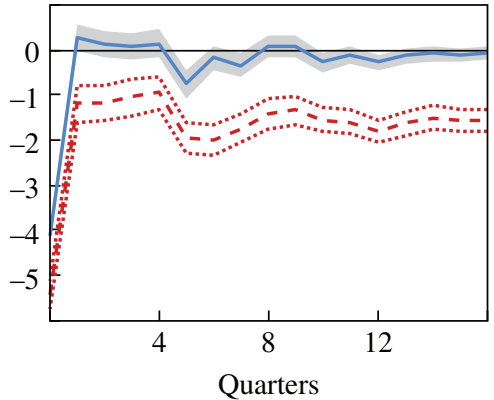

U.S. real GDP

Percent

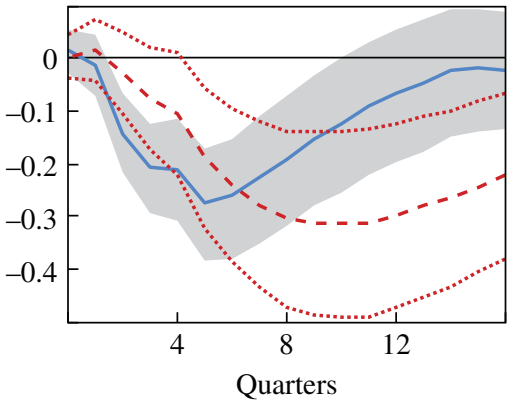

U.S. CPI

Percent

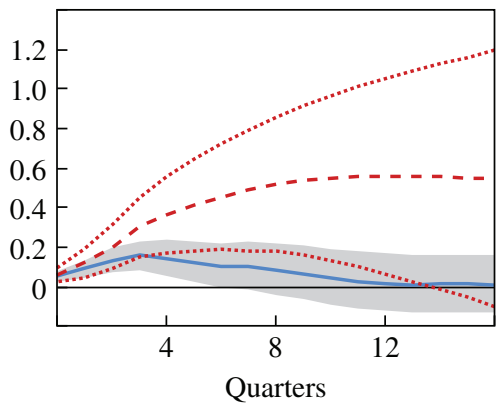

Real food commodity prices

Percent

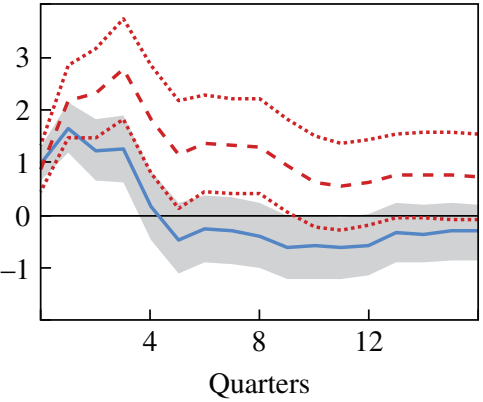

U.S. real personal consumption Percent

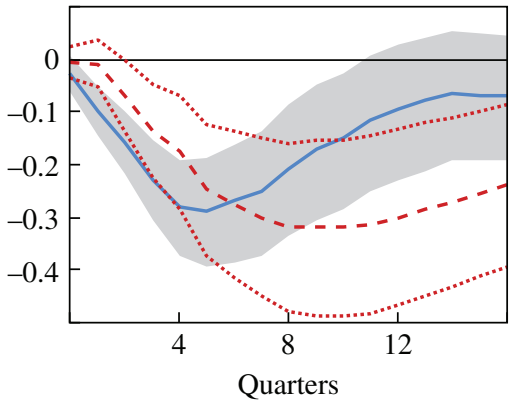

Federal funds rate

Percent

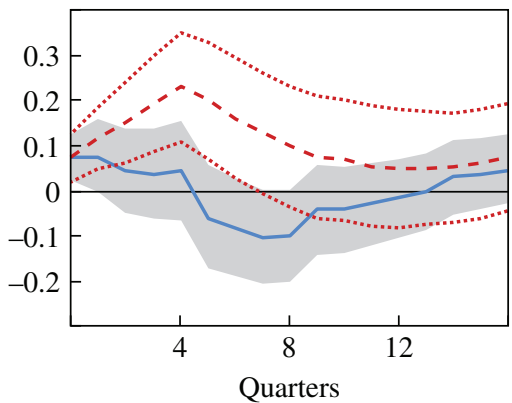

Source: Authors' calculations.

a. The range shown around estimates are the 16th and 84th percentile error bands. The solid line and shaded area are the results of the benchmark VAR (same as in figure 6); the dashed and dotted lines are results of the alternative VAR specification. 
U.S. real GDP. ${ }^{25}$ The results, which are shown in panel B of figure 9, turn out to be very similar to the benchmark results. Notice that this is also the case when we additionally exclude food production of the neighboring countries from the global production index. These impulse responses are not shown in the figure, but are available upon request. In sum, it is unlikely that the identified innovations are picking up other shocks, or that there are significant direct effects of weather variation on the U.S. economy.

ALTERNATIVE VAR SPECIFICATIONS The results are also robust for several other perturbations to the benchmark VAR. More precisely, panel C of figure 9 exhibits the impulse responses of the benchmark VAR model estimated with the real cereal price index instead of the broad food commodity price index. This index - which only contains the price of corn, wheat, rice, and soybeans-is less representative of the global food commodity market but corresponds more directly to the production index. As observed in the figure, cereal prices increase much more than the broad commodity price index after a decline in the production index. The maximum impact of a shock of 1 standard deviation on real cereal prices is 3.0 percent, while the rise in the broad index is 1.7 percent. However, the responses of all other variables are analogous to the benchmark effects. The results are thus not sensitive to the choice of the food price measure. Panel D of figure 9 shows the results with global food production yields as a measure of food production, which also takes into account the area harvested (and planted). The results are again in line with the benchmark findings. The magnitude of the shock is somewhat lower, but the effects on real food commodity prices, real GDP, consumer prices, and all other variables are quite similar to the benchmark estimations.

Finally, we check the robustness of the results for the modeling choices we have made. Specifically, panel E of figure 9 shows the results of

25. External food commodity supply shocks would not have a direct effect on U.S. real GDP unless there is a systematic correlation of non-U.S. food production shocks and U.S. food production. If this is the case, the correlation is probably small given the global level of our analysis. For example, the correlation between the estimated global food supply innovations and the Multivariate El Niño Southern Oscillation Index, the Oceanic Niño Index, and a dummy variable based on the U.S. National Oceanic and Atmospheric Administration's definition of El Niños varies between -.10 and -.11. The correlation between food production shocks excluding U.S. production and the El Niño variables varies between -.14 and -.16 . None of the correlations are statistically significant. Notice that this exercise does not rule out that weather variation has an effect on economic activity beyond food commodity markets in other countries, which could in turn affect the U.S. economy via trade. In section IV, however, we document that trade effects are relatively small and that export is not an important driver of the output consequences. 
the benchmark VAR model estimated in first differences, while panel $\mathrm{F}$ depicts the impulse responses of the key variables estimated with a factoraugmented vector autoregression (FAVAR) model. Differencing the data does not account for cointegrating relationships in the data, but it is less likely that the results are distorted, because initial conditions explain an unreasonably large share of the low-frequency variation in the variables. ${ }^{26}$ The advantage of a FAVAR model is that it uses information from a large number of time series, which reduces the possibility of an omitted variable bias. We borrow the 207-variable FAVAR model that James Stock and Mark Watson (2016) have used to estimate the effects of oil market shocks. The FAVAR is estimated with five lags of two observed factors (that is, the global food production index and real food commodity prices) and six unobserved factors. ${ }^{27}$

The impulse responses of the alternative models in panels $\mathrm{E}$ and $\mathrm{F}$ of figure 9 have been accumulated and are shown in levels. Five interesting observations, which mostly apply to both models, are worth mentioning. First, the contemporaneous decline in global food production is somewhat greater than in the benchmark VAR. Second, there is a permanent decline in global food production, along with a very persistent rise in real food commodity prices. The finding that a bad harvest in one region leads to a long-run decline of food production in another region (despite higher food prices) is rather surprising. A possible explanation is that both models do not account for cointegrating relationships among the variables. Third, whereas the magnitudes are in the same neighborhood of the benchmark VAR results, the shapes of the output effects turn out to be different. In particular, the estimated peak effects of food market shocks on economic activity are approximately one year later in the FAVAR and the VAR estimated in first differences, compared with the VARs estimated in log levels.

26. VARs estimated with ordinary least squares or flat priors tend to attribute an implausibly large share of the variation in the data to a deterministic component. The reason is that the criterion of fit does not penalize parameter values that make the initial conditions unreasonable as draws from the model's implied unconditional distribution. As a result, the model attributes the low-frequency behavior of the data to a process of return from the initial conditions to the unconditional mean. This issue has been raised in the context of Mark Watson's discussion of our paper. Also see Sims (2000) for a discussion on the role of initial conditions for the low-frequency variation in observed time series.

27. This model has also been used by Mark Watson for the discussion of our paper. We are grateful to him for sharing the code and data sets. The 207-variable time series consists of real activity, prices, productivity, earnings, interest rates, spreads, money, credit, assets, wealth, and oil market variables, as well as variables representing international activity. All variables are transformed to a stationary form. See Stock and Watson (2016) for details. 
Fourth, the impact of food commodity market disturbances on consumer prices seems to be much larger than the benchmark effects, particularly in the FAVAR model. Notice, however, that the uncertainty of the estimates is quite high, while the error bands overlap. Fifth and finally, the federal funds rate also rises more strongly in the FAVAR. Overall, although the shapes of several impulse responses are somewhat different, we can conclude that the magnitudes of the macroeconomic consequences of food commodity market shocks are not sensitive to the modeling choices we have made. ${ }^{28}$

SUBSAMPLE ANALYSIS We now assess the robustness of the results across subsamples. A constraint on doing this is the relatively large number of variables and lags in the benchmark VAR model, which causes overparameterization problems for short sample periods. We therefore report the results of two exercises. First, we reestimate the benchmark VAR model for the sample periods 1963:Q1-1999:Q4 and 1985:Q1-2013:Q4, respectively. The former sample period does not take into account the global food crisis of the 2000s and the subsequent collapse of food commodity prices, or the recent rising relevance of biofuels in energy consumption depicted in figure 2. The latter sample period, in contrast, excludes the major swings of food commodity prices in the 1970s and the so-called Great Inflation monetary policy regime.

The results for the subsamples are shown in figure 10. Interestingly, despite the reduced relevance of food consumption in total household expenditures over time, the effects of global food commodity supply shocks on real GDP, personal consumption, and consumer prices are quite similar for both subsamples and are comparable to the benchmark VAR results. A possible explanation is the increased share of biofuels in energy consumption in recent times, which could have offset the declining share of food consumption in household expenditures. In particular, the increased ethanol production in the second half of the 2000s could have led to a

28. By estimating food production equations (with all lagged VAR variables as independent variables), and implementing the residuals in a simple local projection framework, we have also explored whether the existence of nonlinearities could have influenced the estimation results. Specifically, we have examined whether the macroeconomic consequences are different (i) when we allow food production to react differently to increases and decreases of the lagged independent variables, (ii) depending on the quarter of the shock, and (iii) for unfavorable versus favorable shocks. Overall, we do not find evidence that nonlinearities have distorted the average effects reported in this paper. We do find support for the hypothesis that unfavorable shocks have stronger macroeconomic effects than favorable shocks (respectively greater and smaller than the average effects). The standard errors are, however, relatively large. It is worth investigating this more carefully in future research. 
Figure 10. Subsample Analysis Based on Benchmark VAR:

1963-99 versus $1985-2013^{a}$

\section{Global food production}

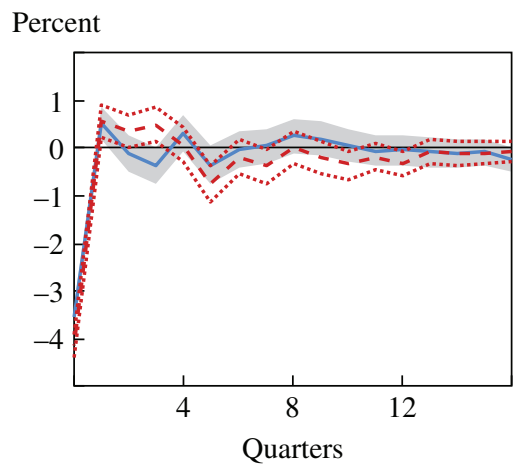

Volume of seeds set aside for planting

Percent

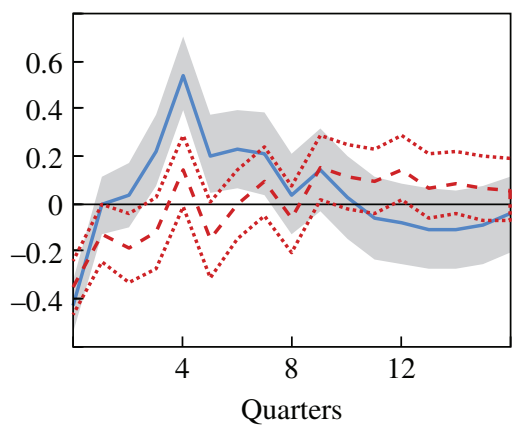

Global oil production

Percent

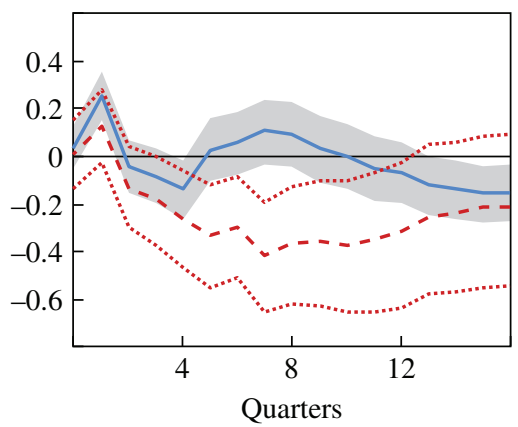

\section{Real food commodity prices}

Percent

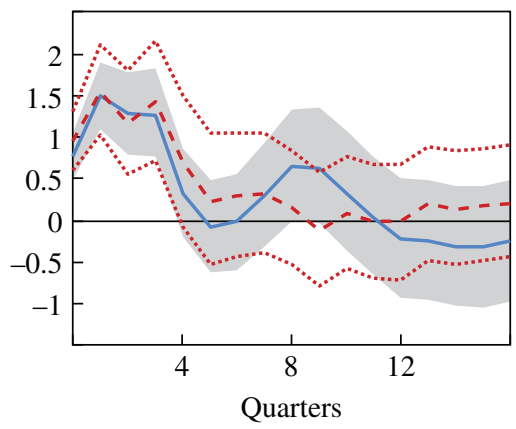

Global economic activity

Percent

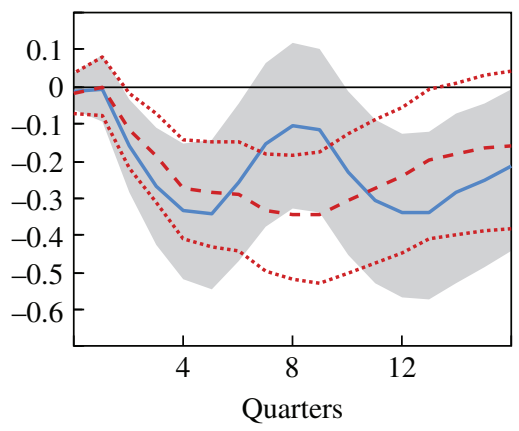

Real oil price

Percent

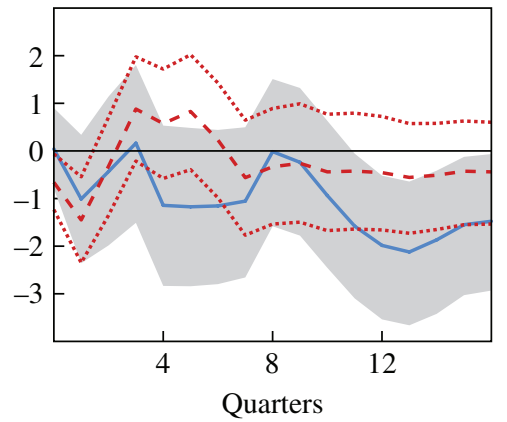


Figure 10. Subsample Analysis Based on Benchmark VAR: 1963-99 versus 1985-2013a (Continued)

\section{U.S. real GDP}

Percent

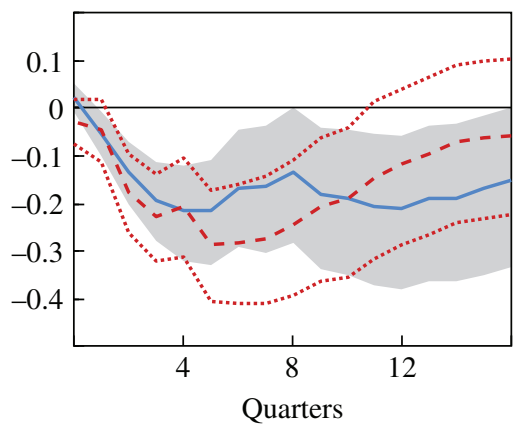

U.S. CPI

Percent

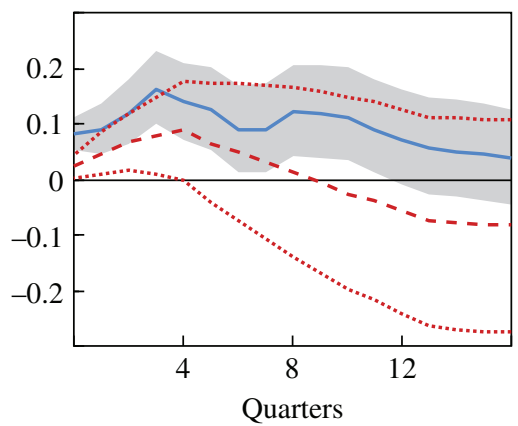

\section{U.S. real personal consumption}

Percent

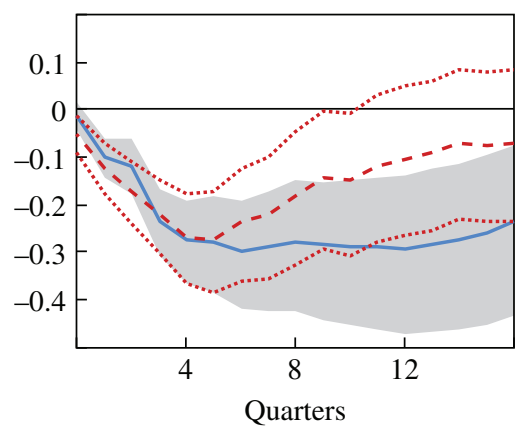

Federal funds rate

Percent

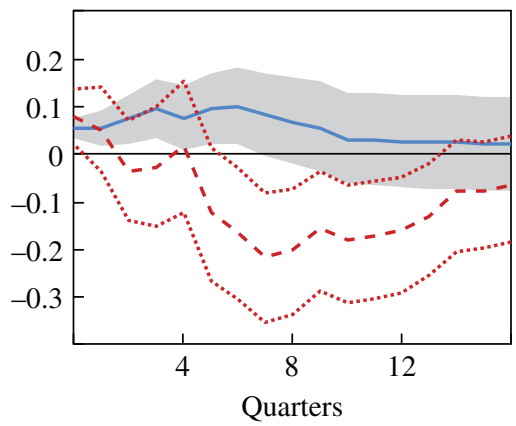

Source: Authors' calculations.

a. The range shown around estimates are the 16th and 84th percentile error bands. The solid line and shaded area are the results for the period 1985:Q1-2013:Q4; the dashed and dotted lines are the results for the period 1963:Q1-1999:Q4.

tighter link between agricultural and energy prices, magnifying the consequences of food commodity market disruptions for the U.S. economy at the end of the sample.

An enhanced link between food commodity markets and energy prices is confirmed by the second exercise to assess time variation. For this exercise, we borrow results from Peersman, Sebastian Rüth, and Wouter Van der Veken (2016). More specifically, elaborating on the present study, Peersman, Rüth, and Van der Veken (2016) estimate a more parsimonious version of the benchmark VAR across subsamples-as well as time-varying 
parameter VARs with stochastic volatility, in the spirit of Giorgio Primiceri (2005) - to examine whether crude oil and food commodities have become more closely linked in recent periods. The VAR used by Peersman, Rüth, and Van der Veken (2016) contains the global food production index, real cereal prices, global crude oil production, the real price of crude oil, and global economic activity. Within the VAR model, global food commodity supply and crude oil supply shocks are identified. The results reveal that unfavorable food commodity supply shocks have no impact on global crude oil prices until 2003, after which their impact starts to gradually rise over time. A similar story emerges for oil supply shocks; that is, oil supply shocks have no significant effects on real cereal prices until 2003, after which the effects become significant. Hence, crude oil and food commodities seem to have become closer substitutes over time, in line with the rising share of biofuels in petroleum consumption.

In the first panel of figure 11, we reproduce Peersman, Rüth, and Van der Veken's (2016) results for the sample periods 1985:Q1-2002:Q4 and 2003:Q1-2014:Q4 for global food commodity supply shocks. ${ }^{29}$ As can be observed in the figure, a food market disturbance that raises real cereal prices also triggers an immediate shift of crude oil prices in the post-2003 period. In the second panel, we show the macroeconomic consequences of the shocks in both periods by adding a set of U.S. variables one by one to the five-variable VAR model. Some caution when interpreting the magnitudes of the responses is required because the rise in real cereal prices is more persistent in the first subsample period. If we take this into account, we can again conclude that the consequences for real GDP, personal consumption, and consumer prices have not dramatically changed over time. But this is not the case for CPI energy. In particular, food commodity supply shocks turn out to have a significant impact on CPI energy in the recent period, in contrast to an insignificant effect in the period before 2003. Put differently, due to the rising share of biofuels in energy consumption, food market disturbances currently also have inflationary effects via energy prices.

29. Notice that the VARs given by Peersman, Rüth, and Van der Veken (2016) are estimated with real cereal prices because cereal prices are more directly linked to biofuels. It is also easier to compare the magnitudes with real crude oil prices and examine their interplay. The impulse responses in both periods have been normalized to the maximum rise of real cereal prices obtained in subsection II.D. Furthermore, because the VAR model does not contain the volume of seeds that are set aside for planting, there is one extra year of data available at the end of the sample period relative to the benchmark VAR in the present paper. 
Figure 11. Subsample Analysis Based on Smaller VAR: 1985-2002 versus 2003-14a

Results of five-variable VAR model from Peersman, Rüth, and Van der Veken (2016)

Global food production

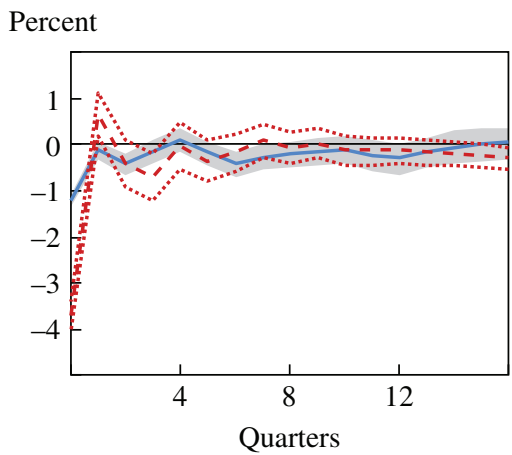

Global economic activity

Percent

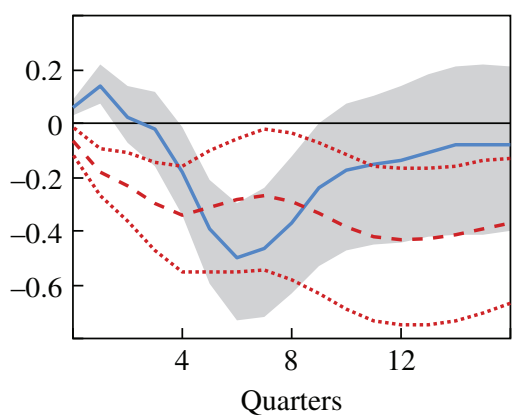

Real oil price

Percent

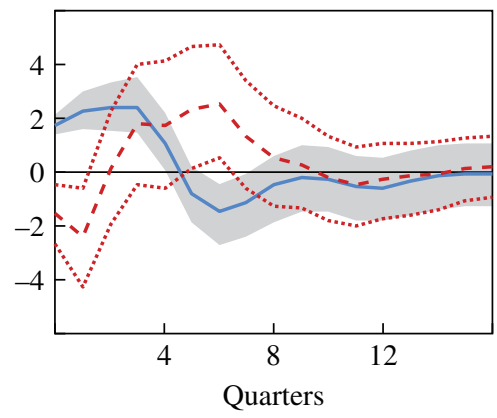

Real cereal prices

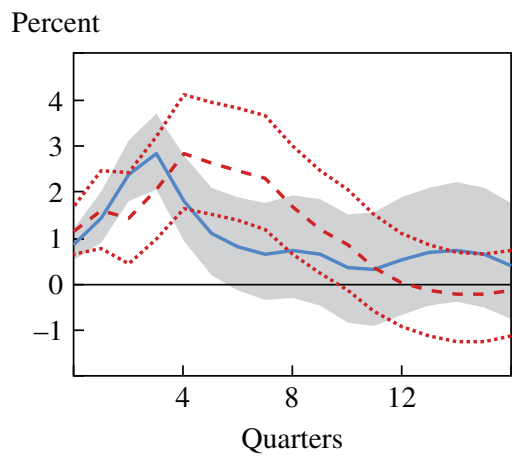

Global oil production

Percent

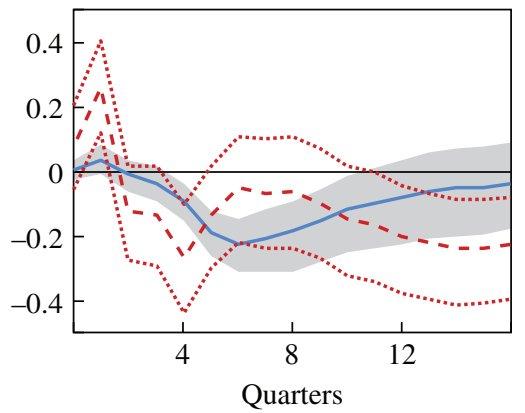


Figure 11. Subsample Analysis Based on Smaller VAR: 1985-2002 versus 2003-14 (Continued)

\section{Impact on U.S. variables ${ }^{b}$}

\section{U.S. real GDP}

Percent

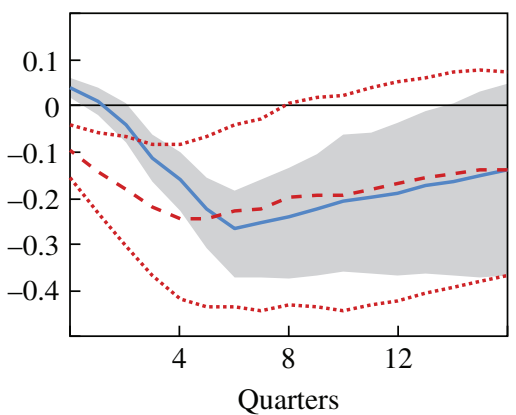

U.S. CPI

Percent

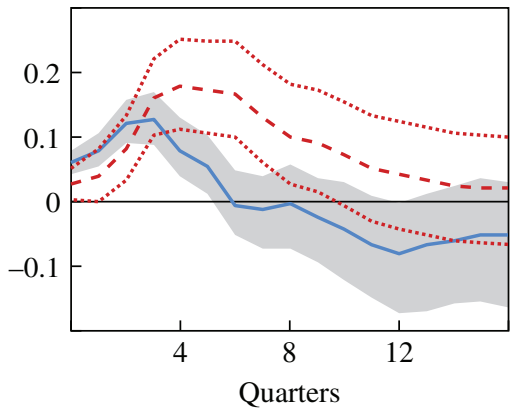

CPI energy

Percent

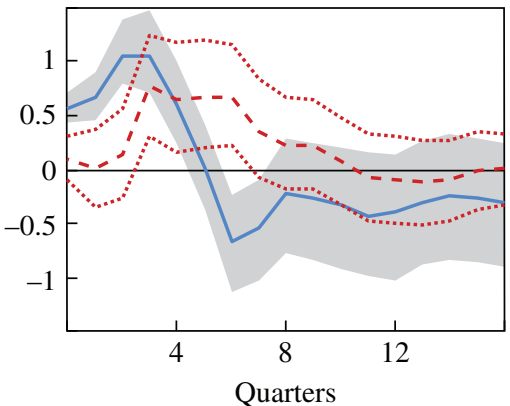

\section{U.S. real personal consumption} Percent

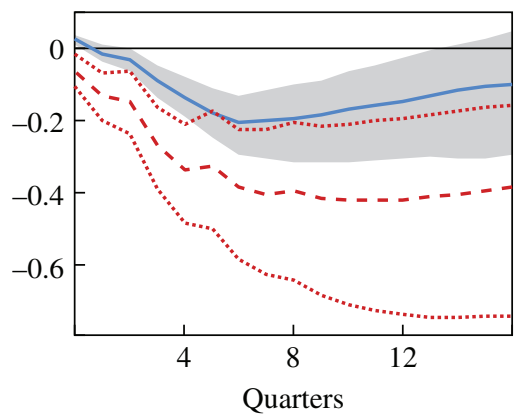

Federal funds rate

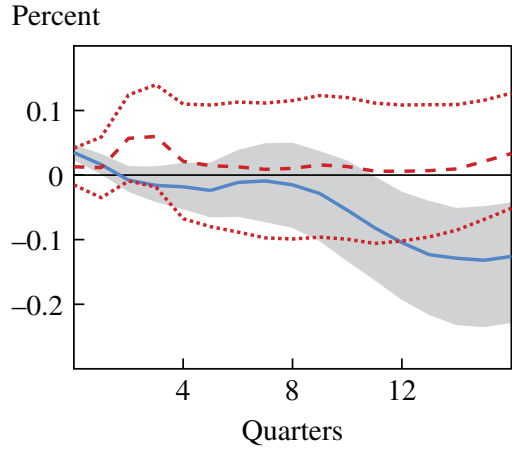

Sources: Authors' calculations; Peersman, Rüth, and Van der Veken (2016).

a. The range shown around estimates are the 16th and 84 th percentile error bands. The solid line and shaded area are the results for the period 2003:Q1-2014:Q4; the dashed and dotted lines are the results for the period 1985:Q1-2002:Q4.

b. Variables are added one by one to the global VAR model. 


\section{A Narrative Approach to Identifying Food Market Disturbances}

As an alternative approach to examine the consequences of food commodity market disruptions for the U.S. economy, we rely in this section on historical documents to identify exogenous food market shocks. Narrative methods to address the identification problem have a long-standing tradition in macroeconomics. For example, they were used by Romer and Romer (1989) to estimate the effects of monetary policy changes. By examining the minutes of the Federal Open Market Committee's policy deliberations, they identify six episodes of large independent restrictive monetary policy shocks, which are then included as a dummy variable in an autoregressive model to estimate the macroeconomic consequences. Similarly, by reading through Bloomberg Businessweek, Ramey and Shapiro (1998) create a dummy variable capturing major military buildups. The dummy is then embedded in a standard VAR to examine the impact of government spending shocks. Ramey (2011) extends this approach by creating a quantitative narrative series of exogenous news shocks on government spending. Romer and Romer (2010) use the narrative record, including presidential speeches and congressional reports, to identify major tax policy shocks. Perhaps most closely related to our application, Hamilton (1983, 2003) considers a number of historical episodes when changes in oil prices were almost solely driven by exogenous disturbances to supply that had little to do with macroeconomic conditions-for example, political and military conflicts in oilproducing countries - to estimate the dynamic effects of oil market shocks.

Whereas VARs are constrained by relatively small information sets, the advantage of a narrative approach is the possibility of incorporating a large amount of information, including expectations. It also requires fewer assumptions, and there is no need to identify a structural form. However, it implies judgment on the part of the researcher, whereas shocks may still contain endogenous components. It can thus be considered a useful complementary analysis for the VAR results based on the global food production index. In subsection III.A, we describe the narrative approach to identify exogenous food commodity market shocks. Subsection III.B discusses the estimation method, and subsection III.C presents the results.

\section{III.A. Historical Episodes of Major Exogenous Food Commodity Market Shocks}

To quantify the macroeconomic consequences of changes in food commodity prices, it is crucial to identify changes in food commodity prices 
that are unrelated to the state of the economy-that is, movements for which the proximate causes are disturbances in global food commodity markets. We rely on FAO reports, newspaper articles, disaster databases, and several other online sources to identify historical episodes of such movements. The task is daunting, given the global level of the analysis. Continuous, and many times even conflicting, events affect food commodity markets somewhere in the world. We therefore only include episodes that fulfill these criteria:

- There needs to be an event that is important enough to affect food commodity markets at the global level, such as weather shocks in a major food-producing region, or unanticipated news on the volume of global food production (for example, a sizable revision of expected agricultural production by the USDA).

- The event should have an unambiguous significant effect on global food commodity prices. A shift in commodity prices is considered to be significant if either the quarterly change in food commodity prices or the accumulated change over two subsequent quarters differs by at least 1 standard deviation from the sample mean. ${ }^{30}$

- There should be no developments in the macroeconomy, alternative events, or macroeconomic news that could also have a discernible impact on food commodity prices. For example, we do not consider admissible food market events if there is simultaneously a significant shift in crude oil prices ( 1 standard deviation from its sample mean) or in economic activity (for example, a U.S. or global recession). Put differently, we eliminate or minimize possible endogenous movements in food commodity prices to current or future fluctuations in the business cycle; that is, the event in food commodity markets must be the proximate cause of the price shift. ${ }^{31}$ No ambiguous cases are selected as episodes.

A narrative approach to identifying exogenous shocks involves judgment calls, which is a concern we acknowledge. However, we believe that we have identified 13 episodes that could reasonably be interpreted as major exogenous food commodity market disturbances that are unrelated to the state of the economy. The estimation results are not driven by a

30. The standard deviations of the quarterly change in food commodity prices and accumulated change over two subsequent quarters are 5.7 and 9.1 percent, respectively, while the means are -0.31 and -0.62 percent, respectively.

31. Crude oil is not only used in the food production process or a close substitute for food commodities to produce energy products. A shift in crude oil prices could also signal changes in (expected) demand for commodities more generally. 
single episode because they are relatively similar if we exclude individual events from the estimations. Six episodes are unfavorable food market disruptions, whereas we have detected seven favorable shocks to food commodity markets. Examples of unambiguously unfavorable shocks include the Russian Wheat Deal (combined with a failed monsoon in southeast Asia) in the summer of 1972 and the more recent Russian and Ukrainian droughts of 2010 and 2012. Conversely, a number of unanticipated significant upward revisions in the expected harvest volume (for example, in 1975,1996 , and 2004) can clearly be classified as episodes of favorable food market shocks. The dates, as well as brief descriptions of all global food commodity market events, are reported in table 1 . A detailed motivation for the selected quarters can be found in the online appendix to the paper. In every case, we attempt to give explanations and quotations so other researchers can see our reasoning for classifying the episodes as food commodity market disruptions. To give an idea of our approach, the appendix at the end of this paper reproduces the motivation for the most recent shock that we identified in 2012:Q3.

\section{III.B. Estimation Method}

There is no one-to-one mapping between the true structural shocks and the observed changes in food commodity prices in these 13 episodes. We therefore first construct a dummy variable, which is equal to 1 for the unfavorable food market disturbances that we have identified and is equal to -1 for favorable food market events. The idea is that this dummy variable series is a noisy measure of the true food market shocks and can be used as an external instrument to identify exogenous changes in global food commodity prices. In this context, Karel Mertens and Morten Ravn (2013) show that a series based on narrative evidence is robust to many types of measurement problems and is a valid instrument, as long as the series is contemporaneously correlated with the structural shock and is contemporaneously uncorrelated with all other structural shocks in the economy.

In the next step, we examine the dynamic effects of shocks to global food commodity prices on the U.S. economy using Jordà's (2005) local projection method for estimating impulse responses. ${ }^{32}$ The advantage of the local projection method is that it is more robust to misspecification than

32. A similar approach has been used by Ramey and Zubairy (2014) to estimate the effects of narratively identified government spending shocks. 


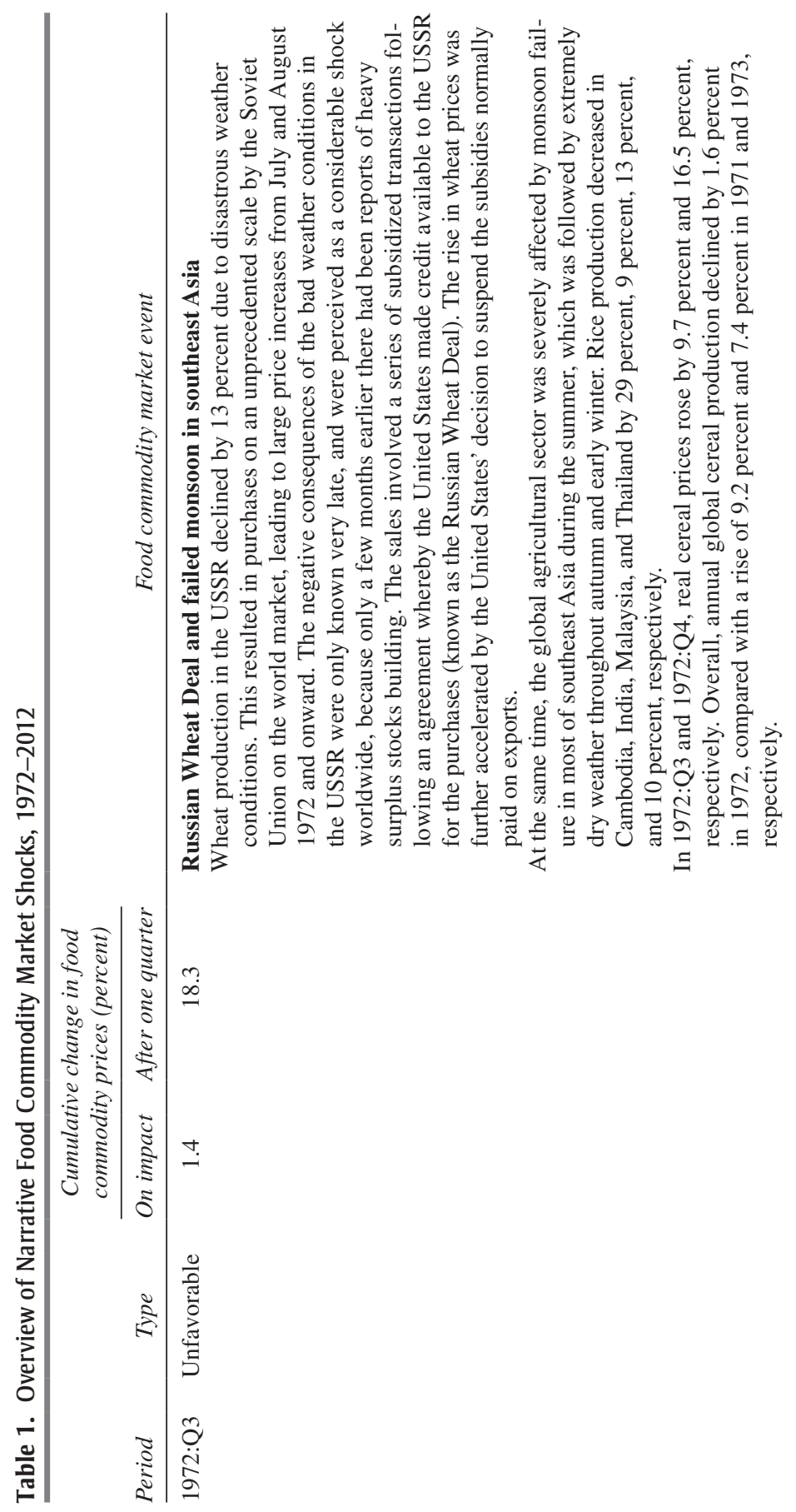




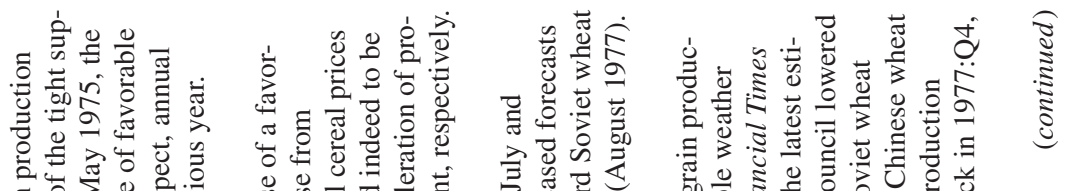

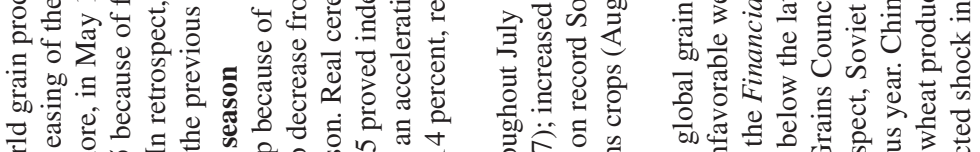

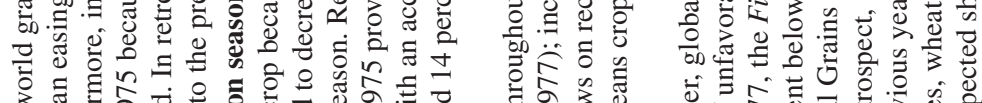

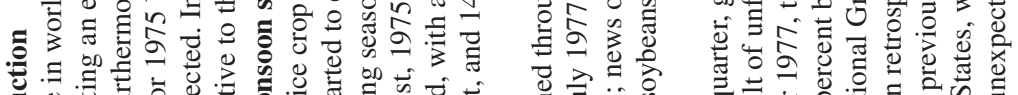

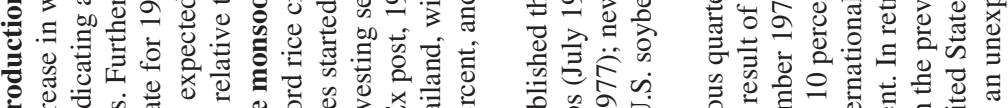

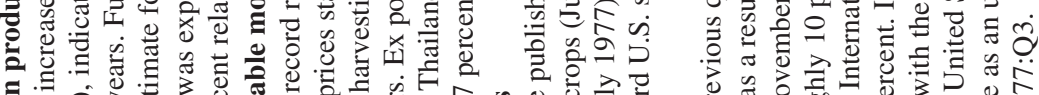

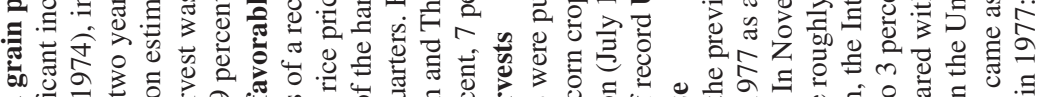

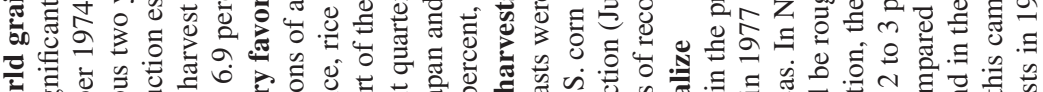

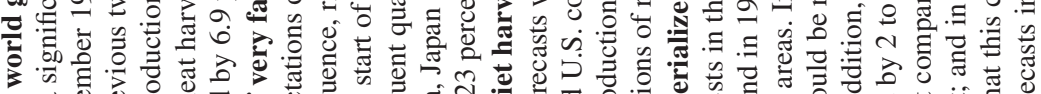

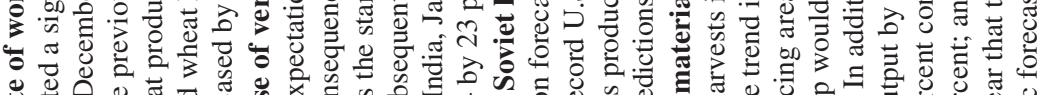

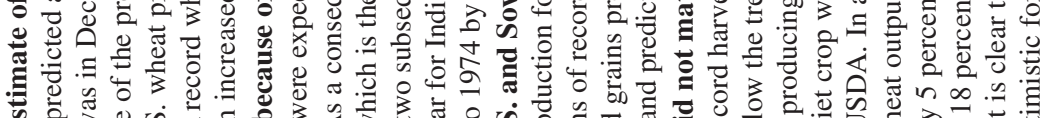

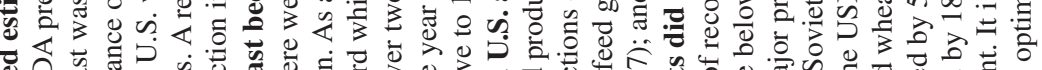

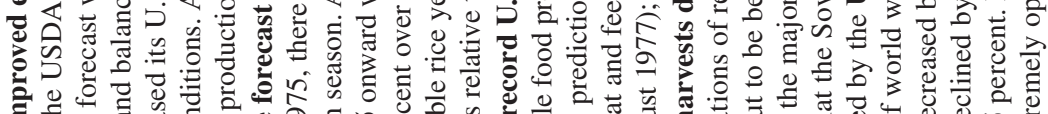

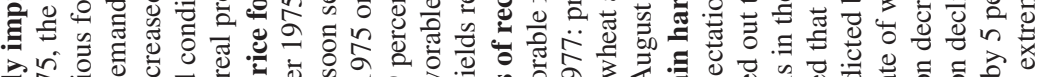

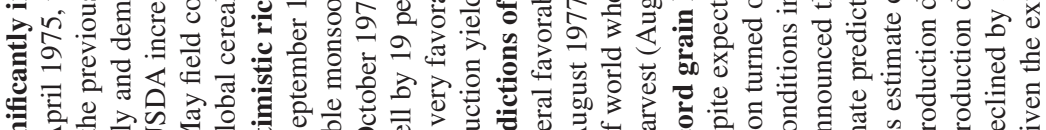

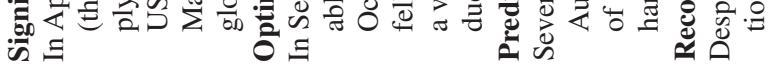

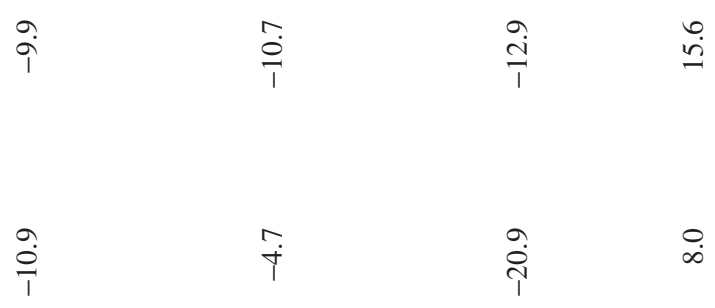

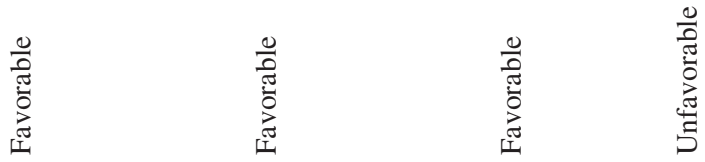

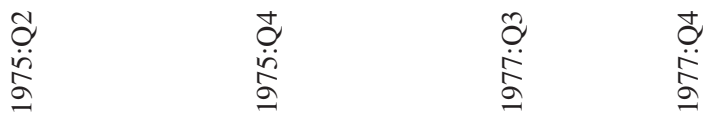




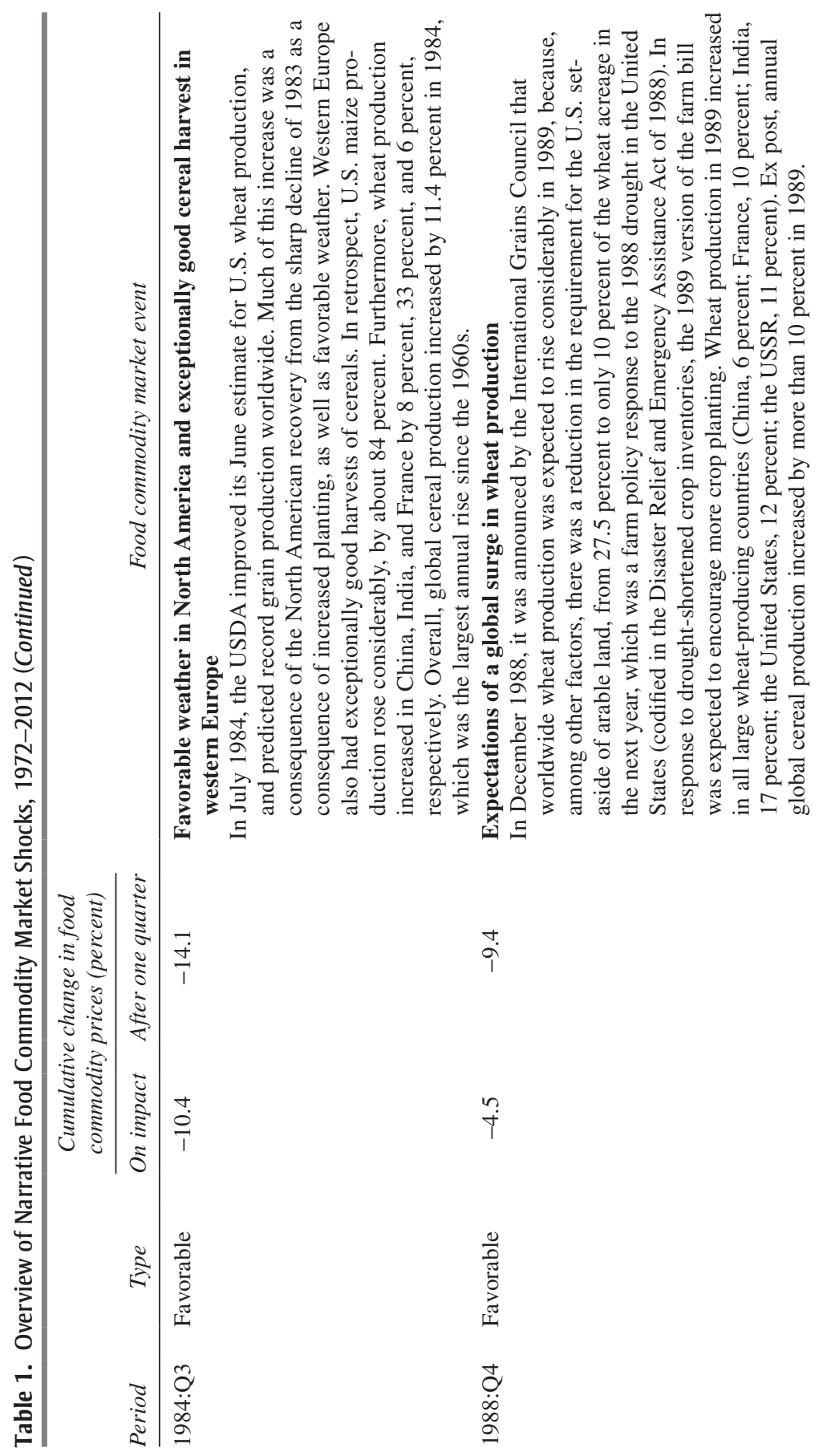




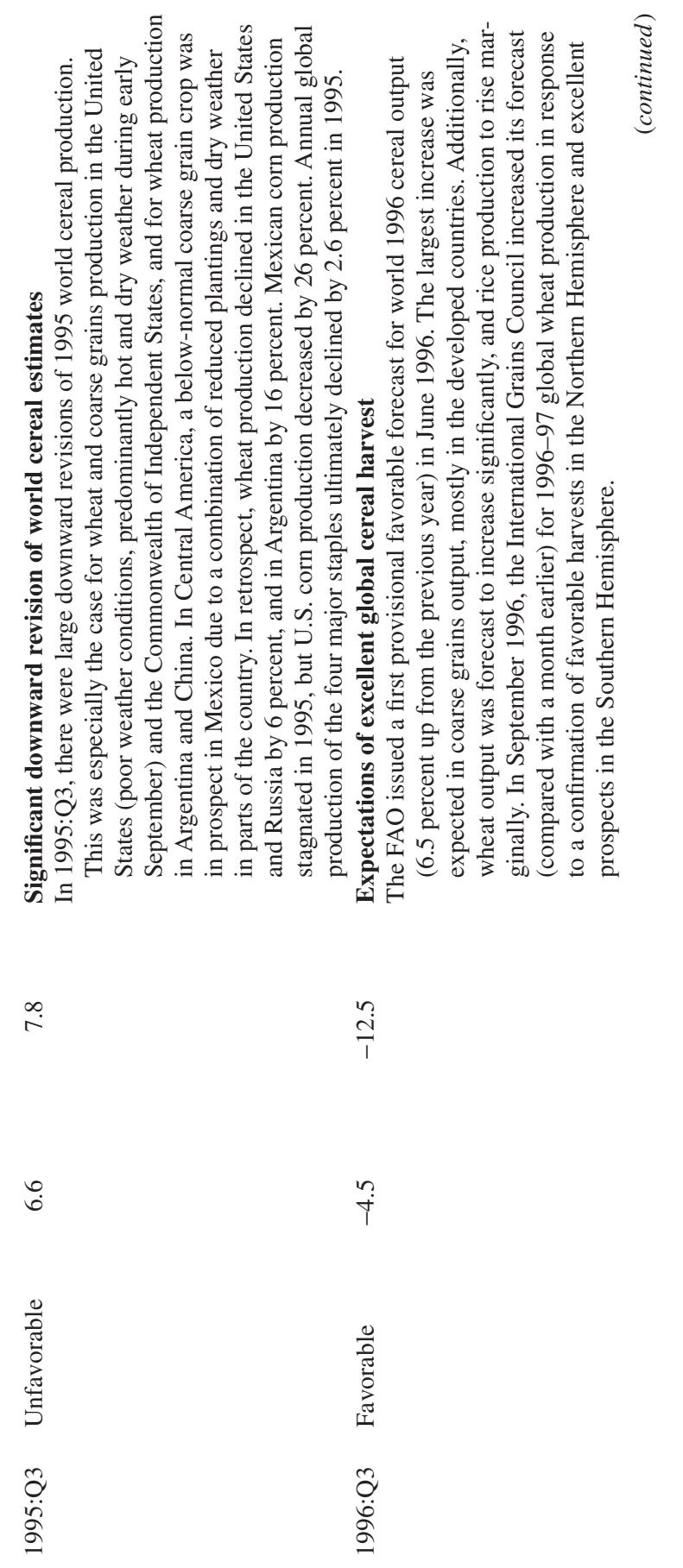




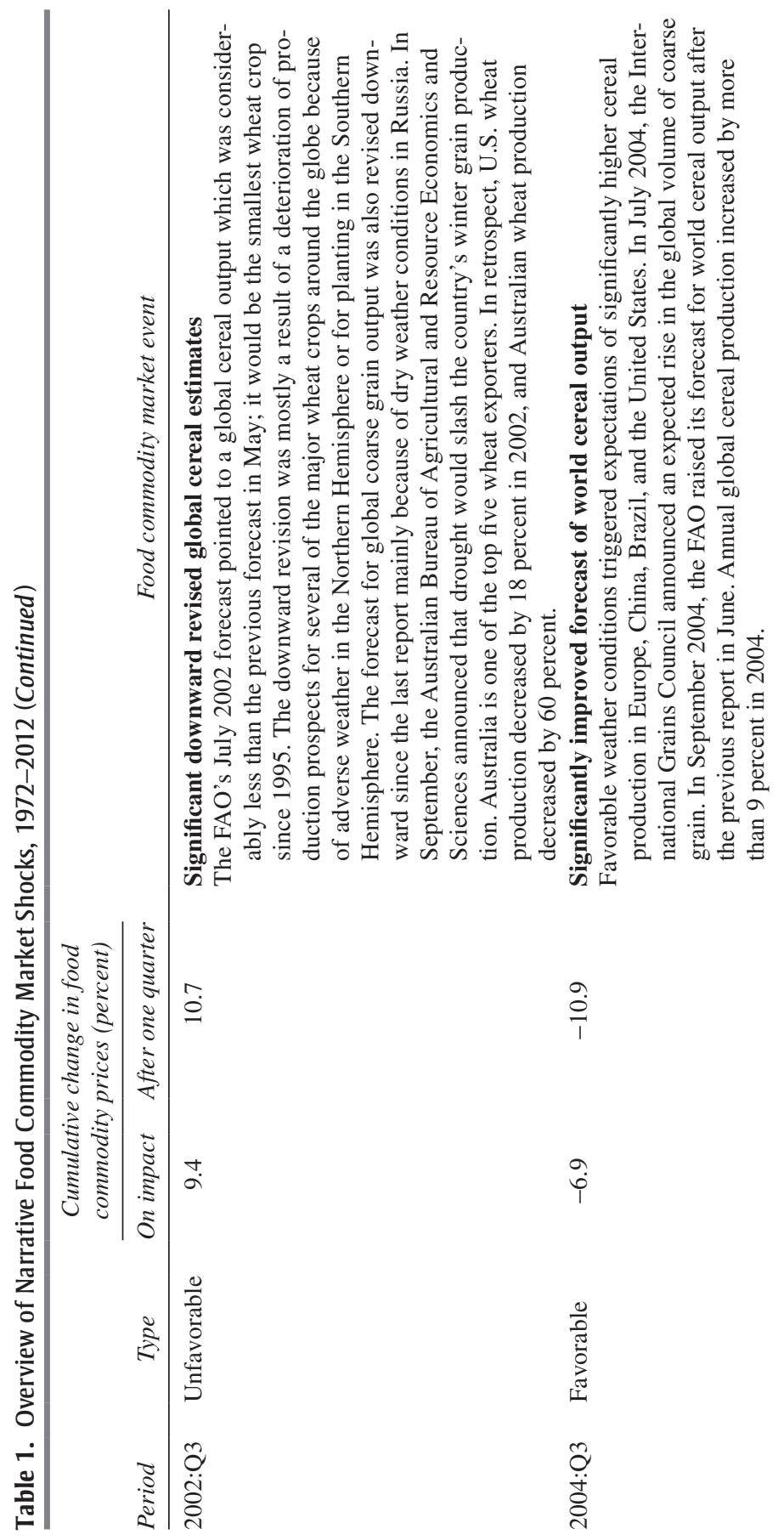




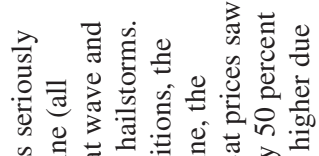

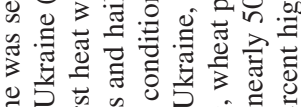

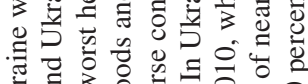

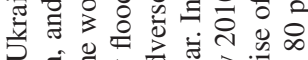

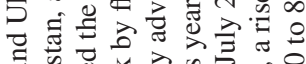

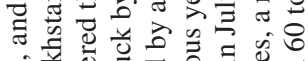

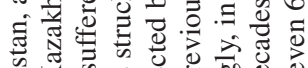

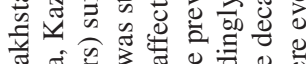

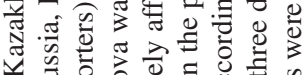

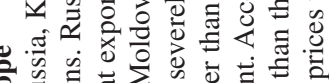

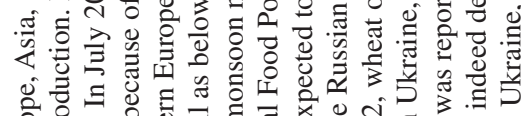

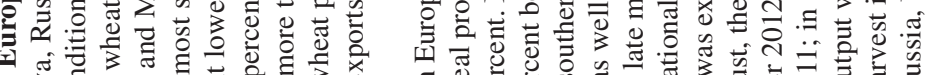

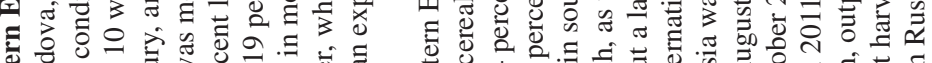

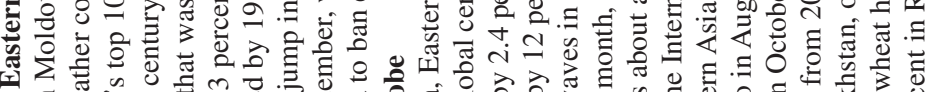

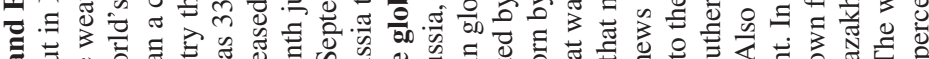

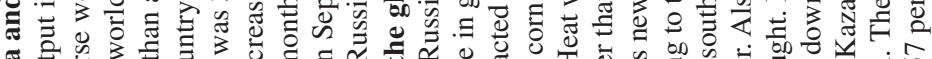

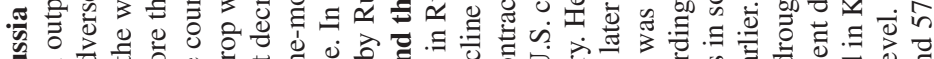

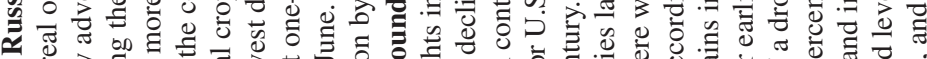

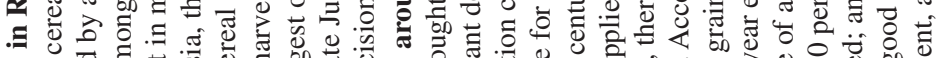

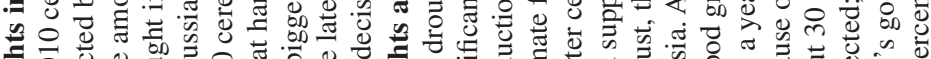

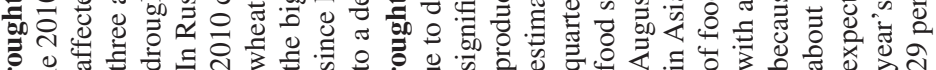
音产

$\overline{\text { ลี }}$

o.

$\stackrel{\infty}{\infty}$

$\stackrel{9}{2}$

苟

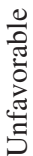

ڤ્م

2

ì 
VARs because it does not impose implicit dynamic restrictions on the shape of the impulse responses, and not all variables are required to be included in all equations. In addition, joint or point-wise analytic inference is simple, and it is easy to incorporate instrumental variables. ${ }^{33}$

For each variable and each horizon, we estimate the following single regression model:

$$
z_{t+h}=\alpha_{h}+\lambda_{h}(L) z_{t-1}+\psi_{h}(L) X_{t-1}+\theta_{h} R F C P_{t}+\varepsilon_{t+h},
$$

where $z$ is the variable of interest at horizon $h$. We consider real food commodity prices and a set of variables representing the U.S. economy: real GDP, real personal consumption, CPI, and the federal funds rate. The term $\alpha_{h}$ is a vector of deterministic terms - a constant, linear, and quadratic time trend $-\lambda_{h}(L)$ and $\psi_{h}(L)$ are polynomials in the lag operator $(L=5)$, and $X$ is a set of control variables. Although the control variables do not have to be the same for each regression, we include all other $z$ variables. Finally, $\theta_{h}$ is the estimated response of $z$ at horizon $h$ to a shock in real food commodity prices $\left(R F C P_{t}\right)$ at period $t$. Because real food commodity prices may be partly endogenous to the U.S. economy, we estimate equation 2 with the narrative dummy and the first lag of the dummy as external instruments for $R F C P_{t}$. The reason that we also use the first lag of the narrative dummy as an instrument is that some of the episodes encompass more than one quarter (see the online appendix). The $F$ statistic of the instruments (dummy and lagged dummy) is 12.6. The $t$ statistics of the dummy and the lagged dummy are 4.9 and 1.9 , respectively.

\section{III.C. Narrative Results}

The estimated impulse responses to a 1 percent increase in real food commodity prices are shown in figure 12 . Because the error terms follow

33. Because this method imposes fewer restrictions, the estimates are often less precise and more erratic at longer horizons because of a loss of efficiency (Ramey 2016). If the data-generating process is adequately captured, impulse responses of VARs are in contrast optimal at all horizons. We have therefore also estimated two VAR models based on the narrative food commodity market shocks. On one hand, we have embedded the episodes as dummy variables in a standard VAR to estimate the macroeconomic effects, an approach similar to that taken by Ramey and Shapiro (1998). On the other hand, we have used the dummy variable as an instrument to identify food commodity prices shocks within a VAR model, as proposed by Mertens and Ravn (2013). The results of both exercises, which are available upon request, confirm the conclusions of the local projections. 
Figure 12. Impulse Responses to Narrative Food Commodity Supply Shocks: Local Projections ${ }^{\mathrm{a}}$

\section{Real food commodity prices}

Percent

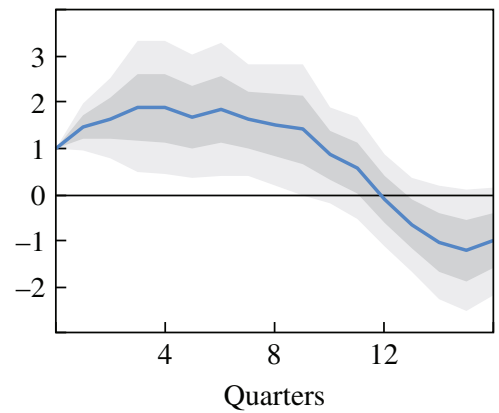

U.S. real personal consumption

Percent

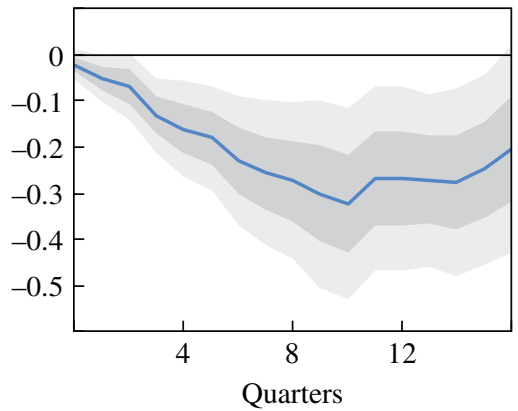

Federal funds rate

Percent

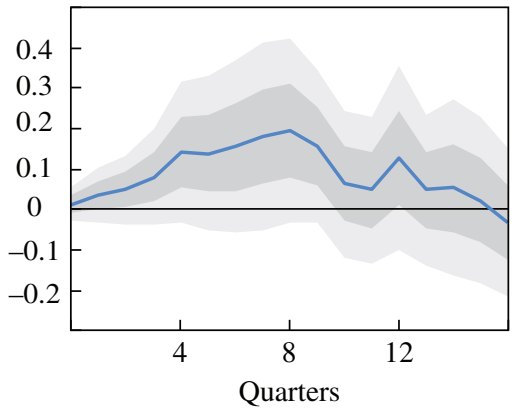

\section{U.S. real GDP}

Percent

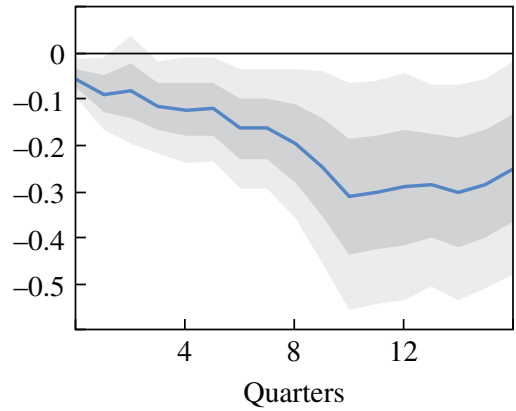

U.S. CPI

Percent

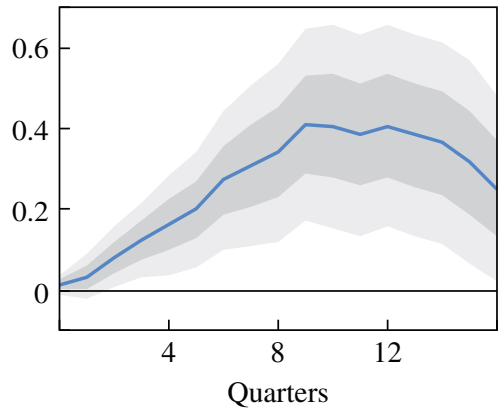

Source: Authors' calculations.

a. The darker shading indicates 1 Newey-West standard error; the lighter shading indicates 2 Newey-West standard errors. 
some form of a moving-average structure, with an order that is a function of horizon $h$, they are serially correlated. Accordingly, we calculate and report Newey-West standard error bands in all figures. The rise in real food commodity prices reaches a peak of 1.9 percent after 3 to 4 quarters. This corresponds to a rise in nominal food commodity prices of approximately 2.1 percent, a magnitude that is somewhat higher than the maximum effect in the benchmark VAR. The narratively identified shocks also have a much more persistent impact on food commodity prices because real food commodity prices only return to the baseline after approximately 12 quarters, compared with 4 quarters in the benchmark VAR.

The persistent rise in real food commodity prices is also reflected in more persistent effects on the U.S. economy relative to the benchmark VAR results. Real GDP and real personal consumption decrease by approximately 0.3 percent, reaching their peak after 10 quarters. Taking into account the more persistent and slightly greater rise in global food commodity prices, the magnitudes of the consequences for the real economy are comparable to the VAR results reported in section II. In contrast, the impact on consumer prices and the monetary policy response seems to be stronger for the narrative shocks. Specifically, consumer prices and the federal funds rate increase by 0.4 and 0.2 percent, respectively, which is roughly twice the impact obtained with the VAR model and global food production index.

Overall, despite being a very different approach, the results of the narratively identified food commodity market disturbances confirm the main messages of the VAR analysis. Hence, we can safely conclude that the repercussions of disruptions in global food commodity markets for the U.S. economy are compelling. In the next section, we examine the passthrough in more detail.

\section{The Pass-Through to Consumer Prices and Economic Activity}

In subsection II.C, we argued that several indirect effects should be at play, amplifying the macroeconomic consequences of food market disruptions. In particular, not only food prices but also other components of the CPI should increase after a surge in food commodity prices, while the decline in consumption cannot solely be driven by the direct loss in purchasing power. In other words, there is more than just a discretionary income effect of the rise in food commodity prices on household expenditures. In this 
section, we pursue a tentative attempt at better understanding the mechanisms and interpreting the magnitudes of these effects. ${ }^{34}$

To do this, we extend the VAR analysis of section I along two dimensions. First, we compare the dynamic effects of food supply shocks with the effects of crude oil supply shocks identified within the same VAR model. The macroeconomic effects of oil supply shocks can serve as a benchmark, because several studies have documented that oil and energy shocks also have an influence on the U.S. economy that is disproportionately large compared with its share in GDP and consumer expenditures. For example, Edelstein and Kilian (2009) find that the response of total consumption to an energy price shock is approximately four times larger than the maximum reduction in discretionary income associated with the shift in energy prices. We identify oil supply shocks by imposing theoretically plausible sign restrictions on the impulse responses, as proposed by Peersman and Ine Van Robays (2009) and by Baumeister and Peersman (2013a). Specifically, unfavorable oil supply shocks are identified as innovations that are orthogonal to the identified food commodity supply shocks and are characterized by a decline in global oil production and a rise in the real price of oil, while world economic activity does not expand. ${ }^{35}$ Second, we reestimate the VAR by adding an additional variable of interest each time. We consider a set of price variables to investigate the pass-through to consumer prices, and we examine the effects on several components of real GDP and household expenditures to learn more about the output effects.

34. To interpret the magnitudes, we conduct a number of back-of-the-envelope calculations, in particular to assess the role of monetary policy. Given the simplicity of the exercise and uncertainty about the exact values of several parameters, these calculations should be taken with a grain of salt and interpreted with more than the usual degree of caution.

35. Since the sign restrictions are based on competitive market forces and the oil price was regulated before 1974, the results for oil supply shocks are based on VARs that have been estimated over the sample period 1974:Q1-2013:Q4. As an alternative approach, Kilian (2009) uses (zero) exclusion restrictions to identify oil supply shocks in a monthly VAR that includes global oil production, a measure of economic activity, and the real price of crude oil. In particular, he assumes that the short-run oil supply curve is vertical, implying that global oil production does not respond to all other (oil demand) shocks in the VAR instantaneously. This assumption might be plausible at the monthly frequency but is not appropriate when quarterly data are used. Notice also that we rely on a uniform Haar prior distribution to implement the sign restrictions. Baumeister and Hamilton (2015) show that this could imply nonuniform distributions for key objects of interest and that Bayesian inference with informative priors can be an improvement. Although this is a promising avenue, this approach is beyond the scope of this paper given that the identification of oil supply shocks is not the focus of this study. 


\section{IV.A. Comparison with Oil Shocks}

Figure 13 compares the impulse responses of the benchmark variables to a commodity supply shock of 1 standard deviation for crude oil and food. Some interesting facts are worth mentioning. First, an oil supply shock of 1 standard deviation corresponds to a rise in real crude oil prices of 4.9 percent on impact, which reaches a peak of 5.6 percent after one quarter, and gradually returns to the baseline after four quarters. The pattern of oil prices after an oil supply shock is very similar to the pattern of food commodity prices after a food supply shock, although the magnitude is approximately three times larger. Second, with a peak effect of -0.39 , the consequences of an oil supply shock of 1 standard deviation for real GDP are approximately 1.5 times stronger. Put differently, the impact of a rise in real food commodity prices on economic activity is roughly twice as large as the impact of a rise in crude oil prices of equal size. Third, the dynamic effects of both shocks on real personal consumption are more or less the same, whereas an average food commodity supply shock has a slightly stronger and more persistent impact on consumer prices than an average oil supply shock. Finally, oil supply shocks reduce global economic activity for a period of two years, have no significant effects on global food production and food commodity prices, and have a negative impact on the federal funds rate.

A noteworthy difference between both shocks is the monetary policy response; that is, the federal funds rate increases by 8 basis points after a food commodity market shock, whereas the policy rate decreases by 11 basis points on impact, and by 20 basis points after one quarter in response to an oil supply shock. In other words, monetary policy seems to amplify the consequences of food market disruptions for economic activity, while partly stabilizing the real effects of oil supply shocks. This is relevant for interpreting the magnitudes of the indirect effects of both shocks. Specifically, a reasonable rule of thumb for monetary policy effects is that a rise in the federal funds rate of 10 basis points leads to a decline in real GDP of between 0.05 and 0.1 percent. ${ }^{36}$ If we take these values seriously, this implies that the contemporaneous monetary policy response to food

36. Christiano, Eichenbaum, and Evans (1999) find that an interest rate innovation of 60 basis points reduces real GDP by 0.5 percent. Bernanke and Mihov (1998) find that a monetary policy shock that raises the federal funds rate by 0.4 percent leads to a decline of real GDP by 0.3 percent. When we also identify a monetary policy shock within the benchmark VAR model (by ordering the federal funds rate last in the Cholesky decomposition), as discussed in subsection IV.B, we find that a 60 basis points rise in the federal funds rate leads to a fall in real GDP and personal consumption by approximately 0.4 percent. 
Figure 13. Comparing Food Supply and Oil Supply Shocks ${ }^{\mathrm{a}}$

Global food production

Percent

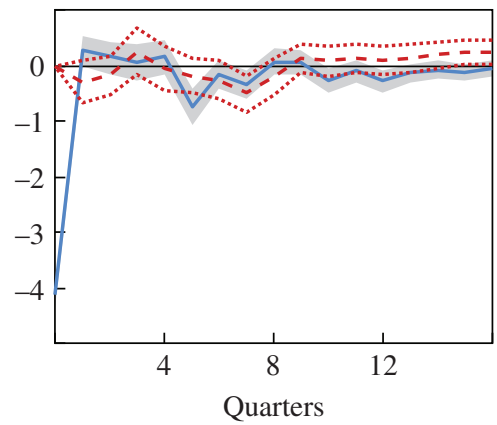

Volume of seeds set aside for planting Percent

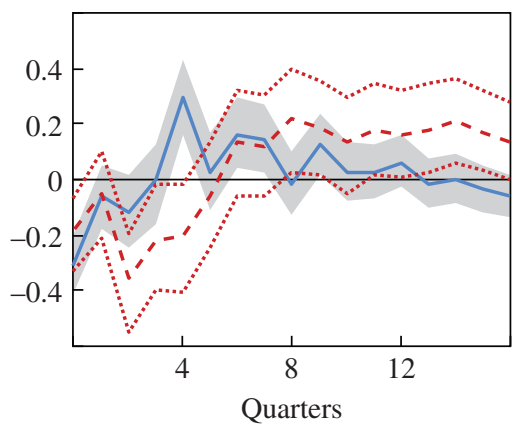

Global oil production

Percent

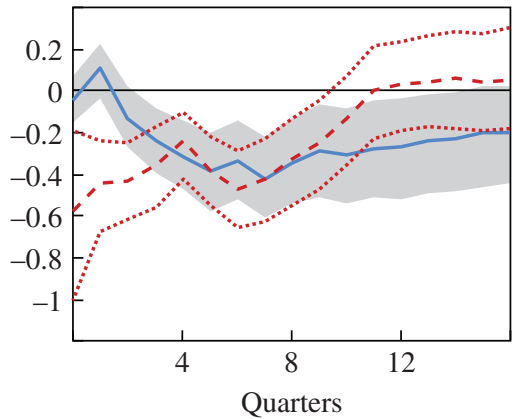

Real food commodity prices Percent

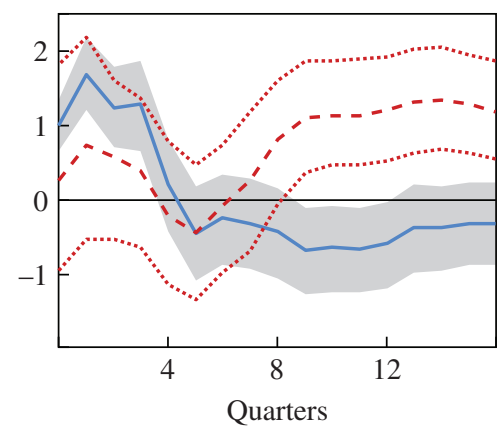

Global economic activity

Percent

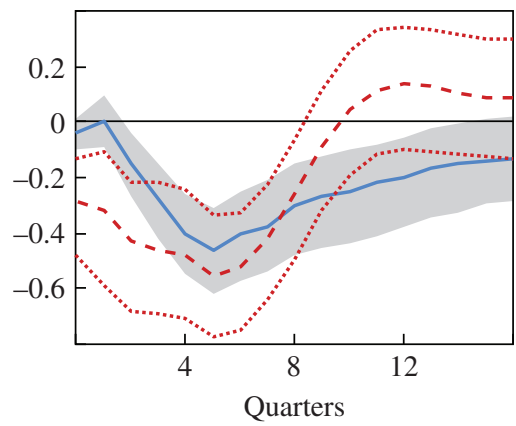

Real oil price

Percent

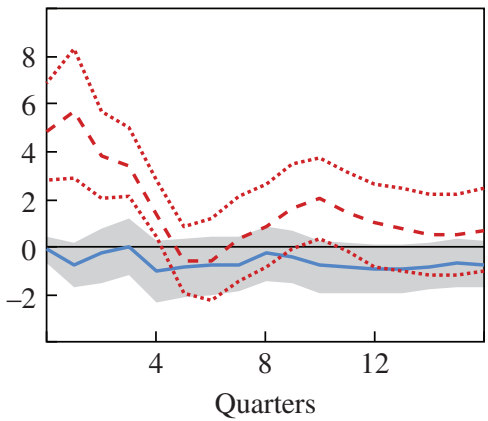

(continued) 
Figure 13. Comparing Food Supply and Oil Supply Shocks ${ }^{\mathrm{a}}$ (Continued)

\section{Real GDP}

Percent

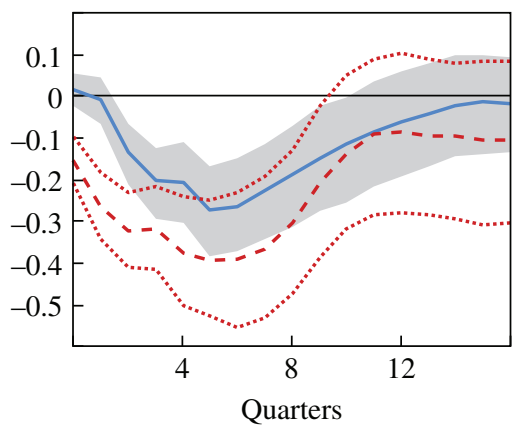

CPI

Percent

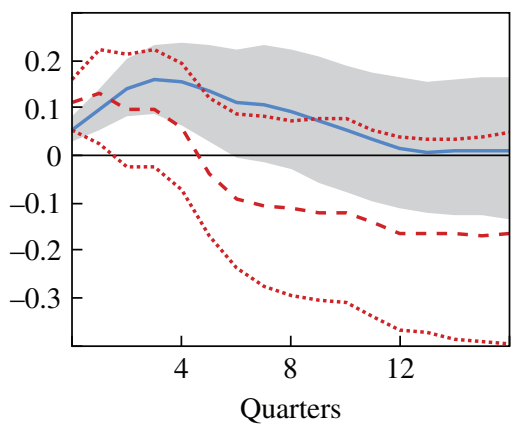

\section{Real personal consumption}

Percent

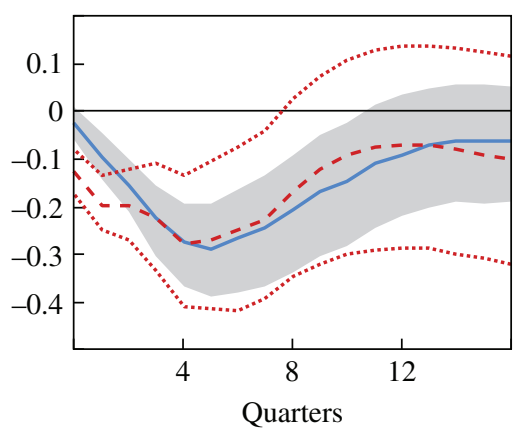

Federal funds rate

Percent

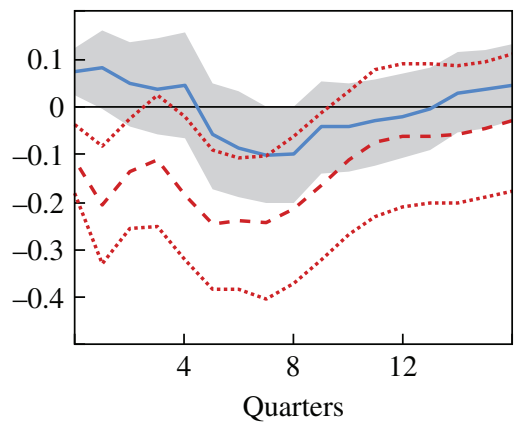

Source: Authors' calculations.

a. The range shown around estimates are the 16th and 84th percentile error bands. The solid line and shaded area are the results of the food commodity supply shocks (same as in figure 6); the dashed and dotted lines are the results of the oil supply shocks.

market disturbances can potentially explain almost one-third of the output effects, while the remaining effects on personal consumption are still at least four times the discretionary loss in purchasing power. In contrast, a similar immediate response to oil supply shocks would have resulted in much stronger output effects of such shocks. If Edelstein and Kilian's (2009) results are representative for oil supply shocks - that is, they find that the impact of an energy price shock on total consumption is approximately four times larger than the maximum reduction in discretionary income - this also implies that the magnitudes of the indirect (nonmonetary 
policy) effects of food commodity and oil supply shocks on consumption are probably in the same neighborhood..$^{37}$

\section{IV.B. Consumer Prices}

The CPI is calculated as a weighted average of prices of different types of goods and services, which can be divided into food (17 percent), energy (6 percent), and core (77 percent) CPI. A rise in food commodity prices can affect these components via several channels. First, there is a direct effect on the CPI's food component. The exact pass-through of food commodity prices to final prices of food products should depend on competition and demand conditions in the food sector. Second, a rise in food commodity prices may augment energy prices, because food commodities are also used for the production of biofuels - from home heating to vehicle fuels, which are a source of energy. Third, if energy prices rise, production costs for firms could also rise. If firms pass these costs through to their selling prices, the consumer prices of nonenergy goods may also rise. Finally, higher inflation or inflation expectations could trigger so-called second-round effects that could greatly amplify and protract the effects of the shock on core inflation. For example, employees could demand higher nominal wages in subsequent wage-bargaining rounds in order to maintain their purchasing power, leading to mutually reinforcing feedback effects between wages and prices. Similar channels have been documented for oil shocks.

The impulse responses of food, energy, and core CPI are depicted in figure 14. Not surprisingly, a rise in food commodity prices has a strong and significant effect on CPI food, with a peak of 0.27 percent after four quarters. Given a share of food commodities in final food products and beverages of approximately 14 percent and a rise of nominal food commodity prices of 1.8 percent, this implies that changes in food commodity prices are more or less fully passed through to food consumer prices. Furthermore, the effects of food commodity market disturbances on CPI energy are positive, but are not statistically significant at the 10 percent

37. In contrast to food commodities, which are only an input factor in the food processing sector (except biofuels in recent periods), it is very difficult to calculate the exact share of crude oil in household expenditures because oil is an input factor that is used for several product categories (as well as investment goods and government purchases). If we only consider the direct share of heating oil and motor fuel in household expenditures, and take into account that about half of gasoline prices is determined by the cost of crude oil, the effects of oil supply shocks on real GDP obtained with the VAR model are also roughly four times the discretionary loss in purchasing power. 
Figure 14. The Pass-Through to Consumer Prices ${ }^{a}$

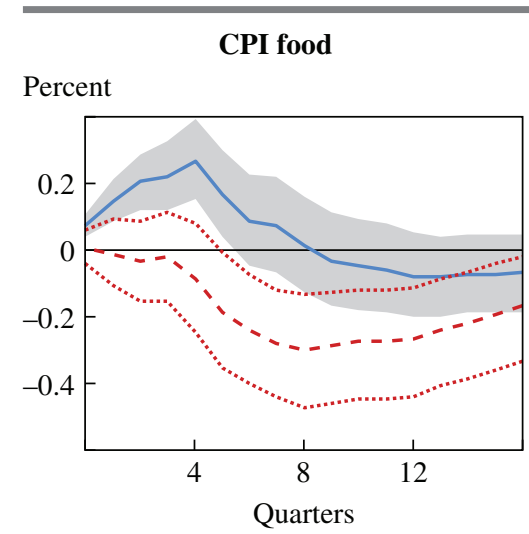

\section{Core CPI}

Percent

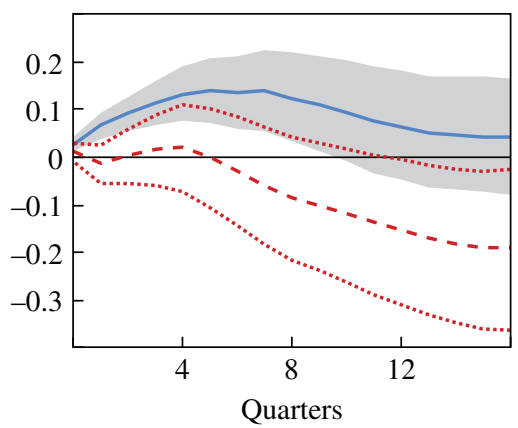

Import deflator

Percent

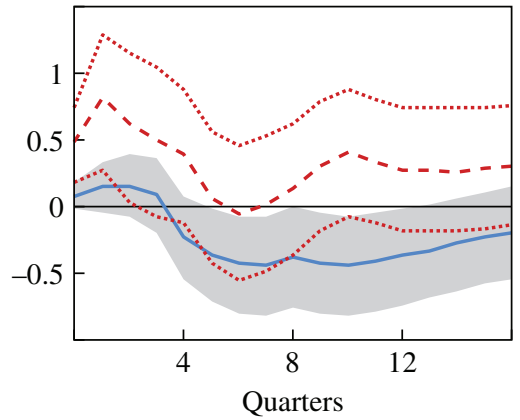

\section{CPI energy}

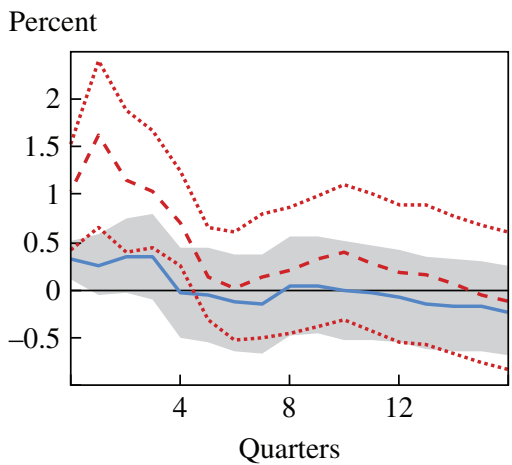

\section{GDP deflator}

Percent

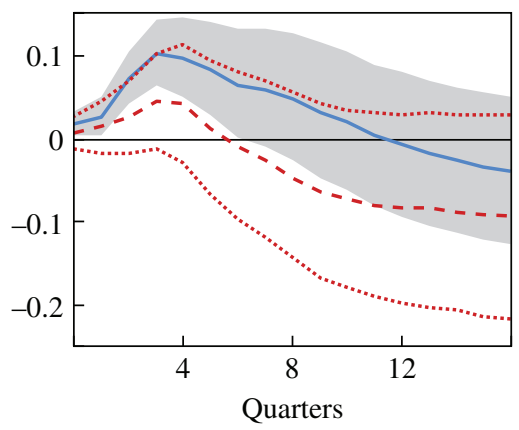

U.S. dollar nominal effective exchange rate

Percent

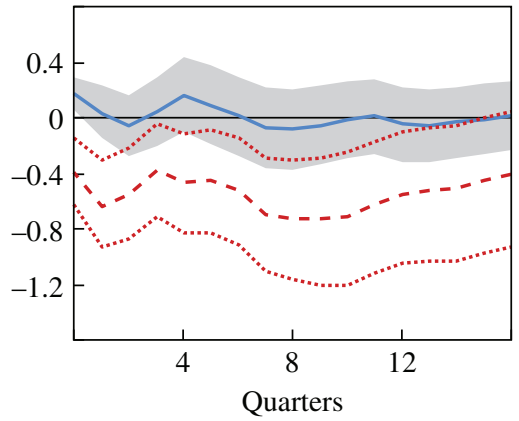


Figure 14. The Pass-Through to Consumer Prices ${ }^{a}$ (Continued)

Nominal wages

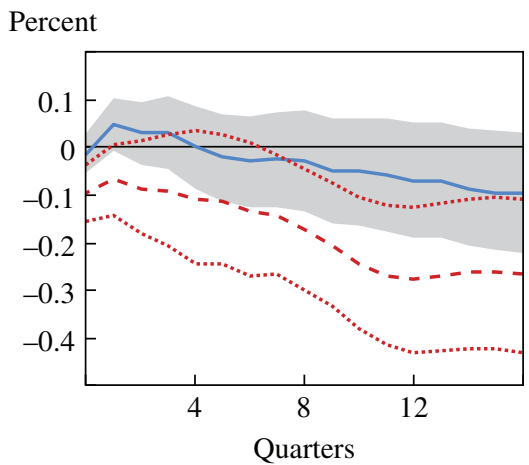

Real consumer wages

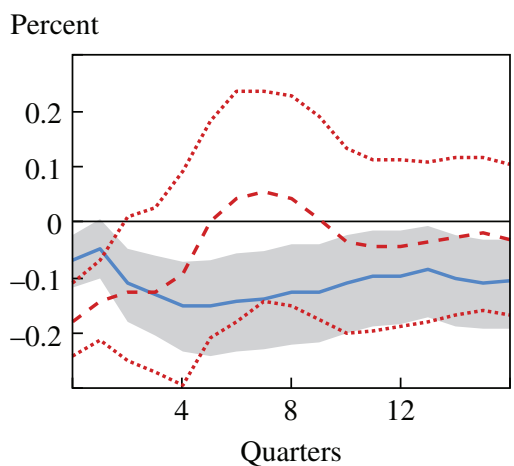

\section{Inflation expectations}

Percent

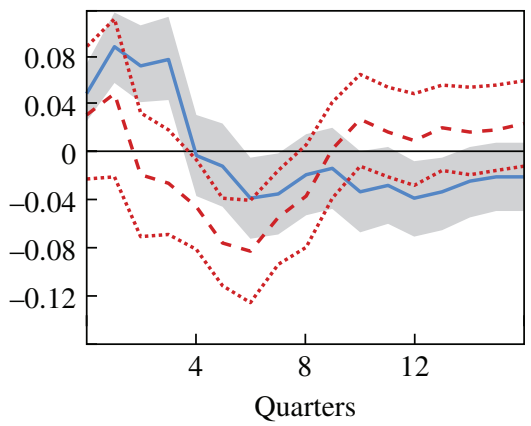

Source: Authors' calculations.

a. The range shown around estimates are the 16th and 84th percentile error bands. The solid line and shaded area are the results of the food commodity supply shocks; the dashed and dotted lines are the results of the oil supply shocks.

level. Notice, however, that the insignificant impact is misleading because it ignores time variation. The use of biofuels as a source of energy is only a recent phenomenon. As was shown in subsection II.D (figure 11), the impact of food commodity market shocks on CPI energy was insignificant before 2003. Conversely, food market shocks seem to have had a significant and strong impact on CPI energy since 2003, in line with the rising share of biofuels in petroleum consumption. Because the latter period is more representative of the current situation, we conclude that fluctuations in food commodity prices likely also affect consumer prices via energy 
prices ${ }^{38}$ Finally, there is a significant rise of core CPI after an unfavorable food market disturbance, which reaches a peak of 0.14 percent after seven quarters. Given the share of core CPI in the overall CPI, this accounts for about two-thirds of total inflationary consequences. The rise in core inflation is hence the reason why the ultimate impact on consumer prices is considerably larger than the effects implied by the share of food commodities in the CPI..$^{39}$

The pass-through of oil supply shocks to consumer prices turns out to be very different. As observed in figure 14, unfavorable oil supply shocks augment CPI energy but do not raise food consumer prices. There is even a decline of CPI food at longer horizons, and core inflation also does not increase. An interesting difference between both types of shocks is that oil supply shocks seem to trigger inflationary effects via a rise in import prices and a depreciation of the U.S. dollar exchange rate, while food commodity supply shocks increase the domestic GDP deflator significantly. In addition, despite the decline in economic activity, nominal wages remain more or less constant after a food market disturbance. In contrast, nominal wages decrease significantly after an oil supply shock. Additionally, real consumer wages decline immediately after oil supply shocks, whereas the response is much stickier after food market shocks.

Overall, these different patterns indicate that second-round effects are a key explanation for the stronger pass-through of food commodity supply shocks to consumer prices compared with oil supply shocks. This hypothesis is confirmed by the impulse responses of inflation expectations shown in figure 14. We observe a persistent and significant rise in inflation expectations after a food supply shock, while the impact of oil supply shocks is very short-lived and statistically insignificant. Higher inflation expectations are typically passed through to actual pricing behavior, in particular to the prices of nonfood and nonenergy goods and services. Furthermore, higher inflation expectations augment the demand for nominal wages in the wage-bargaining process, which further increases firms' costs and the prices of nonfood and nonenergy goods and services. The presence

38. Notice also that the error bands of the effects on CPI energy in figure 14 are relatively large, while the magnitudes of the effects are quite strong, that is, CPI energy increases by 0.31 percent on impact and 0.37 percent at its peak. In contrast, when we reestimate the VAR over a sample period that ends in 2002:Q4, the effects on CPI energy are essentially zero. The difference between the point estimates also suggests that the pass-through to energy prices has become an important channel in recent periods.

39. Notice that core CPI also increases when we estimate VAR models over more recent sample periods, for example, excluding the Great Inflation. Second-round effects of food market shocks are thus still important and have not vanished over time. 
of second-round effects and the greater impact of food market disruptions on inflation expectations and core inflation probably also explain the Federal Reserve's tightening of monetary policy after such shocks, in contrast to a policy easing following oil supply shocks. ${ }^{40}$

\section{IV.C. Household Expenditures and Economic Activity}

Because food is a basic necessity, food demand is considered to be quite inelastic. Unless households increase borrowing, higher food prices consequently erode the disposable income to purchase other goods and services, leading to a decline in expenditures. In subsection II.C, we argued that the upper bound of such a discretionary income effect is 0.04 to 0.05 percent, while personal consumption declines by almost 0.3 percent after a food commodity supply shock of 1 standard deviation. Hence, other propagation mechanisms should also be at play. A first plausible channel is the monetary policy response to control inflation, which curtails aggregate demand. However, as discussed in subsection IV.A, the monetary policy response can at most explain one-third of the overall effects.

Besides the monetary policy effects, how are food commodity market disruptions transmitted to the real economy? There are several reasons to believe that the underlying mechanisms are similar to the pass-through of oil supply shocks to economic activity. First, as argued in subsection IV.A, the magnitudes of the indirect (nonmonetary policy) effects of both shocks are within the same neighborhood. Most important, the dynamic effects of both shocks on the components of household expenditures are also very much alike. This can be observed in figure 15, which shows the effects of food commodity and crude oil supply shocks on several components of household expenditures and investment. Not surprisingly, unfavorable food supply shocks have a significant negative impact on nondurable food consumption - that is, food and beverages for off-premises consumptionwhile oil supply shocks reduce the consumption of energy goods and services, not the other way around..$^{41}$ However, all other impulse responses

40. The finding that inflation expectations (and core inflation) respond more to food prices than energy prices has also been documented by Clark and Davig (2008), among others. Several studies also find that economic agents weigh food prices considerably higher than its share in expenditures when forming inflation expectations, in contrast to energy prices (Murphy and Rohde 2015). A possible explanation why food prices have larger effects on inflation expectations and core inflation is that energy prices are substantially more volatile than food prices.

41. The demand for food and energy products is hence not completely inelastic to shifts in their own prices. In contrast, the impact of food commodity shocks on the consumption of food services and accommodations turns out to be insignificant at the 10 percent level. 
Figure 15. The Pass-Through to Household Expenditures ${ }^{a}$

\section{Food (nondurables)}

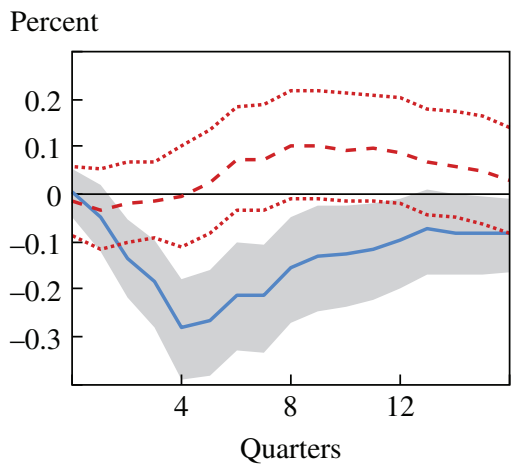

Energy goods and services

Percent

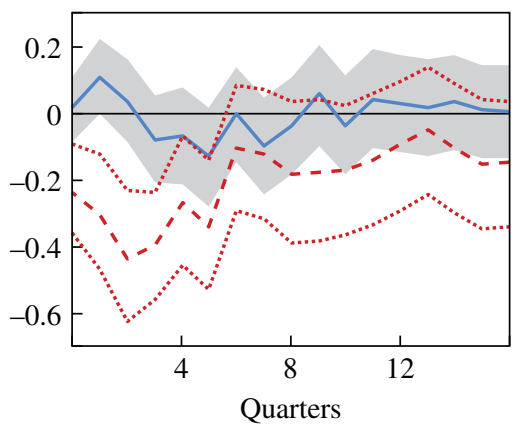

Durables

Percent

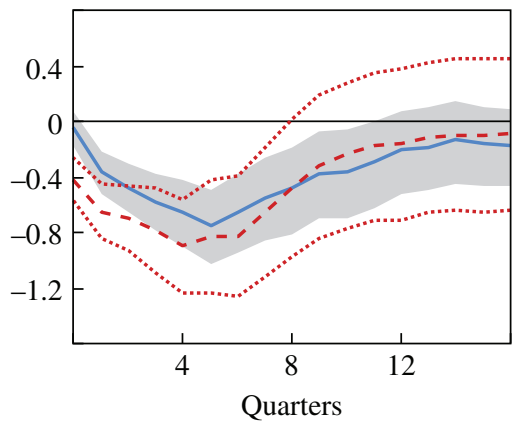

Food (services)

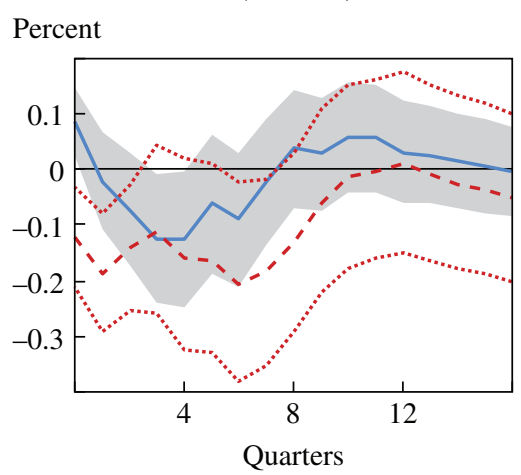

Other nondurables and services Percent

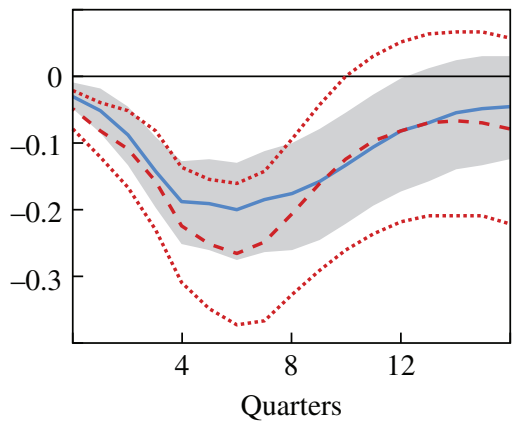

Investment

Percent

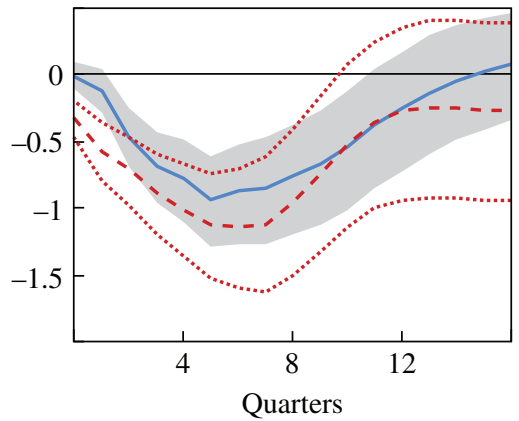


Figure 15. The Pass-Through to Household Expenditures ${ }^{\mathrm{a}}$ (Continued)

Exports

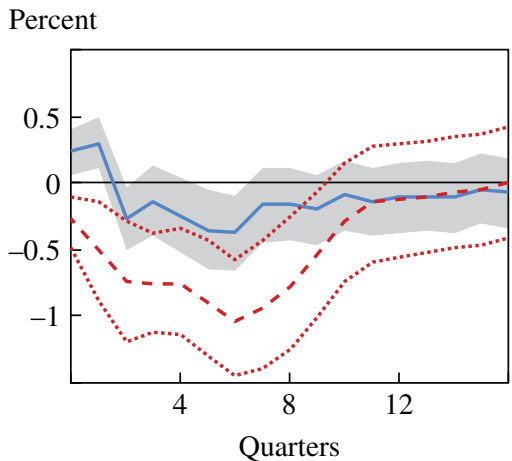

Consumer sentiment

Percent

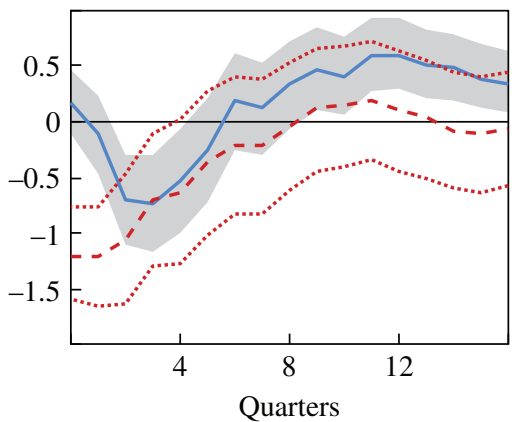

Motor vehicles and parts (durables)

Percent

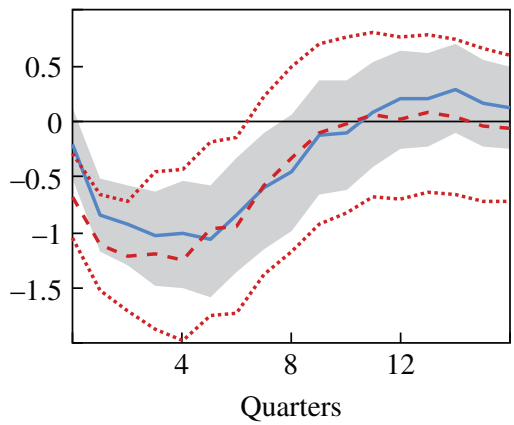

Source: Authors' calculations.

a. The range shown around estimates are the 16th and 84th percentile error bands. The solid line and shaded area are the results of the food commodity supply shocks; the dashed and dotted lines are the results of the oil supply shocks.

behave qualitatively and quantitatively similarly. Strikingly, this is even the case for the consumption of motor vehicles and parts, a subcomponent of durable consumption that is typically considered to be complementary in use with oil, and thus is perceived as being much more sensitive to oil shocks relative to other shocks. Overall, these findings suggest that the dominant mechanisms that lead to a decline in a household's purchases of nonfood and nonenergy nondurables and services, and also purchases of durable consumption goods, are quite similar.

The impulse responses further reveal that a crucial channel whereby food commodity market shocks (and oil supply shocks) affect the economy 
is a shift in the consumption of durables and investment. Specifically, durable consumption decreases by 0.93 percent after a food market disruption, which is three times more than the overall decline in personal consumption. Likewise, there is a reduction in investment of 0.93 percent. The relevance of both output components for explaining the consequences of food market disruptions is illustrated in table 2. The table's first two columns show the maximum effects of both shocks on all the components of figure 15, while the third and fourth columns list the relative responses of the components to the response of total personal consumption. The fifth and sixth columns show the weighted effects of the components, with the weights calculated as the ratio of each component to GDP. As observed, durables and investment are considerably more sensitive to food supply shocks than other components of household expenditures, followed by nondurable food consumption. In addition, despite their limited weights, both components account for the bulk of the output effects. ${ }^{42}$

One argument that could be made against our reasoning is that the stronger effects of food market shocks on the consumption of durables and investment are driven by the monetary policy response rather than other mechanisms, because both aggregates are typically much more sensitive to interest rate changes. Though this is true, we believe that it does not change our conclusion. To illustrate this, we identify a monetary policy shock within the VAR model. ${ }^{43}$ The maximum effects of a shift in the federal funds rate of 8 basis points - that is, the estimated contemporaneous monetary policy response to a food commodity supply shock-on all components are reported in the last column of table 2. Durable consumption and investment indeed react much more to a monetary policy shock than the other components. However, the magnitudes are too small to account for the stronger responses to food commodity supply shocks depicted in the table's first two columns. Even in the absence of monetary policy tightening, the effects on durables and investment are still a multiple of the effects on the other expenditures' components. Hence, the greater impact on durable consumption and investment compared with other categories of goods

42. There is also a decline in the volume of exports of 0.37 percent after a food commodity supply shock. The contribution to the overall output effects, however, is relatively low. The export effects are also statistically insignificant at the 10 percent level. For oil supply shocks, in contrast, there is a strong and significant decline in exports that matters for the overall output effects.

43. For simplicity, we use Christiano, Eichenbaum, and Evans's (1999) identification strategy by ordering the federal funds rate last in the Cholesky decomposition. Other approaches typically find similar output effects. One caveat is that we obtain a so-called price puzzle. 


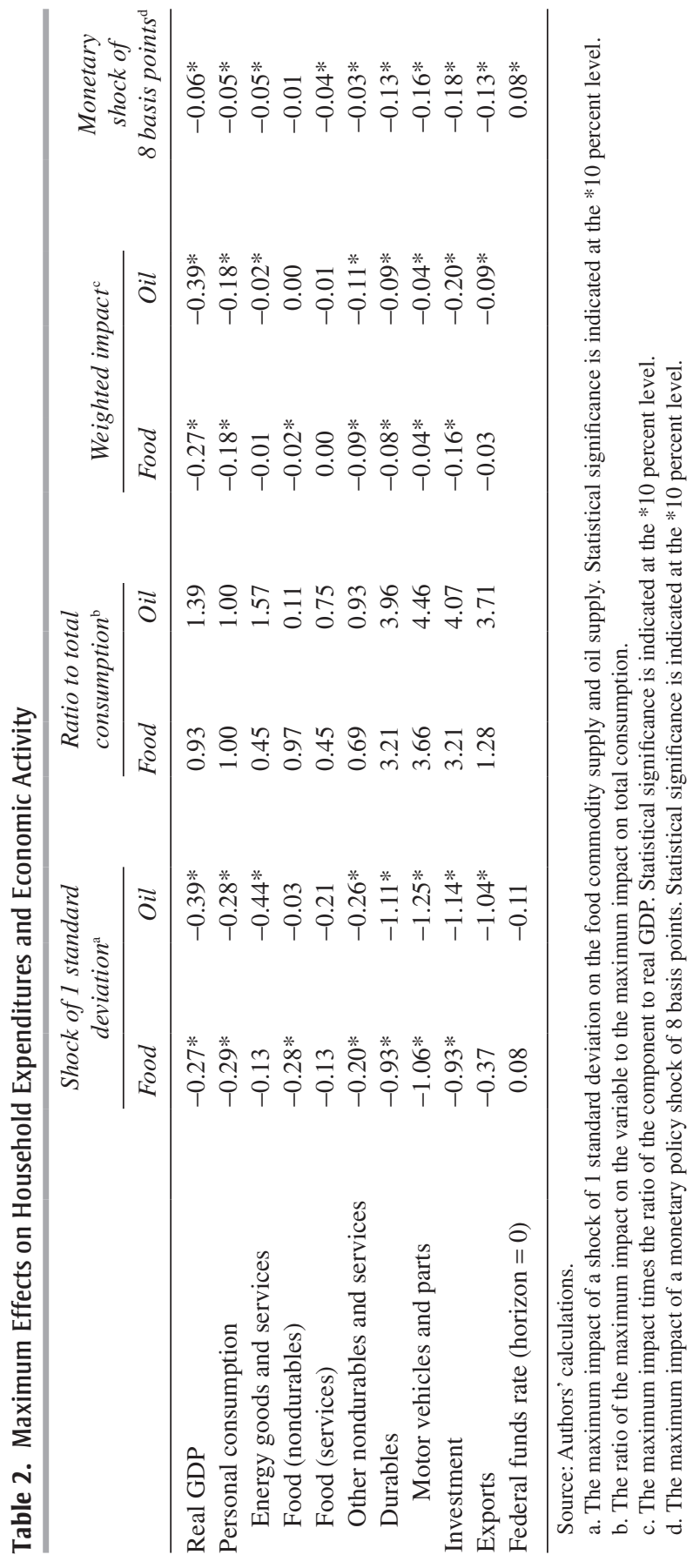


and services can only partly be explained by the monetary policy tightening, and thus other effects on both aggregates are crucial in explaining the consequences of food market shocks.

\section{IV.D. Potential Explanations for Magnitude and Composition of Output Effects}

The remaining question is which nonmonetary policy mechanisms could magnify the consequences of both shocks for personal consumption. In spite of the voluminous literature on the effects of oil price shocks, there is little consensus on the dominant mechanism. Popular channels that have been put forward in the oil and energy literature are the postponement of irreversible purchases of investment and durable consumption goods because of increased uncertainty about future energy prices and a shift in the consumption of durables that are complementary in use with energy (Edelstein and Kilian 2009; Hamilton 2008). However, it is not likely that the postponement of irreversible purchases applies to food prices. Furthermore, because the purchases of motor vehicles react in a similar way to food and oil shocks, complementary effects also cannot be dominant. ${ }^{44}$

There are, however, various other channels that have been documented for oil and energy price shocks, which could also apply to food commodity price shocks. For example, Julio Rotemberg and Michael Woodford (1996) demonstrate that imperfect competition considerably amplifies the effects of shocks on factor prices. With a calibrated, one-sector stochastic growth model with energy input, they show that allowing for a modest degree of imperfect competition increases the predicted effects of a rise in energy prices on economic activity by a factor of five, and that such market imperfections can account for their estimates of the consequences for U.S. output. Mary Finn (2000) shows that variable capital utilization also greatly intensifies the repercussions of shifts in factor prices for the real economy, even in perfectly competitive markets, and can explain the magnitudes found in the empirical literature. Given the critical role of food commodities as an input factor in the food-processing sector, these theories could also apply to food commodity price shocks.

Another class of models in the oil literature focuses on frictions in reallocating capital and labor across sectors that may be differently influenced by oil price shifts (Davis and Haltiwanger 2001; Hamilton 1988). Such frictions lead to higher unemployment and lower capacity utilization in

44. The only possible exception for both arguments is the role of food commodities to produce energy goods in recent periods, but this cannot be the case for the average effects since the 1960 s. 
affected sectors that can magnify the effects on economic activity. ${ }^{45}$ A popular example in the oil literature is a reallocation of capital and labor away from the automobile sector when consumers purchase fewer cars, or a reallocation of resources within the automobile sector when consumers switch toward more energy-efficient cars in response to oil price hikes. However, food market shocks could also lead to a changed composition of aggregate demand, which could result in a costly reallocation of capital and labor across sectors that would reduce economic activity. For example, there could be substitution between the use of food services and accommodations to purchases of food and beverages for off-premises consumption. Most important, the results given in figure 15 show that food price shocks lead to a considerably greater decline in expenditures on durable goods compared with nondurables and services, which could trigger sectoral shifts throughout the economy that further amplify the macroeconomic consequences. ${ }^{46}$

In fact, a stronger response of durable consumption to shocks in households' purchasing power, and possible reallocation effects that protract the macroeconomic consequences, may be a plausible mechanism to explain our empirical results-both the amplification and composition of the output effects-as well as the similarity to the dynamics of oil shocks. Specifically, consumer theory shows that expenditures on luxuries and durables should be more sensitive to transitory income shocks than expenditures on necessities and nondurables. For example, Martin Browning and Thomas Crossley (2009) demonstrate that households can significantly reduce their total expenditures without a significant decline in welfare if they concentrate their budget reductions on durables. The reason is that a substantial reduction in expenditures on durables can be realized with only a modest decline in the consumption of durables because existing stocks of durables could continue to provide a flow of services ${ }^{47}$ Such a mechanism

45. These additional effects can be very large. For example, Acemoglu, Akcigit, and Kerr (2016) show that small shocks can cause sizable aggregate fluctuations due to their propagation through the production network.

46. Notice that the presence of significant reallocation effects implies that the consequences of food price increases for household expenditures should be stronger than food price decreases because such effects amplify the former, while dampening the latter. As mentioned in footnote 28 , we find support for this prediction in the data.

47. Hamermesh (1982), Parker (1999), and Browning and Crossley (2000) also discuss mechanisms for how transitory changes in income could have a disproportionately greater effect on expenditures of luxuries and durables. Bils and Klenow (1998) confirm this prediction in U.S. data for 57 types of consumer goods. Dynarski and Gruber (1997) find that the elasticity of durables to changes in income in the United States is eight times larger than for nondurables. 
can explain why purchases of motor vehicles respond considerably more strongly than several other goods and services to both food price and oil price shocks, without the requirement of being complementary in use. In essence, when food and energy bills increase, households can continue to drive their existing car for a while, rather than buying a new car. Although the welfare losses from this behavior might be small at the individual household level, the macroeconomic accelerator effects may be substantial.

Notice that this accelerator mechanism may be particularly important for food and energy price shocks, because the share of food and energy consumption in household expenditures is substantially higher for lowincome households. For example, according to the U.S. Bureau of Labor Statistics' Consumer Expenditure Survey, the share of food and beverages consumption in total expenditures of the lowest income quintile was 16.2 percent in 2014, compared with only 12.1 percent for the highest quintile. For energy expenditures (natural gas, electricity, fuel oil, other fuels, gasoline, and motor fuels), the shares are 10.7 and 6.4 percent, respectively, for the lowest and highest quintiles. Measured as a percentage of total income after taxes, the differences are even more dramatic: 35.8 and 9.1 percent for food consumption, and 23.6 and 4.8 percent for energy consumption. Because food and energy are basic necessities, and low-income households typically also have borrowing constraints and no liquid assets to smooth consumption over time, they thus have few other options than reducing expenditures on durables.

Finally, when food prices increase, households may decide to consume less and to increase their precautionary savings because of a rise in uncertainty or a greater perceived likelihood of future unemployment and income loss. According to John Cochrane (2016), precautionary savings and risk aversion are prominent ingredients of business cycle fluctuations. In particular, he argues that higher risk premiums and increases in risk aversion triggered by relatively small shocks affecting consumers, rather than risk-free rates and intertemporal substitution, are the central features of recessions. Edelstein and Kilian (2009) provide empirical evidence that shifts in precautionary savings and deteriorating consumer confidence are likely an important determinant of the excess response of household consumption to energy price shocks.

To assess the possibility of precautionary savings effects, the final panel of figure 15 shows the impulse responses of the University of Michigan's Index of Consumer Sentiment to food commodity and crude oil supply 
shocks. As can be observed, there is a significant decline in consumer sentiment after both shocks, which is consistent with increased uncertainty by households. Precautionary savings effects may thus also be an important propagation mechanism of food market disruptions to the real economy. Whether this is indeed the case, and the relevance of the different mechanisms to explain the overall effects, are questions that cannot be answered with the methods used in this paper. This requires other methods, such as general equilibrium models that incorporate food markets, and is left for future research.

\section{v. Conclusions}

Food commodity markets have historically been subject to considerable volatility. In particular, since the start of the millennium, there have been large swings in global food commodity prices. Although the linkages between food commodity market fluctuations and the macroeconomy are important for designing policies that can ameliorate the consequences of these swings, these linkages are poorly understood. With global temperatures expected to rise substantially during the next decades, understanding these relationships will become even more important. In this paper, we have estimated the consequences of disruptions in global food commodity markets for the U.S. economy during the past 50 years. Because food markets also respond to developments in the macroeconomy, the main challenge in doing this is to identify exogenous shifts in food commodity prices. We have used two different approaches for identifying such movements. The first strategy is a joint structural VAR model for global food commodity markets and the U.S. economy, in which food market disruptions are identified as unanticipated changes in a quarterly global food production index that we have constructed based on the planting and harvesting calendars of the four major staples-corn, wheat, rice, and soybeans. As our second, alternative identification strategy, we relied on narratives-from FAO reports, newspaper articles, disaster databases, and several other sourcesto identify 13 historical episodes when significant changes in food commodity prices were mainly caused by exogenous food market events.

The structural VAR analysis and the narrative approach lead to similar conclusions. We find a considerable impact of fluctuations in food commodity markets on the U.S. economy. On one hand, a rise in food commodity prices augments food and core consumer prices, as well as energy prices more recently. On the other hand, there is a persistent decline in real 
GDP and household expenditures. The effects are approximately four to six times larger than the maximum impact implied by the share of food commodities in the CPI and household consumption. An intriguing finding is that households reduce durable consumption much more than food consumption. Additionally, investment declines considerably. Both effects can only partly be explained by a moderate tightening of monetary policy in order to stabilize the shocks' inflationary consequences. A better understanding of these indirect effects' exact mechanisms remains complex and is an interesting topic for future research. The construction of dynamic general equilibrium models for food markets may be useful to answer this question. Other avenues for future research are analyses of cross-country differences and consideration of the question of whether policies, such as public food security programs or monetary policy, could dampen the macroeconomic consequences of food market disruptions.

A PPENDIX

\section{Example of a Narratively Identified Global Food Commodity Market Shock: Droughts around the Globe in 2012:Q3}

Type of shock: Unfavorable.

Food commodity market event:

Due to droughts in Russia, Eastern Europe, Asia, and the United States, there was a significant decline in global cereal production. In retrospect, annual global cereal production contracted by 2.4 percent. In July 2012, the USDA decreased its June estimate for U.S. corn by 12 percent because of the worst midwestern drought in a quarter century. Heat waves in southern Europe added serious concern about global food supplies later that month, as well as below-average rainfall in Australia. In August, there was news about a late monsoon negatively affecting the rice harvest in Asia. According to the International Food Policy Research Institute, production of food grains in southern Asia was expected to decline by 12 percent compared with a year earlier. Also in August, the Russian grain harvest forecasts were reduced because of a drought. In October 2012, wheat output in Russia was estimated to be about 30 percent down from 2011; in Ukraine, a decrease of about 33 percent was expected; and in Kazakhstan, output was reported to be just half of the previous year's good level. The wheat harvest indeed declined in 2012, by 33 percent, 29 percent, and 57 percent in Russia, Ukraine, and Kazakhstan, respectively. The EM-DAT database of international disasters lists droughts in Ukraine (April 15, 2012 to July 31, 2012), Russia 
(June 2012 to September 2012), and the United States (June 2012 to December 2012).

We allocate the shock to 2012:Q3 because this is the period when the severe scaling back of the expected harvests started, resulting in considerable price increases. Real food commodity prices increased by 7.9 percent in that quarter, whereas oil prices decreased by 1.6 percent. The same comment about the Greek debt crisis reported for the 2010:Q3 shock applies for 2012:Q3 (the Second Economic Adjustment Programme for Greece was approved in March 2012). There were no other events that could explain the rise in food commodity prices.

\section{Relevant articles:}

Charles Abbott, "Midwest Drought Slashes Corn Estimate, Jolts Market," Reuters (July 12, 2012).

The worst Midwest drought in a quarter century is doing more damage to U.S. crops than previously expected with the government on Wednesday slashing its estimate for what was supposed to be a record harvest. The U.S. Department of Agriculture said the corn crop will average just 146 bushels an acre, down 20 bushels from its June estimate and a much more dramatic drop than analysts had projected. The report initially reignited a near-record rally in grain prices that could eventually hit consumer grocery bills in North America, although the impact could be more immediate for the world's poor if the drought persists. The severe scaling back of the harvest has sent corn and soybean prices up by more than a third over the past month, as extreme heat and dry conditions stunt growth in the world's largest grower and exporter.

Rudy Ruitenberg, "Europe Heat Wave Wilting Corn Adds to U.S. Drought," Bloomberg (July 24, 2012).

Heat waves in southern Europe are withering the corn crop and reducing yields in a region that accounts for 16 percent of global exports at a time when U.S. drought already drove prices to a record.

Temperatures in a band running from eastern Italy across the Black Sea region into Ukraine reached 35 degrees Celsius (95 degrees Fahrenheit) or more this month, about 5 degrees above normal, U.S. government data show. Corn, now in the pollination phase that creates kernels, risks damage above 32 degrees, said Cedric Weber, the head of market analysis at Bourges, France-based Offre et Demande Agricole, which advises farmers on sales.

The heat wave in Europe is adding to concern about global food supplies as U.S. farmers face the worst drought since 1956, India delays sowing because of a late monsoon and Australian crops endure below-average rainfall. Soybeans and corn rose to all-time highs yesterday and wheat surged 42 percent since June 1 . The United Nations says food prices will probably rebound after falling the most in three years in the second quarter. 


\section{Prabhudatta Mishra, "Rice Harvest in India Set to Drop as Drought Curbs Sowing," Bloomberg (August 16, 2012).}

Rice production in India, the world's second-biggest grower, is poised to slump from a record as the worst monsoon since 2009 reduces planting, potentially lowering exports and boosting global prices.

The monsoon-sown harvest may be between 5 million metric tons and 7 million tons below a record 91.5 million tons a year earlier, said P. K. Joshi, director for the South Asia region at the Washington-based International Food Policy Research Institute. Production of food grains, including corn and lentils, may slide as much as 12 percent from 129.9 million tons a year earlier, he said.

Rice has rallied 6.3 percent in Chicago since the end of May on prospects for a lower Indian crop and export curbs, adding to global food costs that the United Nations estimates jumped 6.2 percent in July. Corn and soybeans have soared to records as the worst U.S. drought in half a century killed crops. Global rice production this year will be smaller than previously forecast, according to the UN's Food \& Agriculture Organization.

Polina Devitt, "Russia Harvest Forecasts Cut as Drought Hits Crop in East," Reuters (August 20, 2012).

Two leading Russian agricultural analysts cut their forecasts for Russia's grain harvest on Monday after harvest data from two drought-stricken eastern growing regions reduced the outlook for the overall crop. SovEcon narrowed their grain forecast to 71-72.5 million metric tons (78.3-79.9 million tons) from a previous 70-74 million tonnes after the start of harvesting campaign in Urals and Siberia regions showed weak crop prospects. It has also cut wheat harvest forecast to 39-41 million tonnes from earlier 40.5-42.5 million tonnes.

The Institute for Agricultural Market Studies (IKAR) has cut its 2012 grain crop forecast to 73 million tonnes from a previously expected 75.4 million tonnes, its chief executive, Dmitry Rylko, said. It has not yet estimated wheat harvest.

"I see the possibility of further downgrading," Rylko said.

Global Information and Early Warning System, "Crop Prospects and Food Situation," no. 3 (October 2012), Rome: United Nations, Food and Agricultural Organization.

FAO's latest forecast for world cereal production in 2012 has been revised downward slightly (0.4 percent) since the previous update in September, to 2,286 million tonnes. The latest adjustment mostly reflects a smaller maize crop in central and southeastern parts of Europe, where yields are turning out lower than earlier expectations following prolonged dry conditions. At the current forecast level, world cereal production in 2012 would be 2.6 percent down from the previous year's record crop but close to the second largest in 2008. The overall decrease comprises a 5.2 percent reduction in wheat production, and a 2.3 percent reduction for coarse grains, while the global rice crop is seen to remain virtually unchanged. 
Severe droughts this year in the United States and across a large part of Europe and into central Asia have been the main cause of the reduced wheat and coarse grains crops....

FAO's latest forecast for global wheat production in 2012 stands at 663 million tonnes, 5.2 percent below last year's level, but close to the average of the past five years. This level is considerably below expectations earlier in the year, largely reflecting the impact of the severe drought that set-in across eastern Europe and central Asia, but also on account of downward revisions for the key Southern Hemisphere producing countries where weather and policy factors in some cases have reduced prospects for the 2012 crop yet to be harvested.

Most of the decline in global wheat production, compared to last year, reflects the negative effects of drought in the major producing CIS countries in Europe and Asia. Wheat output in the Russian Federation is estimated some 30 percent down from 2011, in Ukraine, latest information points to a decrease of about 33 percent, while in Kazakhstan, output is reported to be just half of last year's good level. In other parts of Europe, wheat output also declined, particularly in some central and southeastern countries on the edge of the drought-affected zone. The aggregate output of the EU countries is estimated to be down by 2.6 percent. In the other Asian subregions, record crops have been gathered in the key producers in the Far East, namely, China and India, while in the Near East, results have been mixed: good crops were gathered in Afghanistan and the Islamic Republic of Iran but outputs were down elsewhere, reflecting dry conditions and/or the negative impact of civil disturbances. The 2012 harvest results were also mixed in North Africa, where production recovered in Algeria but was sharply reduced in Morocco due to dry conditions. In the United States, this year's wheat production is estimated to have increased by 13.4 percent to an above-average level of 61.7 million tonnes. In Canada, output is expected to be above average and almost 7 percent higher than in 2011.

In South America, the subregion's aggregate wheat production is forecast at about 21 million tonnes, 12 percent down from the previous year and below average. The expected reduction reflects a general decline in the area planted in response to changes in marketing policy and due to dry weather at sowing time in June and July. In Oceania, prospects for the wheat crop in Australia are mixed, reflecting varied winter rainfall and moisture conditions: overall output is forecast down by about 24 percent from last year's record crop due to lower yields expected in some major producing areas affected by dry conditions.

ACKNOWLEDGMENTS We thank the editor, James Stock, for his valuable comments and guidance in revising the paper. We are also grateful to our discussants, Wolfram Schlenker and Mark Watson, and to the participants in the Fall 2016 Brookings Panel on Economic Activity for helpful comments. We thank Bruno Albuquerque, Selien De Schryder, Gert Elaut, Kevin Lampaert, Viooltje Lebuf, Karel Mertens, Christopher Sims, and Joris Wauters-as well as seminar and conference participants at the São Paulo School of Economics, 
Erasmus University Rotterdam, the Bank of Italy, Norges Bank, the 2015 GhentLille economics workshop, the 2016 Theories and Methods in Macroeconomics (T2M) conference, the 2016 Birkbeck Centre for Applied Macroeconomics workshop, and the 2016 International Association for Applied Econometrics' annual conference-for useful suggestions and feedback on earlier versions of the paper. We acknowledge financial support from the Research Foundation Flanders and Ghent University's Special Research Fund. All remaining errors are ours. 


\section{References}

Abbott, Philip C., Christopher Hurt, and Wallace E. Tyner. 2011. "What's Driving Food Prices in 2011?" Issue Report. Oak Brook, Ill.: Farm Foundation. http://www.farmfoundation.org/news/articlefiles/105-FoodPrices_web.pdf

Acemoglu, Daron, Ufuk Akcigit, and William Kerr. 2016. "Networks and the Macroeconomy: An Empirical Exploration." NBER Macroeconomics Annual 30: 276-335.

Baquedano, Felix G., and William M. Liefert. 2014. "Market Integration and Price Transmission in Consumer Markets of Developing Countries." Food Policy 44: $103-14$.

Baumeister, Christiane, and James D. Hamilton. 2015. "Sign Restrictions, Structural Vector Autoregressions, and Useful Prior Information." Econometrica 83, no. 5: 1963-99.

Baumeister, Christiane, and Gert Peersman. 2013a. "The Role of Time-Varying Price Elasticities in Accounting for Volatility Changes in the Crude Oil Market." Journal of Applied Econometrics 28, no. 7: 1087-109.

2013b. "Time-Varying Effects of Oil Supply Shocks on the US Economy." American Economic Journal: Macroeconomics 5, no. 4: 1-28.

Beaudry, Paul, and Franck Portier. 2006. "Stock Prices, News, and Economic Fluctuations." American Economic Review 96, no. 4: 1293-307.

Bernanke, Ben S., Mark Gertler, and Mark Watson. 1997. "Systematic Monetary Policy and the Effects of Oil Price Shocks." Brookings Papers on Economic Activity, no. 1: 91-142.

Bernanke, Ben S., and Ilian Mihov. 1998. "Measuring Monetary Policy." Quarterly Journal of Economics 113, no. 3: 869-902.

Bils, Mark, and Peter J. Klenow. 1998. "Using Consumer Theory to Test Competing Business Cycle Models." Journal of Political Economy 106, no. 2: 233-61.

Blanchard, Olivier, and Roberto Perotti. 2002. "An Empirical Characterization of the Dynamic Effects of Changes in Government Spending and Taxes on Output." Quarterly Journal of Economics 117, no. 4: 1329-68.

Boldin, Michael, and Jonathan H. Wright. 2015. "Weather-Adjusting Economic Data." Brookings Papers on Economic Activity, Fall: 227-60.

Browning, Martin, and Thomas F. Crossley. 2000. "Luxuries Are Easier to Postpone: A Proof." Journal of Political Economy 108, no. 5: 1022-26.

- 2009. "Shocks, Stocks, and Socks: Smoothing Consumption over a Temporary Income Loss." Journal of the European Economic Association 7, no. 6: 1169-92.

Chavas, Jean-Paul, David Hummels, and Brian D. Wright, editors. 2014. The Economics of Food Price Volatility. University of Chicago Press.

Christiano, Lawrence J., Martin Eichenbaum, and Charles L. Evans. 1999. "Monetary Policy Shocks: What Have We Learned and to What End?" In Handbook of Macroeconomics, Volume 1A, edited by John B. Taylor and Michael Woodford. Amsterdam: North-Holland. 
Clark, Todd E., and Troy Davig. 2008. "An Empirical Assessment of the Relationships among Inflation and Short- and Long-Term Expectations." Research Working Paper no. 08-05. Federal Reserve Bank of Kansas City.

Cochrane, John H. 2016. "Macro-Finance.” Working Paper no. 22485. Cambridge, Mass.: National Bureau of Economic Research.

Davis, Steven J., and John Haltiwanger. 2001. "Sectoral Job Creation and Destruction Responses to Oil Price Changes." Journal of Monetary Economics 48, no. 3: 465-512.

Dawe, David, and Irini Maltsoglou. 2014. "Marketing Margins and the Welfare Analysis of Food Price Shocks." Food Policy 46: 50-55.

Dell, Melissa, Benjamin F. Jones, and Benjamin A. Olken. 2014. "What Do We Learn from the Weather? The New Climate-Economy Literature." Journal of Economic Literature 52, no. 3: 740-98.

Dynarski, Susan, and Jonathan Gruber. 1997. "Can Families Smooth Variable Earnings?” Brookings Papers on Economic Activity, no. 1: 229-84.

Edelstein, Paul, and Lutz Kilian. 2009. "How Sensitive Are Consumer Expenditures to Retail Energy Prices?" Journal of Monetary Economics 56, no. 6: 766-79.

Elliott, Graham. 1998. "On the Robustness of Cointegration Methods When Regressors Almost Have Unit Roots.” Econometrica 66, no. 1: 149-58.

Enders, Walter, and Matthew T. Holt. 2014. "The Evolving Relationships between Agricultural and Energy Commodity Prices: A Shifting-Mean Vector Autoregressive Analysis." In The Economics of Food Price Volatility, edited by Jean-Paul Chavas, David Hummels, and Brian D. Wright. University of Chicago Press.

Ezekiel, Mordecai. 1938. “The Cobweb Theorem.” Quarterly Journal of Economics 52, no. 2: 255-80.

Fanning, Bob. 2012. "Fertilizer Timing for Wheat." iGrow article, March 4. Brookings: South Dakota State University. http://igrow.org/agronomy/wheat/ fertilizer-timing-for-wheat/

Ferrucci, Gianluigi, Rebeca Jiménez-Rodríguez, and Luca Onorante. 2012. "Food Price Pass-Through in the Euro Area: Non-Linearities and the Role of the Common Agricultural Policy." International Journal of Central Banking 8, no. 1: 179-217.

Finn, Mary G. 2000. "Perfect Competition and the Effects of Energy Price Increases on Economic Activity." Journal of Money, Credit and Banking 32, no 3, pt. 1: 400-16.

Furceri, Davide, Prakash Loungani, John Simon, and Susan Wachter. 2015. "Global Food Prices and Domestic Inflation: Some Cross-Country Evidence.” Working Paper no. 15/133. Washington: International Monetary Fund.

Furlong, Fred, and Robert Ingenito. 1996. "Commodity Prices and Inflation." Economic Review (Federal Reserve Bank of San Francisco), no. 2: 27-47.

Galí, Jordi. 1999. "Technology, Employment, and the Business Cycle: Do Technology Shocks Explain Aggregate Fluctuations?" American Economic Review 89, no. 1: 249-71. 
Giffen, Robert. 1879. "On the Fall of Prices of Commodities in Recent Years." Journal of the Statistical Society of London 42, no. 1: 36-78.

Gouel, Christophe. 2012. "Agricultural Price Instability: A Survey of Competing Explanations and Remedies." Journal of Economic Surveys 26, no. 1: 129-56.

Hamermesh, Daniel S. 1982. "Social Insurance and Consumption: An Empirical Inquiry." American Economic Review 72, no. 1: 101-13.

Hamilton, James D. 1983. "Oil and the Macroeconomy since World War II." Journal of Political Economy 91, no. 2: 228-48.

1988. "A Neoclassical Model of Unemployment and the Business Cycle." Journal of Political Economy 96, no. 3: 593-617. 363-98.

2003. "What Is an Oil Shock?" Journal of Econometrics 113, no. 2:

. 2008. "Oil and the Macroeconomy." In The New Palgrave Dictionary of Economics, 2nd ed., edited by Steven N. Durlauf and Lawrence E. Blume. London: Palgrave Macmillan.

Headey, Derek, and Shenggen Fan. 2010. "Reflections on the Global Food Crisis: How Did It Happen? How Has It Hurt? And How Can We Prevent the Next One?" Research Monograph no. 165. Washington: International Food Policy Research Institute.

Ivanic, Maros, and Will Martin. 2008. "Implications of Higher Global Food Prices for Poverty in Low-Income Countries." Agricultural Economics 39, supplement: 405-16.

Jordà, Òscar. 2005. "Estimation and Inference of Impulse Responses by Local Projections." American Economic Review 95, no. 1: 161-82.

Kilian, Lutz. 2009. "Not All Oil Price Shocks Are Alike: Disentangling Demand and Supply Shocks in the Crude Oil Market." American Economic Review 99, no. 3: 1053-69.

Lawes, John Bennet, and Joseph Henry Gilbert. 1868. "On the Home Produce, Imports and Consumption of Wheat." Journal of the Royal Agricultural Society of England 4: 359-96.

Mallarino, Antonio P. 2010. "Is In-Season Fertilization for Soybean Effective?" Integrated Crop Management News, June 29. Ames: Iowa State University. http:// crops.extension.iastate.edu/cropnews/2010/06/season-fertilization-soybeaneffective

Mertens, Karel, and Morten O. Ravn. 2013. "The Dynamic Effects of Personal and Corporate Income Tax Changes in the United States." American Economic Review 103, no. 4: 1212-47.

Mitchell, Donald. 2008. “A Note on Rising Food Prices.” Policy Research Working Paper no. 4682. Washington: World Bank.

Murphy, Robert G., and Adam Rohde. 2015. "Rational Bias in Inflation Expectations." Eastern Economic Journal, advance online publication. http://dx.doi.org/ 10.1057/eej.2015.50

Muth, John F. 1961. "Rational Expectations and the Theory of Price Movements." Econometrica 29, no. 3: 315-35. 
New York Times Editorial Board. 2008. "The World Food Crisis." New York Times, April 10.

Parker, Jonathan A. 1999. "The Reaction of Household Consumption to Predictable Changes in Social Security Taxes." American Economic Review 89, no. 4: 959-73.

Pedersen, Michael. 2011. "Propagation of Shocks to Food and Energy Prices: An International Comparison." Working Paper no. 648. Central Bank of Chile,

Peersman, Gert, Sebastian Rüth, and Wouter Van der Veken. 2016. "The Interplay between Oil and Food Commodity Prices: Has It Changed over Time?" Working paper.

Peersman, Gert, and Ine Van Robays. 2009. "Oil and the Euro Area Economy." Economic Policy 24, no. 60: 603-51.

Pindyck, Robert S. 1993. "The Present Value Model of Rational Commodity Pricing." Economic Journal 103, no. 418: 511-30.

Primiceri, Giorgio E. 2005. "Time Varying Structural Vector Autoregressions and Monetary Policy." Review of Economic Studies 72, no. 3: 821-52.

Ramey, Valerie A. 2011. "Identifying Government Spending Shocks: It's All in the Timing." Quarterly Journal of Economics 126, no. 1: 1-50.

_. 2016. "Macroeconomic Shocks and Their Propagation." In Handbook of Macroeconomics, Volume 2A, edited by John B. Taylor and Harald Uhlig. Amsterdam: North-Holland.

Ramey, Valerie A., and Matthew D. Shapiro. 1998. "Costly Capital Reallocation and the Effects of Government Spending." Carnegie-Rochester Conference Series on Public Policy 48: 145-94.

Ramey, Valerie A., and Sarah Zubairy. 2014. "Government Spending Multipliers in Good Times and in Bad: Evidence from U.S. Historical Data." Working Paper no. 20719. Cambridge, Mass.: National Bureau of Economic Research.

Rigobon, Roberto. 2010. "Commodity Prices Pass-Through.” Working Paper no. 572. Central Bank of Chile.

Roberts, Michael J., and Wolfram Schlenker. 2013. "Identifying Supply and Demand Elasticities of Agricultural Commodities: Implications for the US Ethanol Mandate." American Economic Review 103, no. 6: 2265-95.

Romer, Christina D., and David H. Romer. 1989. "Does Monetary Policy Matter? A New Test in the Spirit of Friedman and Schwartz." NBER Macroeconomics Annual 4: 121-84.

2010. "The Macroeconomic Effects of Tax Changes: Estimates Based on a New Measure of Fiscal Shocks." American Economic Review 100, no. 3: 763-801.

Rotemberg, Julio J., and Michael Woodford. 1996. "Imperfect Competition and the Effects of Energy Price Increases on Economic Activity." Journal of Money, Credit and Banking 28, no. 4, pt. 1: 549-77.

Scharf, Peter C., William J. Wiebold, and John A. Lory. 2002. "Corn Yield Response to Nitrogen Fertilizer Timing and Deficiency Level." Agronomy Journal 94, no. 3: 435-41. 
Schmitt, Michael A., John A. Lamb, Gyles W. Randall, James H. Orf, and George W. Rehm. 2001. "In-Season Fertilizer Nitrogen Applications for Soybean in Minnesota." Agronomy Journal 93, no. 5: 983-88.

Sims, Christopher A. 1980. "Macroeconomics and Reality." Econometrica 48, no. 1: 1-48.

. 2000. "Using a Likelihood Perspective to Sharpen Econometric Discourse: Three Examples." Journal of Econometrics 95, no. 2: 443-62.

Sims, Christopher A., James H. Stock, and Mark W. Watson. 1990. "Inference in Linear Time Series Models with Some Unit Roots." Econometrica 58, no. 1: $113-44$.

Sims, Christopher A., and Tao Zha. 1999. "Error Bands for Impulse Responses." Econometrica 67, no. 5: 1113-55.

Stock, James H., and Mark W. Watson. 2016. "Dynamic Factor Models, FactorAugmented Vector Autoregressions, and Structural Vector Autoregressions in Macroeconomics." In Handbook of Macroeconomics, Volume 2A, edited by John B. Taylor and Harald Uhlig. Amsterdam: North-Holland.

Trostle, Ronald, Daniel Marti, Stacey Rosen, and Paul Westcott. 2011. "Why Have Food Commodity Prices Risen Again?" International Agriculture and Trade Outlook no. WRS-1103. Washington: U.S. Department of Agriculture, Economic Research Service.

Vidal, John. 2010. "Global Food Crisis Forecast as Prices Reach Record Highs." The Guardian, October 25.

Williamson, Lucille, and Paul Williamson. 1942. "What We Eat." Journal of Farm Economics 24, no. 3: 698-703.

Zhang, Wenlang, and Daniel Law. 2010. "What Drives China's Food-Price Inflation and How Does It Affect the Aggregate Inflation?” Working Paper no. 06/2010. Hong Kong Monetary Authority. 


\section{Comments and Discussion}

\section{COMMENT BY}

WOLFRAM SCHLENKER This paper by Jasmien De Winne and Gert Peersman presents an innovative analysis of whether food commodity price shocks have ramifications throughout the larger economy. There is a large body of literature discussing how oil price fluctuations might have an impact on the economy, yet very little work has been done examining the effects of food commodity price fluctuations.

The authors address this question in two ways: empirically, by estimating a vector autoregression (VAR) model; and narratively, by examining the economic response to 13 episodes of significant commodity market surprises. The VAR cleverly extends a previous analysis that used annual commodity yield shocks of the four staple commodities - corn, wheat, rice, and soybeans-as instruments for commodity prices. The authors utilize calendars for the various crops to define the quarters for which production shocks should show up as news. The analysis concentrates on crops and countries where the harvest time falls in a different quarter than the planting time. Farmers endogenously choose how much to plant; but, conditional on the planted area, production shocks at harvest time are predominantly exogenously determined by the effect of weather on yields. The authors find a large effect of commodity price shocks on U.S. GDP. There is even a surprisingly large positive effect on durables like cars.

The VAR is discussed in more detail in Mark Watson's comment. Here, I focus on a puzzle in the mechanism behind the discovered relationship and a reduced-form sensitivity check.

COMMODITY PRICES VERSUS FOOD PRICES When talking about prices, it is important to separate the raw commodity prices that farmers receive for their products from the food prices that consumers pay at the store. Though the latter accounted for, on average, 17 percent of households' expenditures in 
the 1960-2015 period, the fraction that falls on the pure commodity cost is rather minor. Michael Roberts and I (2013) estimate that for a 2,000-calorie daily diet of raw, unprocessed rice, the annual commodity cost fell in real terms during the 20th century, and is currently less than $\$ 100$. Because nobody eats raw, unprocessed rice and nothing else, this is of course a hypothetical example. A meat-based diet would have higher commodity costs; 1 calorie of meat requires more than 1 calorie of feedstock, as a large fraction of the feedstock is used to sustain the animal. But the largest component of the final food price consumers end up paying at the store is the processing and distribution cost. There is a big difference between changes in the price of raw commodities-which can easily double in response to production shocks due to the inelastic demand for commodities-and the change in food prices at the supermarket.

This point has been made by Christiane Baumeister and Lutz Kilian (2014), who show that fluctuations in oil prices do not translate into changes in the food prices consumers pay at the store. They emphasize,

The distinction between retail food prices and the prices received by farmers for grain crops and livestock is important. . . The discrepancy between the slow growth in real consumer food prices and the more rapid growth in the crop prices received by farmers is explained by the small cost share of agricultural products in the food prices paid by U.S. consumers. For example, the farm value of wheat in the price of bread is only about 5 percent, so even substantial wheat price increases are associated with only small increases in the price of bread. (Baumeister and Kilian 2014, p. 736)

This raises a question about the possible mechanism between commodity prices that farmers receive and overall economic fluctuations in the United States: Are the observed commodity price swings large enough to change how much consumers pay at the store? If not, how would higher commodity prices affect consumer spending, and possibly make an impact on the larger economy?

My figure 1 plots the quarterly commodity price index for both the large basket of commodities and the narrower cereal price index from De Winne and Peersman for the years 1996-2015. The dashed lines show the large rise between 2005 and 2008, especially for the cereal index, where prices roughly tripled. The figure also shows food expenditures taken from the diary files of the U.S. Bureau of Labor Statistics' Consumer Expenditure Survey. Weekly expenditures are aggregated to the quarterly level to match De Winne and Peersman's time scale, and are then multiplied by four to get the corresponding annual cost in nominal dollars, as shown on the right vertical axis. The solid black line shows total expenditures, which increase 
Figure 1. Commodity Prices versus Food Price Expenditures, 1996-2015

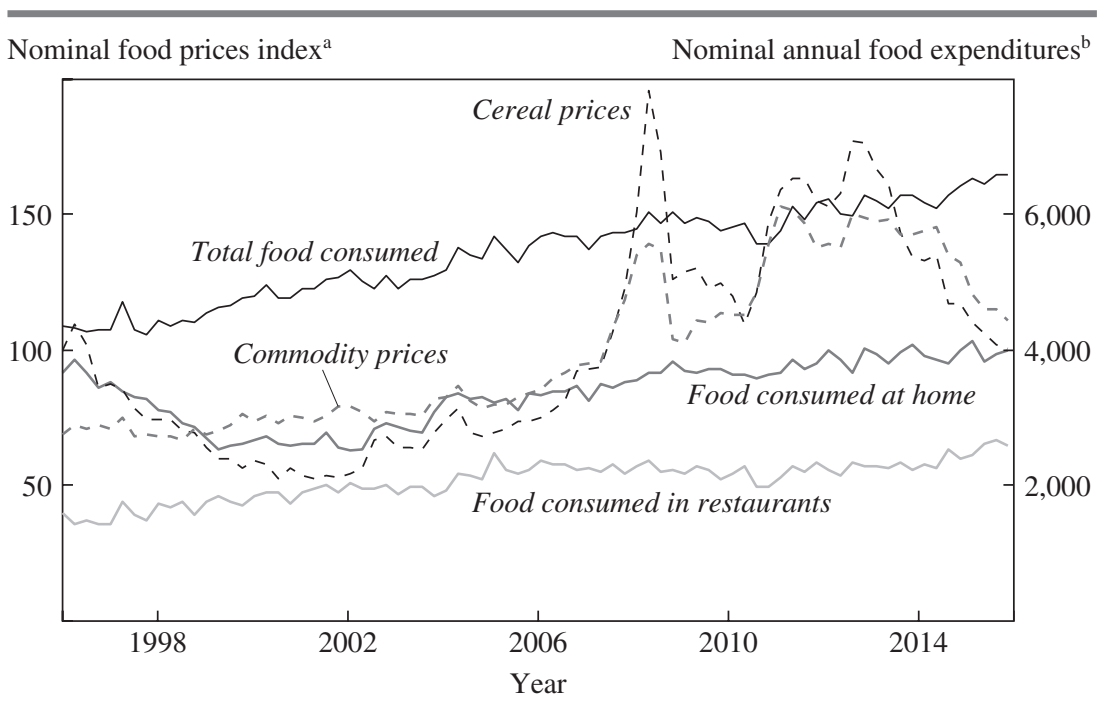

Sources: De Winne and Peersman; U.S. Bureau of Labor Statistics, Consumer Expenditure Survey.

a. The values are indexed so that the average nominal food price equals 100 .

b. Weekly nominal food expenditures are aggregated to the quarterly level, and are multiplied by 4 to give the annual cost.

smoothly over time, from roughly $\$ 4,500$ in 1996 to $\$ 6,500$ in 2015 . The solid gray lines separate total expenditures into ones for food consumed at home and in restaurants. These lines rise smoothly over time as well.

The disconnect between commodity prices and food expenditures is apparent. The former roughly tripled, yet the latter hardly budged at all. There might be differences between farmers' commodity prices and consumers' food expenditures. Stores might choose not to pass on all fluctuations. Alternatively, an increase in prices might be offset by a decrease in the quantity consumed, though the complete unresponsiveness in expenditures when commodity prices triple seems odd, given the highly inelastic demand. For comparison, my figure 2 plots prices for eggs and milk as well as food expenditures from the diary files from the Consumer Expenditure Survey. Both eggs and milk are much harder to store than raw commodities, so farmer prices fluctuate more wildly because shocks cannot be smoothed across time; yet, the two series of farmer prices and store prices appear to be very much linked.

The most likely reason why consumers' food expenditures do not respond to farmers' commodity prices for the four basic staples_-corn, wheat, rice, 
Figure 2. Food Prices versus Food Expenditures for Eggs and Milk, 1996-2015

Eggs

Index ${ }^{\mathrm{b}}$

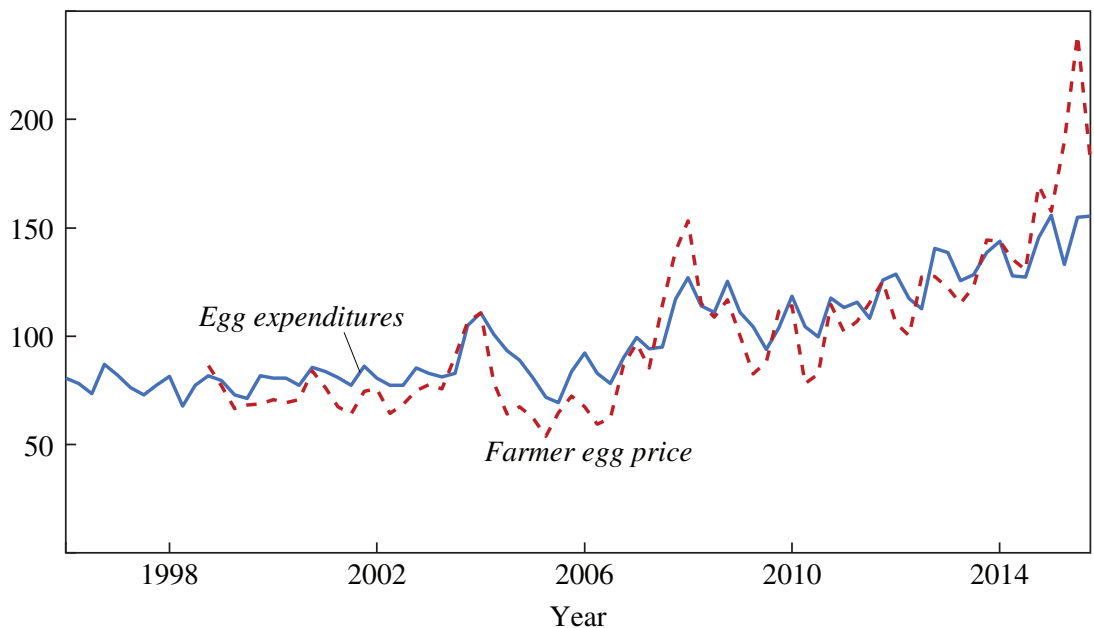

Milk

Index ${ }^{b}$

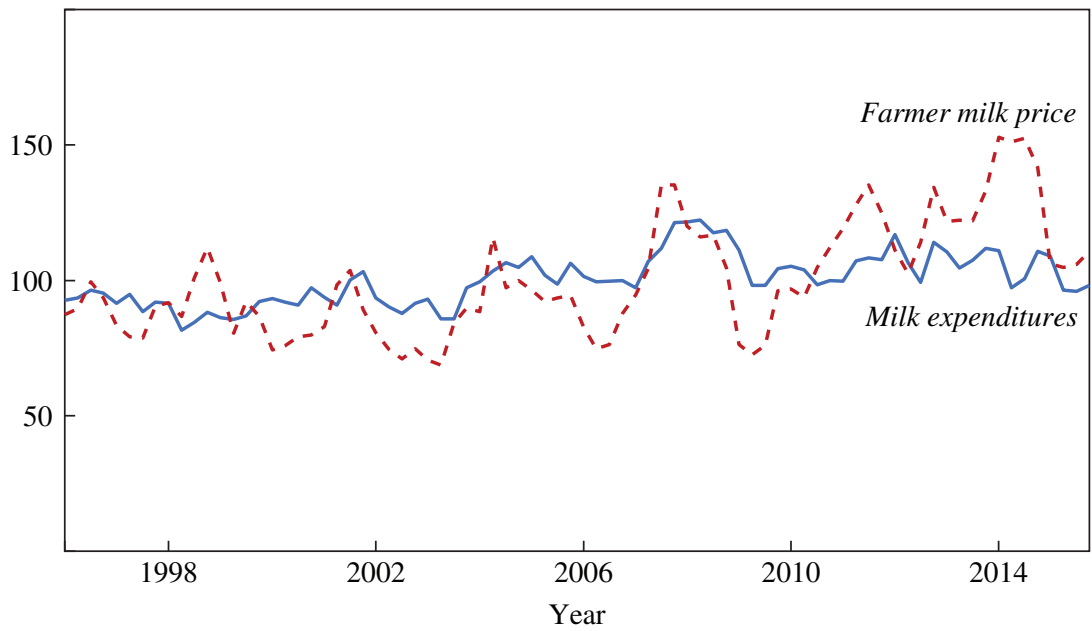

Sources: U.S. Department of Agriculture, National Agricultural Statistics Service; U.S. Bureau of Labor Statistics, Consumer Expenditure Survey.

a. For food prices, monthly data are averaged over the three months of each quarter; for consumer expenditures, weekly data are aggregated to the quarterly level.

b. The values are indexed so that the average nominal food price equals 100 . 
and soybeans-is that the latter are a small fraction of the former. If food expenditures do not respond to commodity prices, is the observed significant relationship between commodity prices and the economy at large real? The next section presents an alternative reduced-form sensitivity check.

REDUCED-FORM ANALYSIS USING CALORIC SHOCKS De Winne and Peersman's VAR uses production in the harvest quarter as a variable. Not all changes in total production are news, given that some are anticipated and endogenous, such as changes in the growing area. This is accounted for in the VAR by incorporating commodity prices, which should reflect all information the market knew at the time of the harvest. However, the linearity in the VAR model might be inadequate to model all nonlinear responses to changes in expectations and prices.

An alternative to including total production as a variable is to construct shocks that are unexpected news. My figure 3 shows such unexpected quarterly caloric shocks, which are constructed as residuals from a regression of $\log$ yields to country- and crop-specific time trends. They are then summed over all countries and crops using predicted production weights and the caloric content of each crop. For a detailed description of how these shocks are derived, see Roberts and Schlenker (2013, p. 2271). The only difference between my figure 3 and Roberts and Schlenker's (2013) methodology is that my shocks are aggregated to the quarterly level, whereas Roberts and Schlenker aggregate to the annual level. The harvest starts as defined by De Winne and Peersman's crop calendar. My figure 3 shows the results when the time trend is modeled as a restricted cubic spline with either four or six knots. The number of knots has a negligible effect on the shocks, because yields have been trending upward very smoothly over time. The shocks (deviations from a country- and crop-specific trend) are exogenous and random in time, making them ideal as an instrument.

My table 1 presents the results of a simple reduced-form regression when various quarterly dependent variables, $y_{t}$, are regressed on the caloric production shocks that are due to yield anomalies $w_{t}$ (both a contemporaneous term and five lags to match the lag structure of De Winne and Peersman), quarterly fixed effects $\alpha_{q(t)}$, and a time trend $f(t)$, which is again flexibly modeled as a restricted cubic spline with either four or six knots:

$$
y_{t}=\alpha_{q(t)}+\sum_{k=0}^{5} \beta_{k} w_{t-k}+f(t)+\varepsilon_{t}
$$

Various variables used by De Winne and Peersman are used as the dependent variable: Columns 1 and 2 use their real commodity price index; columns 3 and 4 use the real cereal price index; columns 5 and 6 use real 
Figure 3. Caloric Shocks, 1960-2015

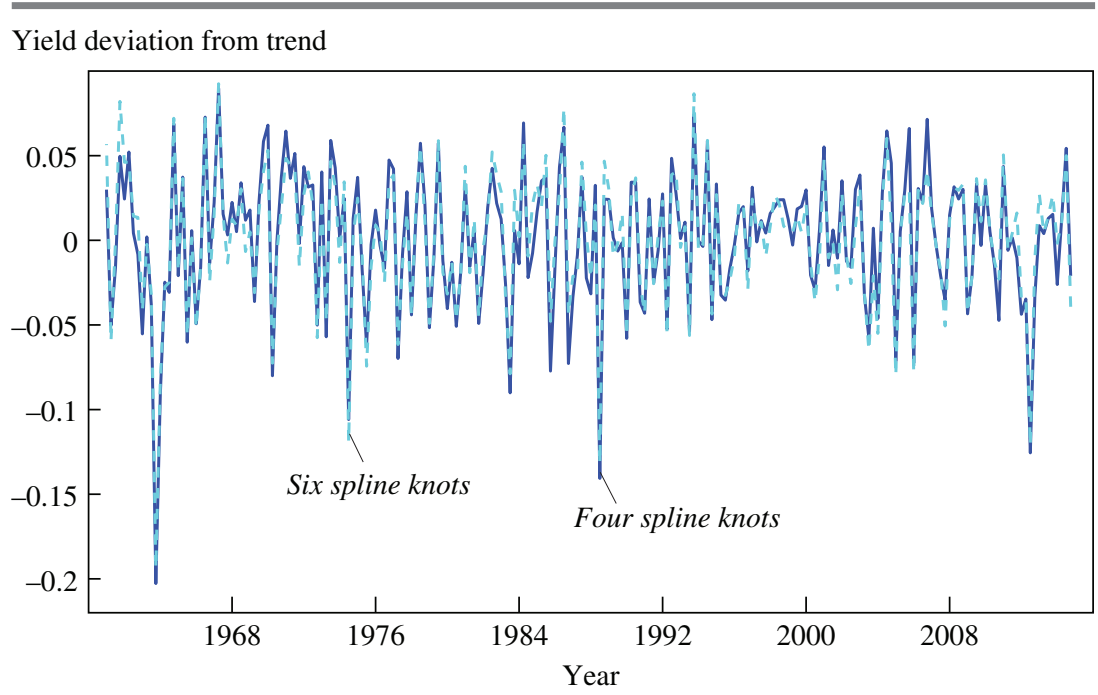

Sources: Author's calculations; Roberts and Schlenker (2013).

a. This figure shows caloric shocks in the harvesting quarter, following the crop calendar used by De Winne and Peersman. The model regresses log yields on time trends for each crop and country, and derives the residuals. The log deviations are aggregated over all crops and countries for the harvesting quarter using the predicted production (yield trend $\times$ actual area), multiplied by a caloric conversion factor as weight. Time trends are modeled as restricted cubic splines with four or six knots.

U.S. GDP; and columns 7 and 8 use real global production. The oddnumbered columns use a restricted cubic spline time trend with four knots, while the even-numbered columns use six knots. The top panel estimates the model in first differences of the log variables, while the bottom panel estimates the model in log levels.

Focus on the differenced results in the top panel: The results for commodity price in columns 1 and 2 are highly significant; an unexpected caloric shock in production leads to a large, significant change in prices of the opposite sign. The large magnitude is due to the extremely inelastic demand for the good, and supply usually requires a full year (four quarters) to respond during the next annual cropping cycle. The timing also seems intuitive; prices move in the two quarters after new production shocks are revealed. The second quarter might be an artifact of the classification scheme, where harvesting periods that span two quarters are assigned to the first. Shocks might not be fully revealed until quarter $t+1$. The coefficients a year later in quarters $t+4$ and $t+5$ are significant and of the opposite sign, as production shortfalls can be counterbalanced in the next growing season by increasing the growing area. The combined effect-the sum of 


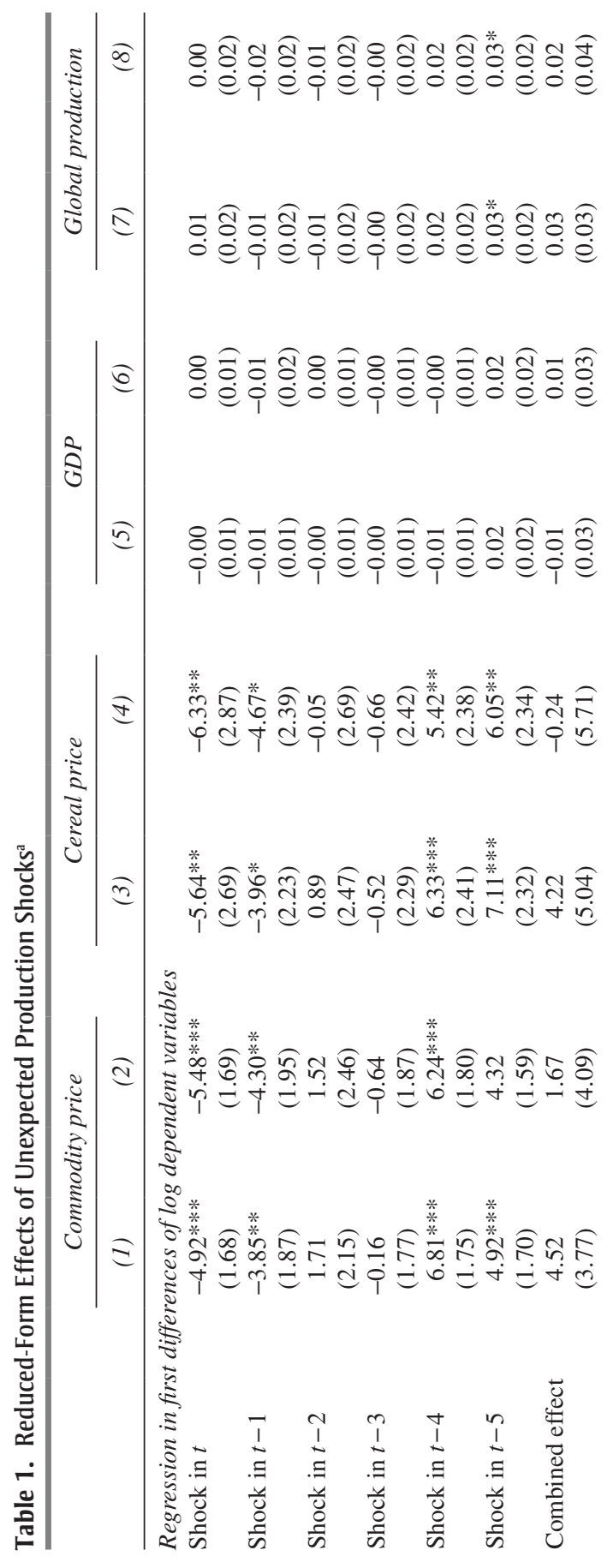




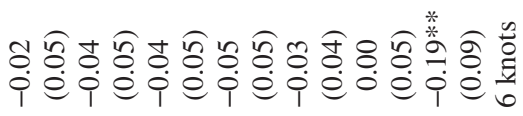

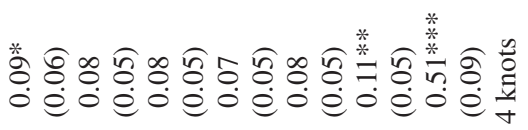

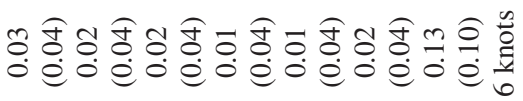

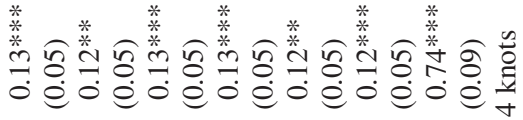

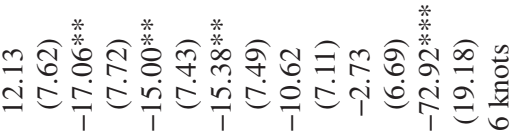

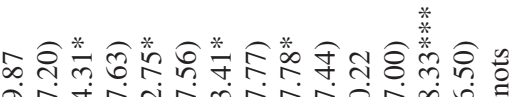

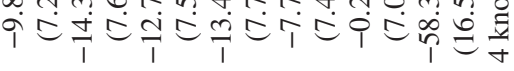

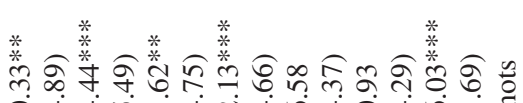

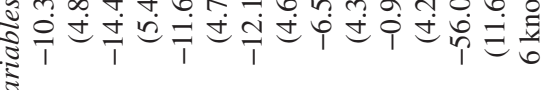

节 。ำ s

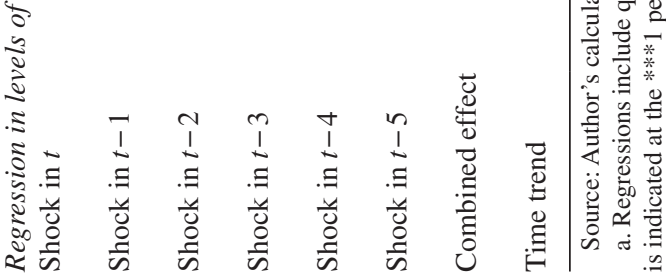


Figure 4. Comparison of Various Commodity Prices, 1960-2015

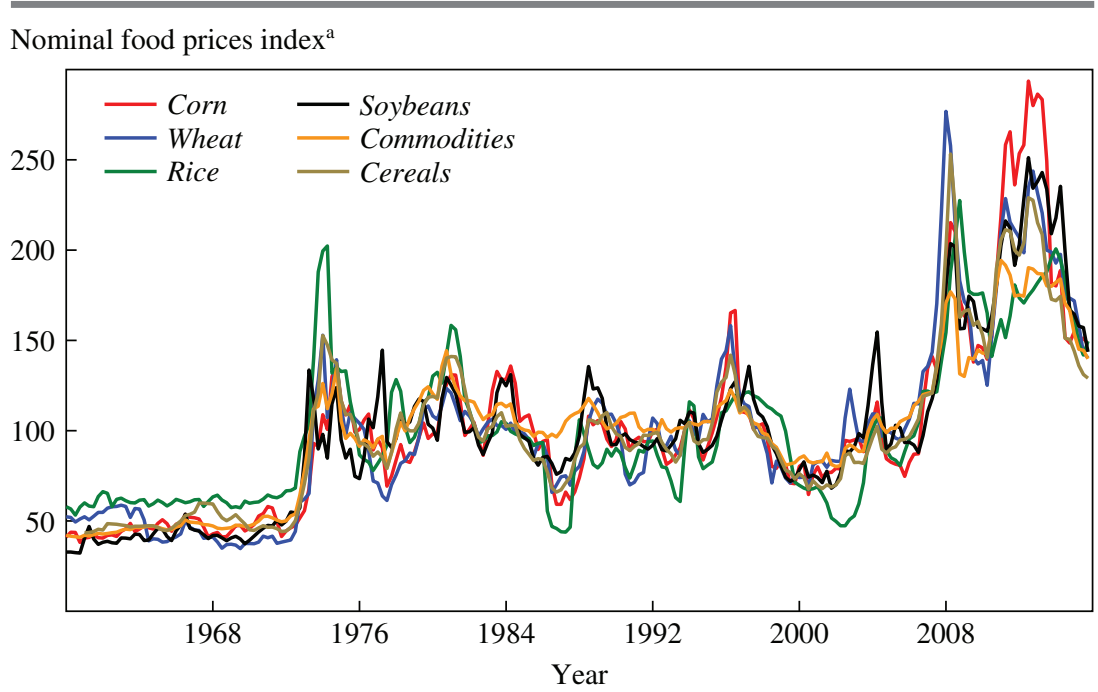

Sources: De Winne and Peersman; U.S. Department of Agriculture, National Agricultural Statistics Service. a. Monthly data are averaged over the three months of each quarter. The values are indexed so that the average nominal food price equals 100 .

the six individual coefficients-is given at the bottom of each panel. They are insignificant because temporary price spikes disappear in the next growing season, when production responses can take place. My figure 4 shows that commodity prices move very closely together; the figure compares De Winne and Peersman's price indexes with data for the four commodities, corn, wheat, rice, and soybeans. Correlations of the price deviations from a time trend are given in my table 2; they are generally very high, on average about .80 .

Conversely, the results for GDP and global production in the last four columns of my table 1 suggest no significant effects of production shocks on GDP or global production in any of the following five quarters. The combined effect is very small in magnitude and not significantly different from 0 .

The bottom panel of my table 1 uses levels as a sensitivity check, which might be questionable for variables that are not stationary but is shown for comparison purposes. Price effects are again significant and of a large magnitude, while the effects on GDP and global production are sometimes significant, but can have the opposite sign found by De Winne and Peersman. The results are highly sensitive to whether one includes four or six spline 


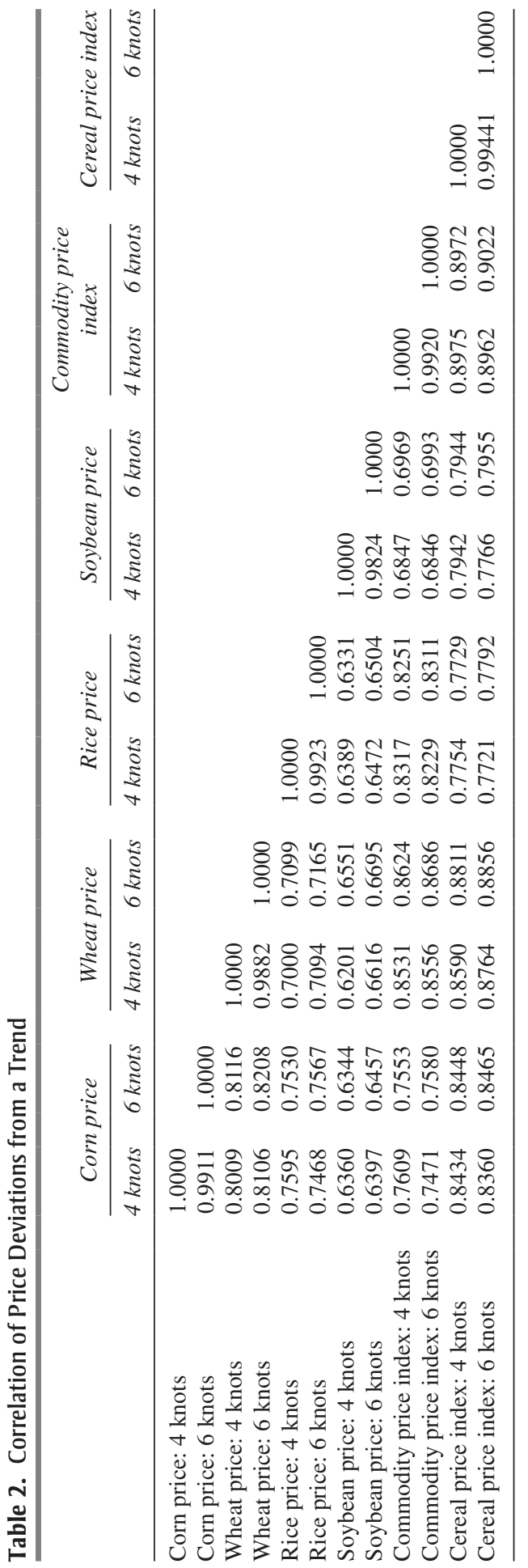


knots. The more flexible specification using six knots gives insignificant results or significant results that have a counterintuitive sign.

In summary, the reduced-form regression linking U.S. GDP and global production to unexpected food price shocks does not corroborate the finding that food price shocks have an impact on the economy at large. So why do the authors find them? One explanation might be that the effects are real but small enough that the reduced-form analysis does not pick them up. A lack of evidence does not necessarily show the lack of an effect, although the standard errors are fairly small.

An alternative explanation might be that instead of food prices affecting GDP, there are omitted confounders. An emerging literature shows that weather has strong influences on GDP growth (Dell, Jones, and Olken 2012; Boldin and Wright 2015; Burke, Hsiang, and Miguel 2015) and conflict (Hsiang, Meng, and Cane 2011; Hsiang, Burke, and Miguel 2013). If detrimental weather shocks cause both agricultural and other sectors to decline while commodity prices spike, there might be an induced correlation that is not causal. The authors address this by only using agricultural shocks outside the United States, but the spurious correlation might even be at work if countries' GDPs are linked through international trade. On top of this, the VAR structure might be too restrictive to force the identification to rest on unexpected shocks. This empirical puzzle-that the VAR detects a relationship that the reduced-form analysis fails to pick up-needs to be addressed by future research.

\section{REFERENCES FOR THE SCHLENKER COMMENT}

Baumeister, Christiane, and Lutz Kilian. 2014. "Do Oil Price Increases Cause Higher Food Prices?" Economic Policy 29, no. 80: 691-747.

Boldin, Michael, and Jonathan H. Wright. 2015. "Weather-Adjusting Economic Data." Brookings Papers on Economic Activity, Fall: 227-60.

Burke, Marshall, Solomon M. Hsiang, and Edward Miguel. 2015. "Global NonLinear Effect of Temperature on Economic Production." Nature 527, no. 7577: 235-39.

Dell, Melissa, Benjamin F. Jones, and Benjamin A. Olken. 2012. "Temperature Shocks and Economic Growth: Evidence from the Last Half Century." American Economic Journal: Macroeconomics 4, no. 3: 66-95.

Hsiang, Solomon M., Marshall Burke, and Edward Miguel. 2013. "Quantifying the Influence of Climate on Human Conflict." Science 341, no. 6151: 1212.

Hsiang, Solomon M., Kyle C. Meng, and Mark A. Cane. 2011. "Civil Conflicts Are Associated with the Global Climate." Nature 476, no. 7361: 438-41.

Roberts, Michael J., and Wolfram Schlenker. 2013. "Identifying Supply and Demand Elasticities of Agricultural Commodities: Implications for the US Ethanol Mandate." American Economic Review 103, no. 6: 2265-95. 


\section{COMMENT BY}

MARK W. WATSON This paper by Jasmien De Winne and Gert Peersman is an ambitious and careful analysis of the effects of global food supply shocks on the U.S. macroeconomy. The authors use a familiar framework — structural vector autoregression (SVAR) — and related distributed lag models. Their key challenge is to identify exogenous variation in global food production that can be used to estimate the dynamic causal effects of global food shocks on the U.S. macroeconomy. They do this in two complementary ways, both involving the construction of new data series.

For their first approach, they construct a quarterly index of crop harvests for four staple food commodities using data covering nearly 200 countries. They argue that much of the unforecastable variation in harvests is exogenous because planting decisions are made in the quarters before the harvest. Using this logic, 1-quarter-ahead forecast errors in their production index are exogenous food supply shocks. The dynamic causal effects of food shocks can be identified by ordering their global food production index as the first variable in an SVAR identified by a Wold causal ordering.

For their second approach, they construct a time series of narrative shocks that isolate quarters in which major changes in food production were caused by judgmentally determined exogenous factors. The authors find 13 such quarters during their 1963-2013 sample period. They use the resulting set of indicator variables as instruments to estimate dynamic causal effects in a series of distributed lag models.

Both approaches yield similar conclusions; an unexpected increase in global food supply leads to (i) a reduction in global food prices, (ii) an increase in U.S. GDP, (iii) a decrease in both overall and core prices, (iv) a decrease in interest rates, and (v) a relatively large increase in expenditures on durable consumption goods. The authors argue that part of the channel from food production shocks to expenditures on consumer durables runs through interest rates - that is, Federal Reserve easing as inflation falls following a favorable food supply shock. ${ }^{1}$ But their estimates suggest that this interest rate channel is responsible for only one-third of the total effect. The channel (or channels) explaining the remaining two-thirds remains a mystery, although the authors provide several interesting conjectures.

Here, I use an alternative econometric framework - a structural dynamic factor model (SDFM) - to estimate the causal effect of global food shocks

1. See Bernanke, Gertler, and Watson (1997) for a related analysis of the monetary policy channel for oil shocks. 
on the U.S. macroeconomy. I have two goals: first, to gauge the robustness of the authors' conclusions; and second, to see if the alternative framework provides additional clues as to why global food supply shocks have such a large effect of expenditures for consumer durables. To preview the results, I find the authors' main empirical conclusions are robust to this alternative framework, but the SDFM suggests that the interest rate channel may be more important than is suggested by the authors' SVAR.

I begin by briefly reviewing the SDFM and how it (usefully, in my mind) extends the authors' SVAR analysis. ${ }^{2}$ A key feature of the SDFM is that it easily scales up to incorporate more variables. In a standard $n$-variable SVAR, the number of parameters to be estimated is of the order $n^{2}$; in an SDFM, the number of parameters is of the order $n$. This makes it possible to include many more variables in an SDFM than would be feasible in an SVAR. For example, I use more than 200 macroeconomic variables in the SDFM to estimate the effect of global food supply shocks. The large number of variables in the SDFM gives it two distinct advantages over an SVAR: First, it attenuates omitted variable and measurement error biases in estimates of the unobserved structural shocks; and second, it provides a coherent framework for estimating the effect of shocks on a large number of macroeconomic variables. The general SDFM has the form

$$
\begin{gathered}
X_{t}=\Lambda F_{t}+e_{t}, \\
F_{t}=\Phi(\mathrm{L}) F_{t-1}+G \eta_{t},
\end{gathered}
$$

where $X_{t}$ is an $n \times 1$ vector of observed variables $(n>200$ in this application), $F_{t}$ is a $k \times 1$ vector of unobserved factors where $k$ is relatively small ( $k=8$ here), $e_{t}$ is a vector of idiosyncratic errors, and $\eta_{t}$ is a vector of the model's structural shocks. My interest is in global food shocks, so they are an element of $\eta_{t}$.

When interest focuses on a structural shock that has only a small effect on most of the variables in the model, its factor needs to be tightly connected to an observed series (Stock and Watson 2016). As De Winne and Peersman show, this is the case for food supply shocks, as they explain

2. Stock and Watson (2016) provide a comprehensive survey of dynamic factor models and how the structural versions of these models, SDFMs, are related to SVARs. The empirical results presented here use this framework, and are closely related to the analysis of oil supply shocks appearing in Stock and Watson's (2016) survey. 
only a small amount of the variability in U.S. macroeconomic variables. This leads me to specify equation 1 of the SDFM as

$$
X_{t}=\left[\begin{array}{c}
Q_{t}^{\text {Food }} \\
P_{t}^{\text {Food }} \\
Y_{t}
\end{array}\right]=\left[\begin{array}{ccc}
1 & 0 & 0 \\
0 & 1 & 0 \\
\lambda_{F-\text {-Food }} & \lambda_{F^{P-F o o d}} & \lambda_{F_{\text {oher }}}
\end{array}\right]\left[\begin{array}{c}
F_{t}^{Q-\text { Food }} \\
F_{t}^{P-\text { Food }} \\
F_{t}^{\text {Ohher }}
\end{array}\right]+\left[\begin{array}{c}
0 \\
0 \\
e_{t}^{T Y}
\end{array}\right],
$$

where $Q_{t}^{\text {Food }}$ is the logarithm of the global food supply index constructed by De Winne and Peersman, $P_{t}^{\text {Food }}$ is the logarithm of the food commodity price index constructed by De Winne and Peersman, and $Y_{t}$ is a vector of more than 200 macroeconomic variables, as described by Stock and Watson (2016). From equation 3 , the first factor, $F_{t}^{Q-F o o d}$, is the global food index and the second factor, $F_{t}^{P-F o o d}$, is the food commodity price index. The other factors, $F_{t}^{\text {other }}$, are not directly observed, and they correspond to macroeconomic factors beyond food supply and food prices that cause common variation in the macroeconomic variables included in $Y_{t}$. Finally, using the same timing assumption as the authors' SVAR, I set the first row of $G$ in equation 2 as $(10 \ldots 0)$, so that the first element of $\eta_{t}$ is the global food supply shock. I estimate the model using six factors in $F_{t}^{\text {other }}$ and four lags of $F$ in the VAR in equation 2.

My table 1 shows the estimated impulse effects, $\partial X_{i, t+h} / \partial \eta_{t}^{Q-F o o d}$, computed using the SDFM model along with the fraction of forecast error variance associated with the food supply shock, $\eta^{Q-F o o d}$. The first row shows that the food shock has a unit impact effect on the logarithm of global food production and an $R^{2}$ of 1 , which follow from the identifying assumptions that the shock yields a 1 log point increase in food production, and this shock explains all of the 1-quarter-ahead forecast error. The next row shows the estimated effect of this shock on the logarithm of the food commodity price index after $h=1$ quarter. Food prices fall by $0.39 \log$ points, and food supply shocks explain just 7 percent of the variance in food prices at this horizon. The SDFM includes more than 200 variables, and the remaining rows of the table show impulse responses for a subset of these variables after $h=5$ quarters.

The SDFM's estimates suggest many of the same conclusions as the SVAR used by the authors. An exogenous $1 \log$ point increase in global food supply leads to (i) a nearly identical fall in global food prices (0.39 in the SDFM versus 0.41 in the SVAR); (ii) an increase in U.S. GDP; (iii) decreases in both overall and core prices, both measured by personal 
Table 1. Estimated Effect of Global Food Supply Shocks on Selected Variables from a Structural Dynamic Factor Model ${ }^{\mathrm{a}}$

\begin{tabular}{|c|c|c|}
\hline Variable & Impulse response at horizon $\mathrm{h}$ & $R^{2}(h)$ \\
\hline Global food production $(h=0)$ & $1.000(0.000)$ & 1.00 \\
\hline Food commodity price index $(h=1)$ & $-0.390(0.110)$ & 0.07 \\
\hline \multicolumn{3}{|l|}{ Other variables $(h=5)$} \\
\hline GDP & $0.037(0.021)$ & 0.01 \\
\hline Consumption & $0.050(0.020)$ & 0.04 \\
\hline Consumption: durables & $0.153(0.070)$ & 0.03 \\
\hline Consumption: nondurables & $0.044(0.019)$ & 0.03 \\
\hline Consumption: services & $0.027(0.010)$ & 0.03 \\
\hline Investment & $0.046(0.082)$ & 0.00 \\
\hline Investment: fixed nonresidential & $-0.002(0.062)$ & 0.01 \\
\hline Investment: fixed residential & $0.340(0.120)$ & 0.04 \\
\hline Industrial production & $0.023(0.040)$ & 0.01 \\
\hline Industrial production: consumer durables & $0.128(0.075)$ & 0.01 \\
\hline Industrial production: automobiles & $0.190(0.107)$ & 0.01 \\
\hline Employment & $0.009(0.016)$ & 0.00 \\
\hline Unemployment rate & $-0.810(0.951)$ & 0.01 \\
\hline Labor productivity & $0.034(0.017)$ & 0.02 \\
\hline Housing permits & $0.656(0.226)$ & 0.04 \\
\hline Retail sales & $0.097(0.039)$ & 0.04 \\
\hline PCE prices & $-0.063(0.028)$ & 0.04 \\
\hline PCE prices: core & $-0.029(0.014)$ & 0.02 \\
\hline PCE prices: food and beverages & $-0.137(0.058)$ & 0.05 \\
\hline PCE prices: durable goods & $-0.038(0.027)$ & 0.01 \\
\hline PCE prices: services & $-0.028(0.015)$ & 0.03 \\
\hline Federal funds rate & $-4.310(2.140)$ & 0.04 \\
\hline 10-year Treasury bond rate & $-2.440(0.880)$ & 0.03 \\
\hline 30 -year mortgage rate & $-3.000(1.130)$ & 0.04 \\
\hline Senior Loan Officer Opinion Survey ${ }^{\mathrm{b}}$ & $3.730(1.300)$ & 0.06 \\
\hline Excess bond premium $^{\mathrm{c}}$ & $-0.660(0.305)$ & 0.01 \\
\hline S\&P 500 Index & $0.293(0.183)$ & 0.01 \\
\hline Housing prices & $0.068(0.034)$ & 0.02 \\
\hline Exchange rates & $-0.114(0.059)$ & 0.02 \\
\hline Consumer expectations & $2.460(0.850)$ & 0.04 \\
\hline Oil production & $0.062(0.026)$ & 0.01 \\
\hline Oil prices & $-0.483(0.260)$ & 0.03 \\
\hline CPI gasoline & $-0.259(0.141)$ & 0.03 \\
\hline
\end{tabular}

Sources: Author's calculations; Stock and Watson (2016).

a. $R^{2}(h)$ is the fraction of the $(h+1)$-quarter-ahead forecast error associated with the global supply shock. Standard errors (computed using parametric bootstrap simulations) are in parentheses.

b. The Federal Reserve Board's Senior Loan Officer Opinion Survey on Bank Lending Practices is a quarterly survey of large banks that seeks qualitative information with respect to changes in bank lending practices in the previous quarter.

c. The excess bond premium measure comes from Gilchrist and Zakrajšek (2012). 
consumption expenditures (PCE) in the SDFM; (iv) a decrease in interest rates; and (v) a relatively large increase in expenditures on consumer durables.

That said, there are interesting quantitative differences in the estimated effects of the SDFM and SVAR that, when coupled with the information from other variables, suggest a more important role for interest rates in the transmission of food shocks to the macroeconomy. For example, in addition to large effects on consumer durable expenditures and automobile production, food shocks have large effects on residential investment and new housing permits. Evidently, sectors that are sensitive to the interest rate are particularly affected by food shocks. The SDFM suggests a somewhat smaller effect of the shocks on GDP (roughly 60 percent of the size of the SVAR effect), and a larger and more persistent effect on the federal funds rates (consistent with the results for the authors' FAVAR model in their figure 11). Longer-term interest rates (10-year Treasury bonds and 30-year mortgage rates) fall significantly following a favorable food supply shock. Other financial variables also move in ways consistent with an easing of monetary policy: Stock prices rise, the dollar falls relative to other currencies, the Federal Reserve's Senior Loan Officer Opinion Survey indicates an easing of credit, and the excess bond premium described by Simon Gilchrist and Egon Zakrajšek (2012) falls.

The SDFM results suggest that interest rates are an important, perhaps dominant, channel for the effect of food shocks on the macroeconomy. The size of the effect of food shocks on sectors that are sensitive to the interest rate (residential investment, expenditures on consumer durables) appears to be roughly what would be predicted by the effect of these shocks on interest rates (Bernanke and Gertler 1995; McCarthy and Peach 2002).

Of course, this SDFM exercise is merely a single robustness check that should be viewed in the context of the large number of careful exercises reported by De Winne and Peersman. Their paper raises a novel and interesting question, and I have no doubt that it will be investigated in future papers using other methods and data. I look forward to following this research.

\section{REFERENCES FOR THE WATSON COMMENT}

Bernanke, Ben S., and Mark Gertler. 1995. "Inside the Black Box: The Credit Channel of Monetary Policy Transmission." Journal of Economic Perspectives 9, no. 4: 27-48.

Bernanke, Ben S., Mark Gertler, and Mark Watson. 1997. "Systematic Monetary Policy and the Effects of Oil Price Shocks." Brookings Papers on Economic Activity, no. 1: 91-142. 
Gilchrist, Simon, and Egon Zakrajšek. 2012. "Credit Spreads and Business Cycle Fluctuations." American Economic Review 102, no. 4: 1692-720.

McCarthy, Jonathan, and Richard W. Peach. 2002. "Monetary Policy Transmission to Residential Investment." Economic Policy Review 8, no. 1: 139-58.

Stock, James H., and Mark W. Watson. 2016. "Dynamic Factor Models, FactorAugmented Vector Autoregressions, and Structural Vector Autoregressions in Macroeconomics." In Handbook of Macroeconomics, Volume 2A, edited by John B. Taylor and Harald Uhlig. Amsterdam: North-Holland.

GENERAL DISCUSSION Lutz Kilian observed that the paper's primary story that food supply shocks raise the price of food and lower the discretionary income of consumers, given that households spend a relatively large proportion of their budget on food, is a sensible starting point for the analysis, but that this view is not supported by the evidence. The first problem is how to define "food prices." On one hand, there are food commodity prices in the global economy; on the other hand, there are U.S. retail food prices. In a recent paper, Kilian and Christiane Baumeister show that, despite large fluctuations in global food commodity prices, there was virtually no change in U.S. retail food prices. ${ }^{1}$ One explanation is that most of the prices of final goods are determined by factors other than commodity prices; for example, data from the U.S. Department of Agriculture suggest that only about 5 percent of the cost of producing bread comes from the cost of wheat. According to this logic, it is easy to see why a fluctuation in the global price of wheat would have very little effect on the retail price of bread. Hence, if there is a channel of transmission from food commodity prices to the macroeconomy, as the authors conjectured, that channel must be about something entirely different, something that links food commodity prices to real GDP.

The interesting part of the paper, Kilian contended, is not the impulse responses and variance compositions; it is the historical decompositions that quantify the cumulative effect of food supply shocks. Kilian stressed that these historical decompositions reveal a puzzle. This puzzle is how food supply shocks that explain little of the evolution of global food commodity prices can explain much of the variation in U.S. real GDP growth and its components at the same time. A good example is the apparently large effect of food supply shocks on automobile purchases by consumers. One potential explanation for this finding might seem to be the discretion-

1. Christiane Baumeister and Lutz Kilian, "Do Oil Price Increases Cause Higher Food Prices?” Economic Policy 29, no. 80 (2014): 691-747. 
ary incomes as food prices change; but as Kilian had just observed, there is little variation in discretionary incomes because retail food prices do not move much. A second possible explanation is that there might be a direct link between crude oil prices, biofuel prices, and food commodity prices; but as Kilian had mentioned, he and Baumeister had found no support for such a link. Yet another possible explanation is that monetary policymakers might have responded to changes in inflation driven by changes in retail food prices, Kilian explained; but there have been no large changes in retail food price inflation, so this explanation does not seem plausible. Finally, Kilian expressed skepticism about the paper's attempt to explain its findings based on other channels of the transmission of food supply shocks (such as reallocation effects or food price uncertainty effects). The latter channels, Kilian pointed out, all require the use of nonlinear models, and hence cannot be used to rationalize the authors' estimates obtained from linear models.

Kilian concluded that, rather than there being some mystery explanation yet to be discovered, the paper likely has a problem identifying food supply shocks. A properly identified model, he contended, would include data on global food prices and quantities, but would also include changes in income that ultimately drive the demand for food. It would also include things like inventories of food commodities, which are difficult to measure. Kilian argued that the paper's model might also have omitted variables as well as measurement problems, pointing to a mismatch between the prices and quantity data for food commodities. For example, the Soviet Union is included in constructing the quality measure, but the Soviet Union only very intermittently participated in global food commodity markets, meaning that the price data do not match the quantity data, invalidating the identification.

Kilian had one final comment related to the paper's results on the effects of the oil supply shocks. He noted that the way the paper identified these shocks was not state of the art; rather, it was done in a way that, according to recent research, is known to be misleading because it does not impose all relevant identifying restrictions. ${ }^{2}$ He suggested discarding that particular

2. See, for example, Lutz Kilian and Daniel P. Murphy, "Why Agnostic Sign Restrictions Are Not Enough: Understanding the Dynamics of Oil Market VAR Models," Journal of the European Economic Association 10, no. 5 (2012): 1166-88; Christiane Baumeister and Gert Peersman, "The Role of Time-Varying Price Elasticities in Accounting for Volatility Changes in the Crude Oil Market," Journal of Applied Econometrics 28, no. 7 (2013): 1087-1109; and Juan Antolin-Diaz and Juan Francisco Rubio Ramírez, "Narrative Sign Restrictions for SVARs," Discussion Paper no. 11517, London: Centre for Economic Policy Research. 
evidence; but more important, he failed to see why that evidence was included in the paper in the first place, given that it is not related to the paper's central question of what the effects of food supply shocks are.

As Mark Watson's discussion had emphasized, Christopher Sims noted that it is hard to reliably estimate the effects of food prices because the contribution to the shocks' variance is small. Sims took issue with Watson's approach in his presentation of taking the first difference of the data, noting that the cointegration literature finds that this is a bad idea because it throws away too much information. It is always possible to get different results with a worse model, he noted. If the authors could show that altering their model to produce a better fit would give different results, this would be a legitimate criticism; but Watson's presentation simply presented a handful of other models, some of which may fit much worse. Sims hoped that the authors would do more to analyze their model's fit.

Sims was surprised that the authors were able to show big impulse responses with good estimates of the error bands. It is hard to know what kind of model would explain the error bands, he noted; but the effects are certainly there, and are statistically significant. To undermine this, one would need to produce a better model showing that the error bands are wrong or that the impulse responses come out in a different way.

Sims mentioned a few possible econometric issues. Specifically, when it comes to food prices, seasonality is extremely important. Seasonality is pervasive in price and output data for commodities, particularly food commodities. The authors' model, as he understands it, includes seasonal dummies and uses seasonally adjusted data. He noted a bit of danger in doing this, because seasonally adjusted data always use future data as part of the adjustment. Unraveling this adjustment using a multivariable vector autoregression could be cause for worry, and so Sims suggested that the authors check for robustness there, by testing whether the seasonal dummies matter or by replacing some series with series that are not seasonally adjusted and by leaving in the dummies. He noted that commodity prices notoriously produce nonnormal residuals due to large outliers. According to the authors' current framework, it would not be too difficult to construct a model that allowed for $t$-distributed errors, which would indicate whether the results were being driven by a few large outliers.

Justin Wolfers noted that what the authors do with the global food index seems to make sense; once a crop is planted, conditional on what is planted, what ends up getting harvested seems exogenous. In the regression context, if one were to include harvests and control for planting, then other exogenous effects would be identified. But the authors did not seem to include 
planting in their model, so he was not sure how harvests turned out to be exogenous.

Looking at the authors' results at face value, Robert Hall thought they seemed totally implausible, which is always interesting, he noted. A big wave in macroeconomic theory, pioneered by Robert Shiller, deals with a concept variously termed confidence, sentiment, ambiguity aversion, or animal spirits. Models that have these features tend to generate the pattern observed by the authors, which is changes in a wide variety of macroeconomic variables that are similar in magnitude and are highly correlated. Within this framework, the price of basic cereals should be profoundly and primordially important for the present paper. It seems sensible, he noted, that they could perhaps trigger changes in confidence; if so, this is interesting because most research in this area has taken it to be totally unobservable and not triggered by some natural phenomenon. He suggested that the present paper could constitute a new branch of this line of thinking.

Martin Eichenbaum bet that a typical consumer has no clue about what is happening in commodity markets, and that the real question consumers face is about the price they are actually paying at the grocery store, not the price of cereals on the commodity market. Hall contended that, in fact, people are well informed through the media about commodity prices, which Eichenbaum stated was possible.

Eichenbaum also commented on variance being small and yet things being estimated precisely. There is an analogue in the literature on monetary policy shocks: When models are estimated in log levels, they explain very little of the variance in output identified with fund shocks, and yet standard errors are generally estimated quite precisely. He suggested that this might be something for the authors to consider.

Building on Hall's comments, James Stock added that there is a lot of evidence that consumer sentiment tends to move with prices that are highly salient, such as those for gasoline and meat. An empirical question is whether this salience-even though it turns out not to be a big deal in bottom-line expenditures-might be a feature.

Narayana Kocherlakota suggested that since commodities have a durable aspect, movements in discount factors could actually have an effect on their prices. He proposed that perhaps the authors' food prices were picking up a spurious correlation, and that discount factors are moving in relation to many other important things in the economy. He suggested that adding stock prices to their model might avoid some of this spurious correlation.

Gerald Cohen noted that there is a nontrivial lag between the effect of input costs for types of feed-like corn and wheat — and the cost of meat. 
He recalled a glut of meat production in the middle to late 2000s, following the increase in corn prices, and suggested that the authors might look into this phenomenon. A related phenomenon is observed in the pig industry, called the corn-hog cycle. This cycle consists of massive fluctuations in pig production caused by overreactions to changes in the market prices of pigs and their feed. In pig rearing, feedstuffs are a large proportion of the economic market cost of a pig, so a change in feedstuff price has an immediate effect on farmers' profits; conversely, cattle primarily eat grass, and specialty feed is normally only a small proportion of total feed costs.

Echoing Sims, Peersman was critical of Watson's stability argument because estimating the model in first differences does not take into account potential cointegration relationships between the data. This approach was also the only one of which he was aware that produced somewhat weaker effects and different dynamics. He noted that estimating several variants of the level specifications for the full sample produces results that are quantitatively and qualitatively very similar.

Regarding variance decompositions, though it is true that the shocks explain only about 10 percent of U.S. GDP variation, Peersman asked, "Did you expect more?" Food prices are obviously not the main driver of the U.S. business cycle, so it is good that the authors did not find big effects, he contended. Notwithstanding, the contribution of food commodity market shocks to GDP variation turns out to be approximately the same as monetary policy or oil supply shocks, which are two shocks that receive a lot of attention in the literature. Peersman agreed with Eichenbaum that the macroeconomic consequences could be estimated quite precisely, even when they explain a relatively small proportion of the variance.

In response to questions of omitted variable bias, he noted that the authors' VAR model does not include global income measures, and that they had tested their model for robustness by including both more and fewer variables. The authors believed that the final model, which includes 10 variables, was sufficient to counter omitted variable bias. This is also confirmed by the FAVAR analysis reported in the paper. Furthermore, the narrative analysis revealed that food commodity market events in the Soviet Union did have an important influence on global commodity prices, even in the 1970s. However, as Kilian had suggested, Peersman noted that data on inventories do not exist at the required quarterly frequency.

Looking at subsamples, Peersman noted that, taking into account the error bands, the results are stable if two decades of observations are excluded at the beginning or the end of the sample period. The results become less stable for shorter sample periods but this should not be a sur- 
prise, because the authors are working with 10 variables and thus many observations are needed to make proper estimates. For more parsimonious versions of the VAR - for example, by including fewer variables or lagsthe results are also stable for shorter sample periods. In general, much variation in the variables is needed to capture the shocks of global food prices and food production, which is why Peersman is not a fan of these types of subsample analysis.

Schlenker was surprised to find that people spend about the same amount on food each year. He stated that a natural question to ask, then, is why there are any effects of food shocks at all. Peersman asserted that this is exactly the point, and might be the mechanism: When people keep on consuming equally as much food because they need to eat every day, they must cut expenditures on some other components of their budgets. The data suggest that households in the lowest quintile of the income distribution spend about 36 percent of their income on food; furthermore, low-income households are typically liquidity constrained, so food price fluctuations might have big effects on these households' other types of spending. There also seems to be a significant decline in consumer confidence, which is a natural amplifier of the macroeconomic consequences.

Peersman disagreed with Kilian's assertion that there is no pass-through from global food prices to domestic retail prices. Peersman argued that there is, in fact, a one-to-one pass-through of global food commodity prices to U.S. food commodity prices, and a pass-through to the food component of the consumer price index proportional to the share of food commodities in final food products. He also stressed that this share has been about 14 percent on average, which is much larger than the share Kilian was insinuating. Regarding the authors' identification strategy for oil supply shocks, Peersman noted that this strategy followed that used in a recent paper he and Baumeister published in the American Economic Journal. ${ }^{3}$ Furthermore, he asserted that imposing the kind of restrictions on the elasticities that Kilian had suggested produces the same results, noting that these restrictions only matter to identify demand shocks in the oil market, not supply shocks.

Peersman conceded that Sims's point about seasonality was a good one. There is indeed much seasonality in the food production index. He noted that they had run specifications without seasonal dummies, and this had no

3. Christiane Baumeister and Gert Peersman, "Time-Varying Effects of Oil Supply Shocks on the U.S. Economy," American Economic Journal: Macroeconomics 5, no. 4 (2013): 1-28. 
influence on the results. The authors also found similar macroeconomic consequences using data that were not seasonally adjusted, as Sims had also suggested. All in all, the authors found that the effects are similar across the various specifications.

Regarding Wolfers's comment about why the authors do not include data on crop planting, Peersman noted that planting data are actually not needed because what is being identified are quarterly shocks, that is, shocks within the harvesting quarter. Everything that happens before this quarter should already be included in the information of the model's other variables. Food commodity prices, for instance, should contain all the relevant information about planting that is in principle reflected in the price just before the harvesting quarter.

Regarding Kocherlakota's suggestions that there could be a common shock to commodities that is basically driven by rates of returns and discount factors, Peersman noted that this was indeed one of the authors' concerns, and they did a lot of work to figure out whether this was the case. For example, in the paper they show that only food commodity market variables react on impact. Similarly, GDP and other variables only start to decline after a couple of quarters, meaning that on impact, there is no shock directly affecting GDP. More importantly, equity prices also do not shift on impact.

Finally, Peersman noted that estimating the impact of food prices on exports shows that the effects are not strong. Even though there is a decline in global economic activity, exports do not appear to be the culprit; they decline a bit, but the effect is not statistically significant. He concluded that domestic consumption is what really seems to drive the output effect. 